\title{
THE USE OF MUSIC THERAPY TO SUPPORT SPEECH AND EXPRESSIVE LANGUAGE DEVELOPMENT FOR PRE-SCHOOL CHILDREN WITH SPECIAL NEEDS
}

\author{
BY \\ SHARI K. LUDLAM \\ An exegesis \\ submitted to the Victoria University of Wellington \\ in partial fulfilment of the requirements for the degree of \\ Master of Music Therapy
}

New Zealand School of Music,

Victoria University of Wellington

2012 



\begin{abstract}
Client-centred music therapy with individual pre-school children, involving playful but focused songs, behaviours and instrumental play, can enhance their speech and expressive language development. Four constructs were inductively created using the principles of grounded theory to represent how music therapy was used to support speech and expressive language development for pre-school children with special needs. Secondary analysis was undertaken of qualitative data drawn from usual clinical practice including clinical notes, reflective journal, audiovisual recordings, and notes from communications regarding two children from a student music therapist's caseload at a specialist centre in New Zealand. A case vignette is presented to illustrate these four meaningful constructs of individual music therapy and concepts that constitute each are presented, along with sample quotations from the data, and are theoretically integrated within wider music therapy literature. A tree model was used to capture these findings, which further suggested 'playfulness' may be a central aspect of the work. Implications for my developing and future clinical practice of music therapy are discussed, along with directions indicated for future research.
\end{abstract}




\section{Acknowledgements}

I would like to express my special thanks to the following people:

To the late Sir Roy McKenzie and the late Marion Rayward and their committees for the McKenzie Music Therapy Scholarship and Marion Rayward Memorial Trust Awards respectively, for enabling me to complete my Master of Music Therapy and this piece of research in Auckland.

To the team at the facility, my clinical supervisor and clinical liaison in particular, for supporting me throughout my placement and in undertaking my research.

To my clients and their families for agreeing to their involvement in this research and for teaching me so much about what music can do and how I can be.

To my research supervisor, Sarah Hoskyns, for supporting me in undertaking my second year in Auckland and for your guidance and insights throughout.

To my family, my mum in particular, for taxiing me from music lesson to band practice to concert for decades, putting up with my night-owl practicing, providing me with an outstanding education that nurtured and shaped my potential, and for continuing to support me in my choices.

To Luke, for your suggestions and endless support when I got stuck with the literature, the analysis, the process, the pressure, the people, the music, the thinking, the writing, the critiquing, as well as the travelling and airport visits. I continue to immensely appreciate your clear, levelheaded approach to life. 


\section{Table of Contents}

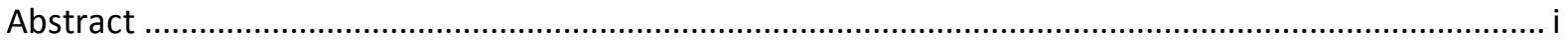

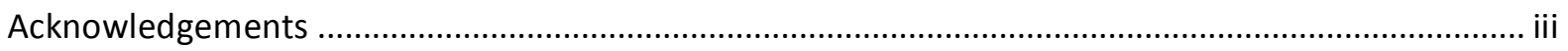

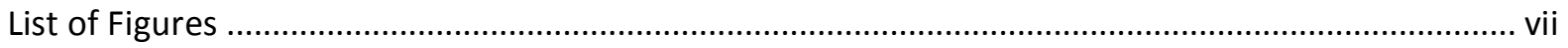

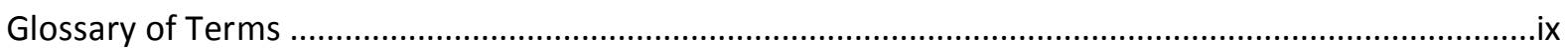

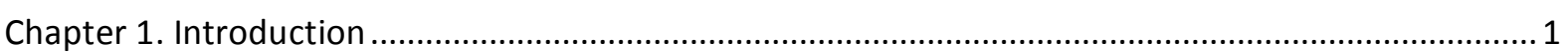

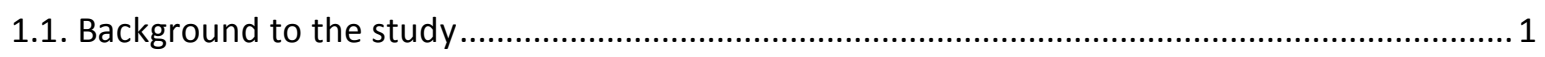

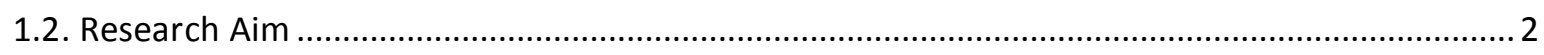

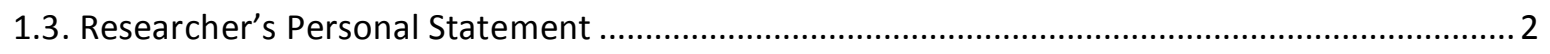

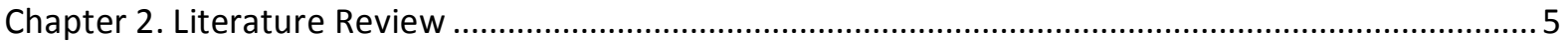

2.1. Speech and language development and difficulties ............................................................. 5

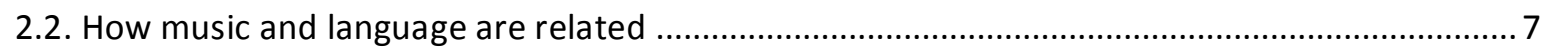

2.3. How music therapy supports speech and language development ............................................. 9

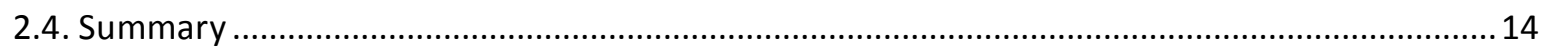

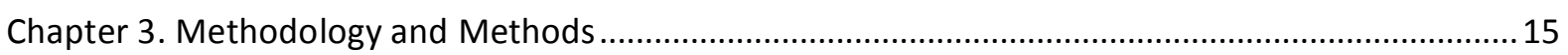

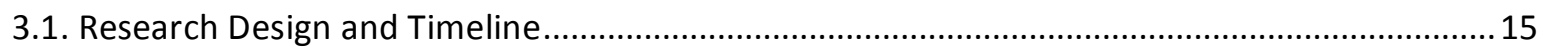

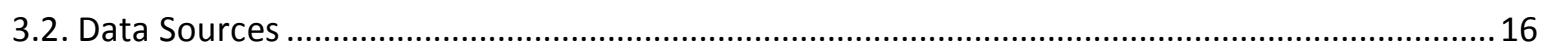

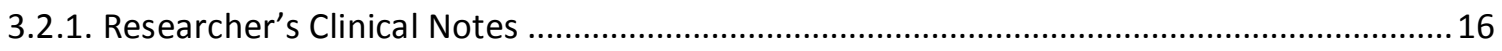

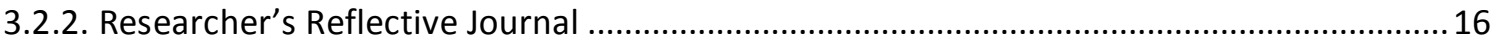

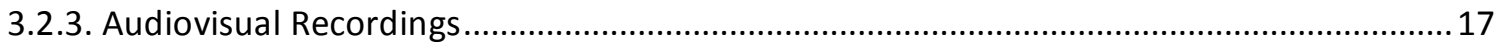

3.2.4. Notes from Communications …………………........................................................... 17

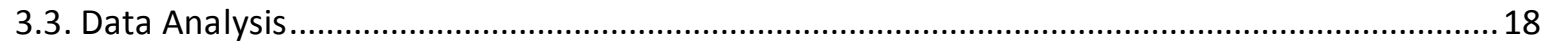

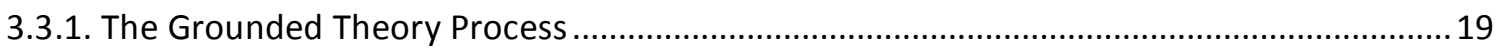

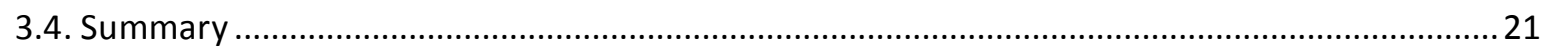

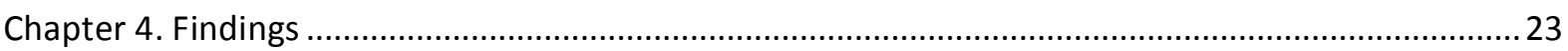

4.1. A client-centred approach, drawing on strategies for choice, intuition and planning to

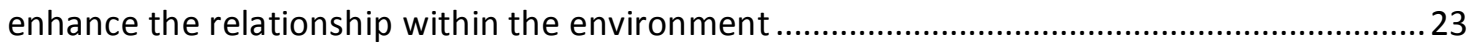

4.2. Engaging in and enhancing verbal, musical and non-verbal behaviour .....................................26

4.3. Capturing children's preferences and vocal activity in the content and structural aspects of

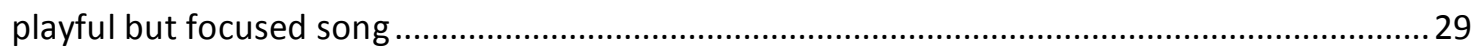

4.4. Incorporating children's preferences for themed and functional instruments .......................... 31

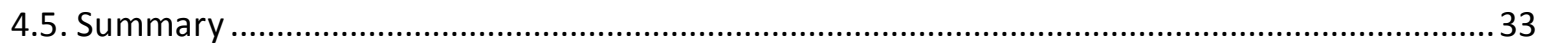

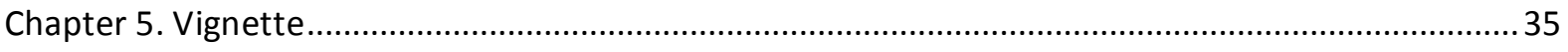




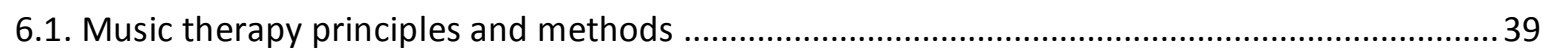

6.2. A music therapist's 'speech-and-expressive-language-specific' tool set .................................4 41

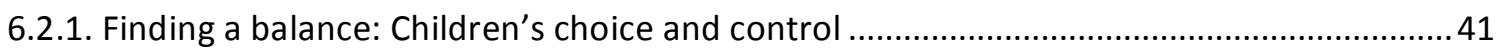

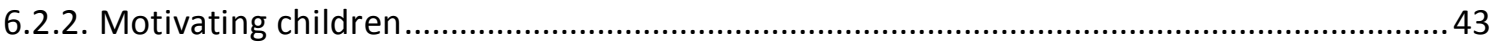

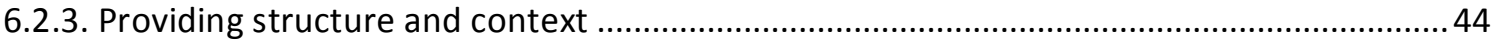

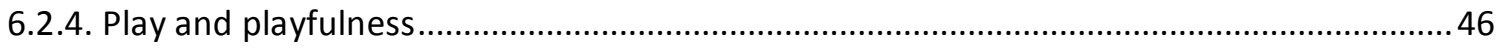

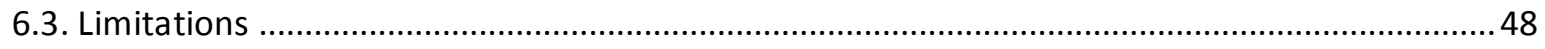

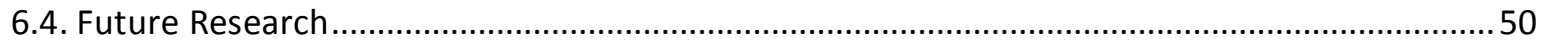

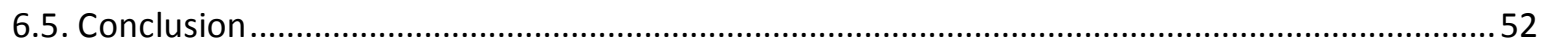

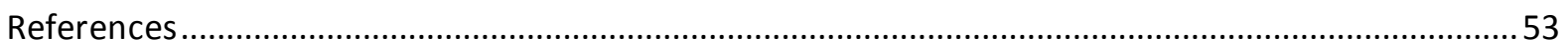

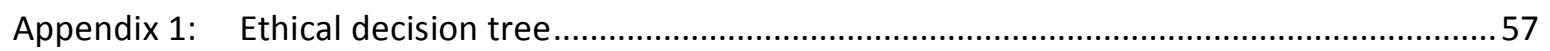

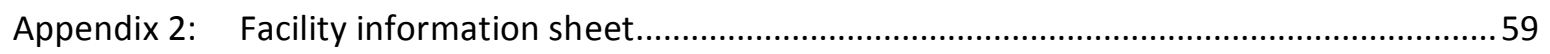

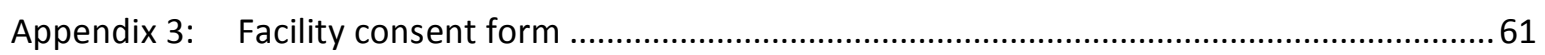

Appendix 4: Information for Families about Music Therapy Research 2011: Shari Ludlam..........63

Appendix 5: Consent form for Families about Music Therapy Research 2011: Shari Ludlam.......66

Appendix 6: Information for Specialist Service Professionals about Music Therapy Research

2011: Shari Ludlam....

Appendix 7: Consent form for Specialist Service Professionals about Music Therapy Research

2011: Shari Ludlam ........................................................................................................ 71

Appendix 8: Examples of grounded theory data analysis process: Analytic Memos ...................73

Appendix 9: Examples of grounded theory data analysis process: Coding ................................ 74

Appendix 10: Examples of grounded theory data analysis process: Initial list of categories ........ 76

Appendix 11: Examples of grounded theory data analysis process: Axial Coding .......................77

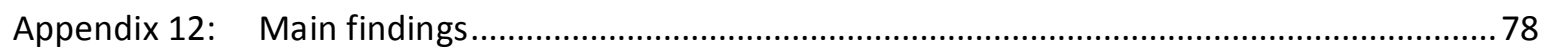

Appendix 13: Adaptation of children's song Teasing Mr Crocodile .............................................87

Appendix 14: Children's song Five Little Monkeys Jumping on the Bed .......................................8 88

Appendix 15: Adaptation of children's song Are You Sleeping ..................................................89

Appendix 16: Traditional children's song Five Green and Speckled Frogs (also known as Five Little

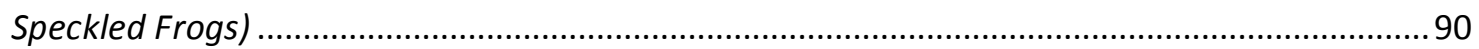

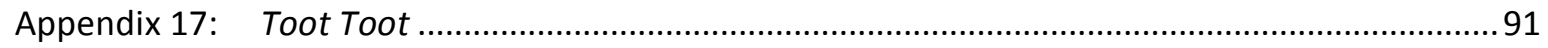

Appendix 18: $\quad$ Adaptation of children's song Galoop Went the Little Green Frog ........................92

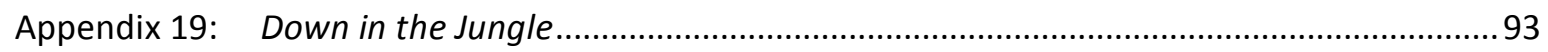




\section{List of Figures}

Figure 1: Tree model used to capture the four meaningful constructs that represent how music therapy has been used to support speech and expressive lanugage development for preschool children with special needs. 


\section{Glossary of Terms}

Client-centred approach - based on Person-Centred Theory developed by Carl Rogers, this approach allows the client increased power, control and decisionmaking, is based on unconditional positive regard, the development of trust, and a relationship in which the client and therapist are equals.

Critical period for language acquisition - also termed a sensitive period, this involves the capacity for optimum development in the first few years of life given the abundance of neurological activity and plasticity in early childhood

Melodic Intonation Therapy - a highly structured, repetitive technique involving sung and tapped phrases, uniquely effective in engaging the right hemisphere, priming the sensorimotor and pre-motor cortices, used with those with aphasia

Nativism - a theory of language acquistion, proposed by Noam Chomsky in 1957, posits that children acquire language through the use of an innate language acquistion device (LAD). This contains the basic information about rules of syntax and enables children to form and test hypotheses. Evidence of cases showing that without social interaction language does not develop provides support against Nativism, and for Social-Interactionist Theory

Neuro-linguistic theory - a theory of language acquistion, proposed by John Locke in 1997, posits four sequential neurologically based phases, based on long-term memory stores

Object metaphor - The association of an instrument to a different object

Onomatopoeia - a word that imitates or suggests the source of the sound that it describes, here refers to a word or vocalisation of the sound an instrument or animal makes

Plasticity - the premise that the brain is not hard-wired but is in fact governed by competition for precious resources. In the event of injury or dysfunction in an area of the brain, neighbouring brain cells can change their function. During the critical period the cortex is very plastic and its strucutre can be changed with exposure to new stimuli.

Recitative - style of monody (accompanied solo song) that emphasizes and indeed imitates the rhythms and accents of spoken language, rather than melody or musical motives. A sung commentary of what is happening.

Social-Interactionist Theory - a theory of language acquistion. In 1983 Bruner proposed an innate Language Acquisition Support System (LASS) to address the 
interplay between language cognition and social development, wherein evidence shows that language is embedded in the social-emotional context of the family.

Sprechstimme - inflected or heightened speech

Utterance-Acquisition System - the second phase of Locke's Neurolinguistic theory, follows 'Vocal learning' and involves children's first words and short, formulaic phrases, learned from listening to others

Utterance-Analysis System - the third phase of Locke's Neurolinguistic theory begins at about 20 months of age and involves an internal system which acts on information learned and retained during the second phase, enabling analysis and computation of grammar and syntax

Vocal-holding technique - the music therapist can provide the vocal means for a patient to explore sound, breath and voice, thus developing the capacity for vocalisation. Diane Austin's technique utilizes the voice of both client and therapist in grounding and mirroring within psychotherapy.

Wet voice - excess saliva resulting in a gurgly or 'wet' voice after swallowing

Zone of proximal development - The difference between the child's actual development and potential development with aware and capable support. Children advance their skills best when adults adjust their level of play to that just beyond the child's level. 


\section{Chapter 1. Introduction}

This research is based on the principles of music therapy wherein music is a powerful tool that, when applied within a supportive relationship, has the potential to be used therapeutically towards goals including the development of communication skills.

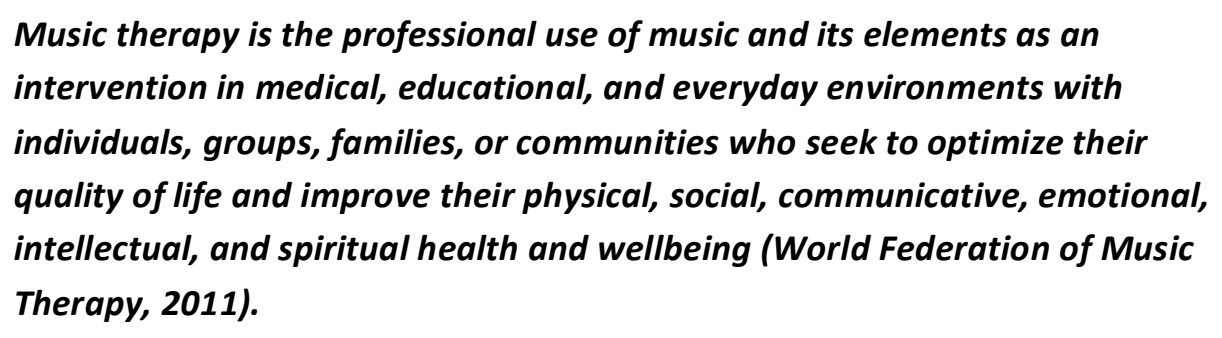

\subsection{Background to the study}

As a student music therapist I developed a particular interest in speech and language orientated goals within music therapy practice with clients who have communication difficulties. This interest emerged over time through my tertiary training and was highlighted at a seminar I attended at the University of Auckland 'Brain Day' given by Professor Suzanne Purdy (2011) on the connection between memory and the emotional element of song versus speech. Communication difficulties including speech delay arose as a common need in my clinical practicum experience working with children with special needs.

I was fortunate to undertake my second year clinical placement at a specialist music therapy centre (hereafter 'centre') in New Zealand. Children with special needs are referred to the centre by parents, carers, and other professionals. Following a consultation meeting and short investigatory music therapy session with the Head of Clinical Services, a Registered Music Therapist, clients are likely to be placed on the waiting list until a suitable time and therapist becomes available. That music therapist then carries out four to ten assessment sessions to explore the client's physical, emotional, social, behavioural and musical strengths and weaknesses. These are discussed with parents or carers in order to form goals and focus areas for ongoing long-term individual or small-group music therapy.

Many questions about the clinical practice when working with this population centred on communication difficulties, with verbal communication goals common across the caseload. I chose to focus specifically on how music therapy could be used to support speech and 
expressive language development by undertaking secondary review of data drawn from usual clinical practice.

\subsection{Research Aim}

The purpose of my research was to explore retrospectively how music therapy has been used

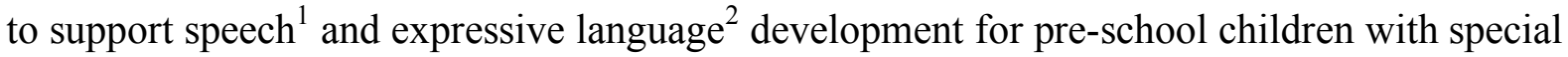
needs. This research focused on areas relevant for global developmental delay and neuromuscular weakness wherein children presented with speech and language delay or disorder.

It was beyond the scope of this research to consider all relevant topics within speech and language development. For clients with autism, aphasia, brain injury, and auditory impairment there is a wealth of knowledge within music therapy specifically related to and distinct for their needs. The use of music therapy to support speech and language development within these areas would require a particular focus which warrants separate analysis and review.

\subsection{Researcher's Personal Statement}

I come from a large family and have worked in childcare, as a piano teacher and entertainer, and thus the prospect of working with children in this age group was not daunting as I began this placement. One of my main challenges was being able to adapt my repertoire of children's music and musical skills to most effectively address my clients' needs in a music therapy framework. It was also important for me to modify my childcare strategies in order to create an appropriate therapeutic environment.

Within my undergraduate degree in psychology I was introduced to fields including child development, speech and language therapy and neuroscience. In my approach to this piece of research I was interested in exploring and incorporating knowledge from these professions and disciplines within my exploration of how to support communication goals as a student

\footnotetext{
${ }^{1}$ The American Speech-Language-Hearing Association defines speech as "the oral form of language" and language as "a code made up of rules that include what words mean, how to make words, how to put them together, and what word combinations are best in what situations" (King, 2007, p. 13).

${ }^{2}$ Expressive language is further distinguished as "the conceptualization of an idea and the production and articulation of speech sounds" as opposed to receptive language, "the reception of those sounds and comprehension of their meaning" (King, 2007, p. 13).
} 
music therapist. As a second year Master of Music Therapy student at the New Zealand School of Music, my training has consisted of a humanistic and client-centred approach to music therapy. It is important to acknowledge my role in the research analysis and recognise the potential influence that my undergraduate background in psychology, statistics and composition as well as my music therapy training may have had on the analysis process and findings.

Further, I acknowledge that my research process throughout the year as well as my learning as a student have likely impacted on and had an influence on my clinical practice. I have consistently held in mind something my clinical supervisor said to me early on in the year, which is also aligned with developmental thinking: As music therapists thinking about our clients from a psychodynamic perspective we believe that all behaviour has meaning. It is our role to hold, interpret, and respond to our clients' behaviours in a way that we understand to best meet their needs. As such, although I have had verbal communication goals in mind during music therapy sessions, it has been important for me to keep my research interests to one side. At times when I have had the ideal song ready, incorporating a child's previously expressed interests and tailored to develop certain speech sounds, I have had to be flexible, focus on other goals and respond to their needs in the moment, which is something my research supervisor would say is: the nature of the work. 


\title{
Chapter 2. Literature Review
}

\author{
"An important feature of childhood development is the acquisition of speech \\ and the ability to communicate meaningfully with another person" (Aldridge, \\ 1996, p. 245).
}

This review focuses on recent literature concerning the use of music therapy to support speech and language development with pre-school children with speech and language difficulties or disorders. It was beyond the scope of this piece of research to examine areas of inquiry throughout the literature specifically related to autism, aphasia, brain injury and auditory impairment, which would require a more particular focus. Literature was sourced from books, hand searches of music therapy journals, conference proceedings and electronic databases. Search platforms Web of Science, Web of Knowledge, and EBSCOhost were used and articles were sourced from Academic Search Elite, Journals@Ovid, JSTOR, MEDLINE (PubMed), Proquest, PsycINFO, ScienceDirect, Scopus, and Wiley, as well as online journals including Voices: A World Forum For Music Therapy and Cambridge Journals Online. It was also fortunate to attend a presentation and obtain access to materials from Professor Suzanne Purdy regarding as yet unpublished research. The initial literature search focused primarily on speech and expressive language development and the music therapy research and literature particularly as it related to developing speech and language skills with children with special needs. In this process 32 sources were identified and analysed in terms of language acquisition and development, related difficulties or disorders, the relationships between and within music and language, and the music therapy research particularly as it related to developing speech and language skills with children with special needs.

\subsection{Speech and language development and difficulties}

When working with young children to develop their communication it is important to understand how language is acquired and developed (Lorenzato, 2005; Wheeler, Shultis, \& Polen, 2005). This helps the therapist understand a child's difficulties, determine the techniques, activities and processes within the intervention that can best meet their needs, and rationalise change as it occurs (Bunning, 2003; Newham, 1998; Wilkinson, 2008). While Nativism, as proposed by Noam Chomsky, argues for an innate Language Acquisition Device 
in conjunction with exposure to speech, Social-Interactionist theorists are interested in the interplay between language, cognitive, and social development, and Neurolinguistic theorists posit four phases of development through the interplay of biology and linguistics (Bjorklund, 2005). Despite different views as to the mechanism of language acquisition ${ }^{3}$, the current consensus is for the importance of context, both in terms of the socio-emotional environment in which children learn as well as the use of context as an aid for what they are learning (Bjorklund, 2005; Sloboda, 1989, as cited in Loewy, 2004). Indeed, "The younger the age, the more children rely on contextual information" (Jentschke, Koelsch, \& Friederici, 2005, p. 233).

It is widely accepted that there is a critical period for language acquisition. This critical or sensitive period involves the capacity for optimum development in the first few years of life given the abundance of neurological activity and plasticity in early childhood (Bjorklund, 2005; Seybold, 1971; Turner \& Ioannides, 2009). A child with typical language development goes from screaming newborn to babbling 10-month-old with two-syllable words, and by two-years-old is using nouns and has two-word sentences (Bjorklund, 2005). However language acquistion not only involves the development of vocal and verbal comprehension and expression but also the nuances of gesture, body language, facial expression and other aspects involved in developing meaningful communication. This can occur without the use of voice, for example through sign language. Further, language is made up not only of phonology (the sounds produced), but also morphology (the structure of words), syntax (the structure of sentences), semantics (the meaning of language terms), pragmatics (the ability to use language in a social context), and communicative competence (the effective combination of the above) (Bjorklund, 2005).

For some children processing language related information may be slower and require more effort as well as support and greater sensitivity from adults (Bunning, 2003). Children whose context, 'utterance acquisition system' or both are insufficient during the critical language acquisition period will likely be delayed in acquiring the building blocks i.e. words. If the development of words is delayed until after the neurodevelopmental optimum for grammar and syntax there are ensuing difficulties in progressing with language. These difficulties result from a potentially inadequate 'utterance analysis system' or analytic-computational capability (Bjorklund, 2005). A neurological study involving event-related potentials as a

\footnotetext{
${ }^{3}$ See Children's thinking: cognitive development and individual differences (Bjorklund, 2005) for further explanation and debate of these theories.
} 
measure of brain activity indicated that linguistically impaired five-year-olds had difficulties in the processing of musical syntax, syntactical relationships and configurational aspects of grammar (Jentschke et al., 2005). Cognitive and socio-emotional difficulties associated with delayed or disordered language include reading, spelling, and other learning, symbolic and social play, attention and listening skills and other school-related problems (Bunning, 2003; Grosz, Linden, \& Ostermann, 2010).

Speech production impairments are distinguished by speech and language therapists as either neuromuscular or articulation based (Bunning, 2003) $)^{4}$. "About 95 per cent of the energy of vocalisation is spent in the production of extended vocables or vowels, and muscular production and control of this energy in the vocal organs determines the quality or timbre of the voice" (Powers \& Trevarthen, 2009, pp. 214-215). For some children, beginning preschool (kindergarten) accelerates development (Bunning, 2003). Some are referred to specialist professionals such as speech and language therapists, music therapists, or both to foster the expression of communicative intent, facilitate the development of muscle tone, vocal qualities, fluency, and pragmatic skills i.e. the use of language (Bunning, 2003; Michel \& Jones, 1991). It is believed that although neurological changes after early childhood are slower, the capacity for auditory learning even in adulthood can be facilitated by adequate motivation (Turner \& Ioannides, 2009).

\subsection{How music and language are related}

Throughout the literature the concept that music and language are closely related has been debated (DeThorne, Johnson, Walder, \& Mahurin-Smith, 2009; Jentschke et al., 2005; Loewy, 2004; Malloch \& Trevarthen, 2009; Overy, Norton, Cronin, Winner, \& Schlaug, 2005; Ozdemir, Norton, \& Schlaug, 2006; Patel, 2008). Comparisons are made between how each developed, structural aspects, neurological foundations, and reciprocal impact. Many authors agree that music-making and communicative musicality developed before language and evolved through an inherant or innate need to communicate, interact with others, form bonds and for social cohesion (Bannan \& Woodward, 2009; Dissanayake, 2009; Jentschke et al., 2005; Turner \& Ioannides, 2009). Music and language are both auditory-vocal, contextdependant, innate human qualities for expression (Cohen, 1994; Loewy, 2004). Both systems

\footnotetext{
${ }^{4}$ It is important to note that there are different views in the literature regarding definitions of speech, language, and language disorder and its use as an umbrella term (King, 2007; Wright $\&$ Kersner, 2001). Therefore there are discrepancies in the data regarding speech development disorders (Grosz et al., 2010).
} 
involve sequences of discrete elements that are constructed via a set of rules i.e. syntax, with an infinite number of possible combinations that are transcribable with the use of symbols (Jentschke et al., 2005; Loewy, 2004). Elements including rhythm, tempo, phrasing, tonality and prosody as well as affect, motor skills, sensory perception and an understanding of context and intent are also shared across the complexities of both music and language learning processes (Loewy, 2004; Panksepp \& Trevarthen, 2009).

When an adult speaks to an infant or child with distinct musical features including higher tones of voice, more high and low tones, and more rising tones, this is termed child- or infantdirected speech (Bjorklund, 2005; Powers \& Trevarthen, 2009). An instinctively functional means of engaging a child, the prosody within this speech conveys many language qualities. A child learns about control via movement of oral features and the resulting vowels and consonants, pitch and pitch order, rhythm, tempo, use of sustained sound, and silences. Along with shared socio-emotional expression and meaning, these vocal qualities enable prediction and anticipation of patterns in story and song, and are perceived by a child prior to phoneme and word comprehension (Bjorklund, 2005; Loewy, 2004; Panksepp \& Trevarthen, 2009; Powers \& Trevarthen, 2009; Turner \& Ioannides, 2009). Termed 'proto-conversation' (Bateson, 1979; Malloch \& Trevarthen, 2009) this parent-child interaction serves as a connecting, comforting, communicative precursor to speech and facilitates development through emotional engagement. It is suggested that it is the combination of this and learning through reciprocal imitation that language acquisition arises (Bannan \& Woodward, 2009).

It is agreed that the neural apparatus for music and language are related, however to what extent remains in contention and is beyond the scope of this research to explore in detail. ${ }^{5}$ Syntax and pitch perception in both music and language are arguably processed in both left and right cerebral hemispheres, with specific commonalities in inferior frontal and frontolateral areas (DeThorne et al., 2009; Jentschke et al., 2005; Ozdemir et al., 2006; Turner \& Ioannides, 2009). However, linguistic processing is weighted or more strongly lateralised to the left hemisphere, while musical features are arguably more bilateral (Turner \& Ioannides, 2009) with prosody and emotional sounds and words processed in the right hemisphere (Jentschke et al., 2005; Panksepp \& Trevarthen, 2009; Purdy, 2011). It is contended that the hemispheric bilaterality of music processing enables music to create a pleasing and satisfying coherence and further lower anxiety, increase motivation and memory response

\footnotetext{
${ }^{5}$ See Music, language and the brain (Patel, 2008) for a comprehensive account of the complexity of the field from a certain perspective.
} 
(Dissanayake, 2009; Loewy, 2004). DeThorne et al. (2009) posit the compensatory value of right-hemisphere specific tasks for children with language difficulties, and although further understanding is needed as to the neural basis of such effects (Norton, Zipse, Marchina, \& Schlaug, 2009), recent evidence indicates positive cognitive transfer effects from music to language domains (Jentschke et al., 2005).

\subsection{How music therapy supports speech and language development}

Music therapy is widely considered an effective therapy for developing speech and language skills of children with difficulties or disorder. Clinically and statistically significant, positive effects of music therapy for children's speech and language development have been reported in the literature. These include phonological capacity and children's understanding of speech (Grosz et al., 2010), verbal imitation skills, memory and word retrieval (Cohen, 1994), listening and speech-related practical reasoning, (Aldridge, 1996), targeted production of initial consonants, words and phrases incorporating nouns, numbers, and other cognitive tasks (Kouri \& Winn, 2006; Michel \& Jones, 1991), as well as spontaneous speech (Kouri \& Winn, 2006; Seybold, 1971). "[Music therapy] does not seem to influence individual isolated aspects of speech development but might address and integrate many different aspects in a comprehensive way that are important for speech development...[and] may provide a very fundamental, basic, and supportive therapy for children with developmental speech delay" (Grosz et al., 2010, p. 47).

Music is an attractive, appealing, accessible, unpressured medium that encourages and motivates children to communicate more intensively, effectively and confidently (Aldridge, 1996; Cohen, 1992, 1994; Grosz et al., 2010; McCarthy, Geist, Zojwala, \& Schock, 2008; Michel \& Jones, 1991). "As children begin to explore their voices, they discover their power to create 'soundscapes' that emerge from within" (Bannan \& Woodward, 2009, p. 473), and indeed music and the human voice provide avenues for expression (Bannan \& Woodward, 2009; Cohen, 1994; Dissanayake, 2009; Powers \& Trevarthen, 2009). Prosody, a musical element of vocal expression, is contended to be an important contributor and aspect of the development of language in infancy and throughout life (DeThorne et al., 2009; Grosz et al., 2010; Jentschke et al., 2005; Panksepp \& Trevarthen, 2009). Music therapy can effectively develop rhythmic-prosodic abilities when impaired, thereby enabling more of the working memory for the processing and understanding of language (Grosz et al., 2010). 
Matching rhythmic patterns, for example in drumming, with speech patterns has been recognized as a constructive strategy towards working memory and speech production (Leung, 2008; Silverman, 2007). Children's vocal activity is often spontaneously accompanied by movement or manual gestures (Bannan \& Woodward, 2009; Panksepp \& Trevarthen, 2009). It is posited that the stability of a controlled yet flexible, rhythmic structure and the development of hand-eye co-ordination are key components within active musical playing toward the development and organisation of both speech and hearing, when impaired (Aldridge, 1996; Grosz et al., 2010). Meaningful development and integration of several senses such as motor skills, emotion and hearing is considered to maintain children's attention and be a highly important contribution to verbal communication (Grosz et al., 2010).

Structure is an integral aspect of language acquisition (Grosz et al., 2010; Jentschke et al., 2005). Flexible and variable opportunities for building perception and understanding of structure are provided by active music-making, "the use of purposive, coordinated movements which occur in a context of time and relationship" (Aldridge, 1996, p. 250). Jentschke et al. (2005) posit that evidence of positive effects of musical training on the efficiency of typically developing children's musical and linguistic processing may be of value within music therapy for those developing atypically. Following music therapy with children with delayed speech development significant measurable improvements in phonological memory, understanding of sentences, and generation of morphological rules were seen (Grosz et al., 2010). Moreover, these improvements in speech development throughout music therapy correlated with a significant decrease in the difference between developmental age and biological age.

Song, as discussed by many authors, consists of strong rhythmic components and structure and a range of melodic frequencies (pitch) broader than that within speech. Further, sustained phonations i.e. longer vowel sounds and vibrations can be produced when singing, resulting in increased volume and projection. Emotional qualities can be exaggerated within timbre, and there is need for efficient diction and intelligibility as well as effective breathing when singing (Cohen, 1992, 1994; Powers \& Trevarthen, 2009). Although arguably not the reason for its development (Bannan \& Woodward, 2009), singing can support common elements in speech such as range of pitch and vocal intensity, particularly within impaired speech. Rhythmic imitation is arguably easier in music than speech and vocal exercises that emphasise consonant articulation may develop intelligibility (Cohen, 1994). 
Through his examination of rhythm within music and language Patel (2008) outlined the potentials for more empirical investigation in this field. These included the comparison of musical metre of different cultures' children's songs and the comparison of verbal and musical accents when setting text and within rap music. Research which assessed participants' recall of information when paired with pitch, rhythm, or both suggest that varying pitch may in fact hinder recall (Silverman, 2007). However further research is called for in order to assess the potential implication for therapy and education that rap, chant, or monotonic singing may be more beneficial than conventional song, and if this depends on the client's culture.

Music therapy can address other difficulties that are often associated with speech and language delay or impairment, including cognitive, emotional, and behavioural development (Beathard \& Krout, 2008; Grosz et al., 2010; Hoskyns, 2009; Seybold, 1971). Further, the music therapist has the flexibility within their therapeutic approach to be able to assess, prioritise, and adapt to meet clients' needs on a session-by-session basis (Aldridge, 1996; Leung, 2008). Recent evidence within neuroscience further supports the use of song as being connected with emotion in a way that speech is not with regards to connectivity and activation of associated areas of the brain (Levitin, 2009; Ozdemir et al., 2006; Purdy, 2011). Juslin and Västfjäll (2008) discuss the concept of spontaneous and genuine emotional responses to music as distinct from those evoked in other activities. Dissanyake (2009) discusses the adaptive benefits of the use of music through shared expression and perception of emotion, and the combination of vocal, visual and kinesic behaviours and associated physiological and neurological responses. Music therapy can empower children with a sense of control, can provide motivation as well as emotional support, and thereby decrease levels of frustration, stress and anxiety during the process of working on their speech (Cohen, 1994; Leung, 2008; Seybold, 1971).

The importance of the development of a therapeutic relationship is an overarching music therapy principle that is also discussed in speech and language related literature. Authors indicate the necessity of building a supportive relationship and safe environment in which the child feels at ease and allows language to develop naturally (McCarthy et al., 2008). Music is in itself a form of communication, and in communicating musically and intentionally via instruments the relationship develops (Michel \& Jones, 1991). The child experiences being part of a conversation with a common point of focus and the benefits of listening and being listened to, without the pressure to vocalise (Aldridge, 1996; Hoskyns, 2009). These 
communicative experiences include developing social skills and abilities in relating to others, self-awareness, perception of self and others and related emotions, which are then transferable to speech and language (Aldridge, 1996; Grosz et al., 2010). This correlation appears to be reciprocal in nature, in that with the development of verbal communication comes more social interaction and the client-therapist relationships develop further. Developing relationships and increased social skills can be generalised outside of the music therapy room (Aldridge, 1996; Grosz et al., 2010).

Research indicates that music therapists may employ a number of strategies and techniques to meet a child's communication needs. Central to music therapy is the individualised approach, particularly inherent within improvisation that incorporates and reflects the musical and vocal expressions of each child (Grosz et al., 2010). In some accounts music therapists report simply playing in improvised creative therapy, not targetting specific words or sounds but eliciting spontaneous speech through an unpressured environment (Aldridge, 1996; Seybold, 1971). Aldridge (1996) contended that as developmentally delayed children each have different needs, targetting specific sounds in group music therapy did not seem appropriate. While descriptions of the 'best candidate' for the use of Melodic Intonation Therapy (MIT) ${ }^{6}$ appear to include aphasia yet discount children with speech delay or disorder, reports indicating positive improvements for the latter warrant further investigation (Cohen, 1992). Loewy (2004) adapted a 'vocal holding technique', developed by Diane Austin who, like other music therapists may do, drew ideas and inspiration from Paul Newham's Therapeutic Voicework (1998). Ideas such as vocal holding, grounding and mirroring through use of the voice can elicit vocal response (Loewy, 2004).

A more structured approach to target specific speech is also discussed throughout the literature. Music therapists utilise visual systems and songs tailored specifically to each child's individual needs, capabilities and expressions (Aldridge, 1996; Grosz et al., 2010; Hoskyns, 2009; Michel \& Jones, 1991). Repetitive sequences and the use of pauses and prompts at the end of phrases in familiar songs such as Old MacDonald, Wheels on the Bus and If You're Happy can motivate children to anticipate and contribute, while personally created songs can evoke a sense of musical identity and ownership (Beathard \& Krout, 2008; DeThorne et al., 2009; Michel \& Jones, 1991). Music therapists portray the value of songs in

\footnotetext{
${ }^{6}$ The successful use of Melodic Intonation Therapy (MIT) specifically with clients who have aphasia is discussed in the literature (Beathard \& Krout, 2008; Cohen, 1992; DeThorne et al., 2009; Kouri \& Winn, 2006).
} 
context and incorporating the child's interests, such as 'Hide-and-Seek' and animals, as well as vocally matching an engaged child's play or the sound of an instrument to create meaning and incentive for speech (Grosz et al., 2010; Hoskyns, 2009). The potential value of evoking any vocal activity initially is considered, including animal noises and vehicle sounds, alongside the use of toys or books (Beathard \& Krout, 2008). Creative, spontaneous, clientled, engaging and collaborative play, as well as having fun appear key in the music therapy approach with this client population (Beathard \& Krout, 2008; Hoskyns, 2009; Wilkinson, 2008).

Speech and language therapists undertake similar approaches to those mentioned throughout the music therapy literature. These include non-directive, child-led play, experiential learning in play contexts, as well as incorporating imitation and reflection of the child's spontaneous speech and their play/activities (Bunning, 2003; DeThorne et al., 2009). Further strategies include minimising the pressure to speak, utilizing exaggerated intonation (prosody) and slowed tempo, and enhancing auditory, visual, tactile and proprioceptive feedback (DeThorne et al., 2009). DeThorne et al. (2009) recommend further investigation of strategies including utilizing carrier phrases, pairing vocalisation with "analogous" cross-modality movements, encouraging vocal play and incorporating metaphoric devices. Speech and language therapists employ a systematic approach to intervention through enactment processes and many technical skills involved in these resonate with music therapy (Bunning, 2003).

A recent survey showed that collaborative work between a music therapist and speech and language therapist is common. Although often difficult due to scheduling challenges, where possible it enables knowledge sharing and is reportedly of most benefit to professionals (McCarthy et al., 2008). Music therapists and speech and language therapists can work collaboratively to create communication goals including improving intelligibility, volume and speed of speech. Music therapists are also equipped to discern how they can support or complement goals created by the speech and language therapist and flexibility is important here (Leung, 2008; McCarthy et al., 2008). Seybold (1971) concluded that simultaneous, complementary music therapy and speech and language therapy would be the ideal programme for children with speech and language difficulties.

The potential for offering music therapy for speech delay and disorder is encouraged by the work of Malloch and Trevarthen (2009) in developing a body of research that investigates the shared meaning developed between humans engaged in musical communication, both early 
and later in life. Several authors address the relationship between and within language and music. In a very recent publication, Baker and Uhlig (2011) offer in-depth examples conveying a variety of approaches and benefits of vocal interventions in music therapy. While work with children with autism spectrum disorders and the use of rap with 'at risk' children and adolescents are described, the various client populations included in this publication exemplifies the lack of focus in the wider literature regarding children with speech and language delay or disorder. Query regarding the connection between singing and speech development has largely centred on aphasia (Racette, Bard, \& Peretz, 2006; Schlaug, Marchina, \& Norton, 2009) and acquired brain injury (Bradt, Magee, Dileo, Wheeler, \& McGilloway, 2010). Several authors address the debate regarding research design and recognise the need for further research of higher validity (Aldridge, 1996; Grosz et al., 2010).

\subsection{Summary}

There are many aspects and qualities about the use of music as a therapeutic tool towards communication. An attractive medium, music can provide an avenue for developing expression, rhythmic-prosodic abilities, structure, common elements across speech and song, as well as address cognitive and emotional needs. In music therapy it is not a mere matter of sitting a child down and presenting them with words or sounds to learn and practice producing. Instead, a range of strategies are reportedly employed in a client-led approach together with a therapeutic relationship within a playful, unpressured environment that engages and motivates the child. Lexical learning and speech development appear to develop as a part of the whole process over time. In order to capture a true representation of the nature and efficacy of music therapy, it can be argued that undertaking research of music therapy within a natural environment is therefore necessary. Further, researchers have identified the need to investigate the underlying mechanisms of effective strategies as discussed here, particularly with a client population who have as yet been on the periphery of a growing body of research evidence. 


\section{Chapter 3. Methodology and Methods}

\subsection{Research Design and Timeline}

This research is based in the principles of theoretical research as described by Bruscia (2005b) whereby I examined "what is, or what is done, based on [my] perceptions and perspectives" (p. 541) and applied those perspectives to the work of other theorists and practitioners in the field. Following the general principles of qualitative research and empirical analysis within the framework of grounded theory, this research was designed to generate meaning and discover processes within music therapy practice through theory building (Amir, 2005; Bruscia, 2005b). I employed principles of grounded theory within a 'Straussian' or 'evolved' grounded theory approach, as detailed by Corbin and Strauss (2008), developing theory inductively from the data. This meant that concepts and theory were constructed without preconceived ideas or hypotheses about the categories that might arise. In my role as researcher I sought to ground these constructions in the data, without influence from the preliminary literature review (McCallin, 2003; Payne, 2007), drawing upon my personal experiences to obtain insight into what the data was describing but not to impose my experience on the data (Corbin \& Strauss, 2008). Other music therapists' descriptions of their use and understanding of grounded theory helped and guided my journey (Amir, 1993; Daveson, O'Callaghan, \& Grocke, 2008; McFerran, 2009; Wheeler \& Baker, 2010).

The research was reviewed and approved by the New Zealand School of Music Postgraduate committee. The Chairs of Massey University Human Ethics and Health and Disability Ethics Committees have given generic approval for music therapy students to conduct studies of this type. The music therapy projects have been judged to be low risk and, consequently, are not separately reviewed by any Human Ethics Committees. With no direct research participants, research data was drawn from processes within usual clinical practice at the centre. The New Zealand School of Music Master of Music Therapy Ethical Decision Tree Part A and B were followed (see Appendix 1). Consent was obtained from involved parties and an information sheet and copy of the signed consent form was given to each (see Appendix 2 to 7). The approach was centred in qualitative study of clinical notes, reflections, 
audiovisual recordings of music therapy sessions and notes from communications. Data was collected from that recorded within usual clinical practice between 16 March and 9 September 2011.

\subsection{Data Sources}

Data was drawn from processes within usual clinical practice at the centre. The detail and amount of the documentation may have been enhanced, but otherwise it was no different to that potentially carried out by professionals. The families of two children from my caseload were approached by the clinical liaison at the centre for their permission for their child's clinical data to be used for research purposes. Accompanying therapies, such as speech therapy and early intervention programmes, continued uninterrupted. With the support of the research supervisor, the data was limited to sources from two children, who will be known as Yvan and Zack (pseudonyms). Audiovisual data relating to only one of those children, Zack, was included due to practical difficulties including the size of the project and time. Analysis of audiovisual recording samples were chosen as theoretically relevant samples within the grounded theory process to test and further develop categories that emerged from the analysis of other data sources (Corbin \& Strauss, 2008). "Collecting data from multiple sources is intended to ensure that emergent findings are comprehensive" (Chamberlain, 1999, p. 198).

\subsubsection{Researcher's Clinical Notes}

Qualitative data by means of carefully documented clinical notes regarding the two children provided rich meaningful information. These clinical notes are part of a music therapist's usual clinical practice, were written following each session, and included progress notes in the narrative and key points related to the goals within the monitoring sheet. The data collection period consisted of 38 sessions (19 for each child), which culminated in a total of 69 pages of clinical notes for coding.

\subsubsection{Researcher's Reflective Journal}

Rich descriptive notes from a reflective journal were also reviewed. A reflective journal is part of a music therapist's usual practice and is a way to document personal reflections, learning process, critical thinking and the like. This was a valuable source 
of information related to my viewpoint as the clinician aiming to work towards communication-related goals. Journal entries documented the process of discovery as a clinician working with these particular children, reference to strategies that had worked or not, proposed reasons and thoughts about why and how and what to try next. These served to contribute to and supplement the developing theory and my working knowledge as the researcher in conjunction with analysis of other data sources.

\subsubsection{Audiovisual Recordings}

As part of clinical evaluation, I regularly reviewed audiovisual recordings of music therapy sessions and it is usual practice at the centre for music therapists to index observations related to clients' goals and focus areas. The cameras in the music therapy rooms are fixed to the wall, are positioned for optimum view of the session, and the audiovisual material is recorded directly onto disc. 540 minutes of audiovisual material of Zack were available, so time samples were chosen to systematically reduce the amount of time involved. Using the programme 'QuickTime Player', Sessions 3, 6, 9, 12, 15 and 18 were reviewed in order to index and record meaningful, qualitative data relating to Zack's speech and language development at different points across the period of music therapy. I reviewed audiovisual recordings between minutes 5 and 15 of each of the six sessions, a point at which Zack was anticipated to have settled after the routine greeting. The beginning of each session (minute 0 ) was defined as the first entry into the music therapy room. This resulted in a total of 60 minutes of audiovisual material for analysis. The use of audiovisual recordings as a data source enabled review and analysis of how music therapy supported speech and language development through a different perspective or viewpoint. This allowed a broader view of the interaction between myself and Zack, the role of the music and my behaviours that may not have been represented in other data sources, thereby providing a more thorough account of the subject.

\subsubsection{Notes from Communications}

Communicating and collaborating with others involved in children's lives is often a part of a music therapist's usual practice and is considered to be a valuable part of the

\footnotetext{
${ }^{7}$ See http://www.apple.com/quicktime/what-is/
} 
work at the centre. Communications with a child's parent(s) and carer(s) before and after music therapy sessions were documented in the clinical notes and used as a data source. These included checking in about the child's health, behaviour, and any other factors that might indicate what goals to focus on or how to address them in the ensuing session. Review meetings were held every six months with parent(s) and carer(s) as a part of centre practice however these were intentionally not included as a data source as they were not considered relevant to this research. These could perhaps be more appropriate to include in future research to gain parents' and carers' perspectives if, for example, evaluating or measuring children's progress, which was not the aim here. Notes from communications with Early Intervention teacher(s) and Speech and Language Therapist(s) as well as other music therapy professionals were also documented within clinical files and later used within the analysis with permission.

\subsection{Data Analysis}

The research process involved looking back (secondary review) over children's clinical files including the clinical notes written following each child's music therapy sessions as well as notes from communications, re-examining notes written in a reflective journal, and reviewing audiovisual recordings. It is important to note that the qualitative analysis of clinical notes and reflective journal were carried out prior to that of the audiovisual recordings and therefore may have shaped my approach and response to that data (Bruscia, 2005a). The computer software programme 'Preview' was used to create computerized colour-coded annotations in the form of note-pad comments, key points and highlighting on pdf copies of raw data.

Classified as 'variable-orientated analysis using a cross-case approach' (Bruscia, 2005a), I looked at the data for each child to identify variables, or categories, and then compared across the cases to identify common categories and thematic relationships among these. I analysed and reflected on the qualitative data drawn from the data sources outlined above in six-week blocks using the principles of grounded theory (Corbin \& Strauss, 2008; Daveson et al., 2008). I used 'purposive sampling' searching for certain aspects within practice. As a beginning researcher, I carried out a literature review as part of the research proposal prior to applying grounded theory in

\footnotetext{
${ }^{8}$ See http://support.apple.com/kb/ht2506
} 
order to gain knowledge about the topic and methodology, and to formulate initial questions (Corbin \& Strauss, 2008; McCallin, 2003). Therefore it was important that I be reflexive, cautious in dealing with expectations, and that the research supervisor guide throughout the process (Amir, 2005; Chamberlain, 1999; Hawker \& Kerr, 2007).

\subsubsection{The Grounded Theory Process}

\subsubsection{Analytic Memos}

Researcher insights, thought process, and analytic decisions throughout the analytic process were documented in written memos (see Appendix 8). These memos, which are common practice within qualitative research, are a form of methodological log that enables themes, ideas, questions and challenges to emerge about the data (Bruscia, 2005a; Payne, 2007). I included raw data in my memos to ensure that the developing theory remained true to the data, which is emphasized by constructivist grounded theorists (Mills, Bonner, \& Francis, 2006). Care was taken to note and minimise any of my own theoretical influences (Payne, 2007). Further, conceptual detail and integration of analysis during the process was recorded and could be drawn on whilst writing (Corbin \& Strauss, 1990, 2008).

\subsubsection{Open Coding}

After carefully reading and re-reading the material concerning Yvan and Zack, I identified and highlighted units of interest and of relevance to the research question. With an inductive approach to coding as recommended by Corbin and Strauss (1990, 2008), words, phrases or longer segments of text were labelled using words in the data (see Appendix 9). A list of categories soon developed, with codes initially developing in the areas of vocal/verbal responses and physical responses (see Appendix 10).

\subsubsection{Axial Coding}

Examining, comparing, and reflecting upon each category allowed me to discover relationships between categories, further define properties, as well as re-categorise and re-organise sub-categories under broader related categories (see Appendix 11). This process is known as axial coding (Amir, 2005; Hawker \& Kerr, 2007; Payne, 2007). Corbin and Strauss (1990, 2008) emphasised the importance of defining 
categories by the arising conditions, how each is expressed and the language used, as well as the effects of each in order to facilitate the explanatory power of more abstract concepts.

\subsubsection{Theoretical Sampling}

Using a second six-week block of data I began another round of the above steps of the coding process in order to develop categories further. Careful consideration and constant comparison was again required to focus on the research question. This ensured that, although immersed in the categories and patterns that emerged from the first sample of data, I remained open to new categories and that each label was true to each unit of interest. At times it seemed clear that interpretive codes were more appropriate than descriptive codes, as my knowledge of music therapy allowed insights, interpretations and inferences to be drawn from the raw data (Bruscia, 2005a). For example, the construct 'client-centred approach' was created in response to axial coding. Descriptive concepts that were identified such as being playful and keeping it simple were prevalent throughout the data collected and a larger interpretive construct regarding my client-centred music therapy approach served to unite foundational aspects of my work (see Appendix 12, Table 1).

Theoretical sampling continued through a third round of 'purposive sampling' from each of Yvan and Zack's data sources and the respective cumulative data analysis. A couple of new categories arose which served to refine axial codes, however during this third round it soon appeared clear that a saturation point had been reached.

\subsubsection{Saturation}

Key to grounded theory, the method of constant comparison was employed (Hawker \& Kerr, p. 88). This involved moving between new data, old data and categories already identified to compare and contrast (Corbin \& Strauss, 2008). As more data was coded, broader, more analytical categories and new sub-categories emerged, necessitating revising, relabeling, merging and splitting of categories, which then enabled more efficient ongoing labelling. During coding of the third six-week block of data it seemed that with four core categories a saturation point had been reached, and the categories were then defined or re-defined as appropriate. 


\subsubsection{Grounding the theory}

In order to satisfy that the theory I had developed was conceptually meaningful and gave a coherent account of how music therapy had been used to support children's speech and expressive language development I returned to the data. To test the theory for validity, quality and goodness of fit, segments of text from the data were explored deductively and systematically compared and fitted within the theory produced from the analysis using rigorous constant comparison (Chiovitti \& Piran, 2003; Payne, 2007).

\subsubsection{Core Category}

The culmination of one core category through the process of selective coding is considered an integral representation of the central phenomenon, construct or main analytical idea of the research (Amir, 2005; Corbin \& Strauss, 1990). However there are different views as to whether or not theoretical integration must result in one core category (Payne, 2007) and some authors describe the culmination of several core categories as 'conceptual ordering outcomes' rather than a complete grounded theory (Daveson et al., 2008). While a core category is proposed as a working hypothesis (see discussion and conclusion), the four core categories that arose through the process of this research could be considered as conceptual ordering outcomes.

\subsection{Summary}

This piece of theoretical research involved secondary analysis of qualitative data drawn from usual clinical practice including clinical notes, reflective journal, audiovisual recordings, and notes from communications regarding two children from my caseload. I reviewed, coded, categorised and recategorised the data using the method of constant comparison and analytic memos within the process and principles of grounded theory. The four core constructs that were inductively created are presented as the main findings demonstrating how music therapy has been used to support speech and expressive language development for pre-school children with special needs. 


\section{Chapter 4. Findings}

Client-centred music therapy with individual pre-school children, involving playful but focused songs, behaviours and instrumental play, can enhance their speech and expressive language development. These four main constructs were inductively created using the principles of grounded theory to represent how music therapy was used to support speech and expressive language development. Each of the four constructs comprise of a number of concepts and subconcepts, in bold through the text. Details of these concepts and examples of data illustrating each are included in four tables, see Appendix 12.

\subsection{A client-centred approach, drawing on strategies for choice, intuition and planning to enhance the relationship within the environment}

By establishing a therapeutic relationship within a stable, safe environment, planning, working intuitively, and providing avenues for choice I was able to approach my work with children in ways that fostered, facilitated and encouraged their individual motivations for expression and communication in order to develop their speech and expressive language.

Establishing a therapeutic relationship within a stable, safe environment was evidently important in my work and is considered to have a reciprocal relationship with the other theorised constructs and concepts. As I noted in my reflective journal, "before my strategies can be explored or start to result in speech and language development AND before the client feels comfortable to volunteer there needs to be a relationship. BUT at the same time, the relationship develops along with the communication experiences" (01/10/11). Events of vocal activity appeared spontaneous at times yet often occurred when children seemed at ease, settled, engaged with me and the music and confident to explore within the space. Through my appropriate responses and encouragement these children appeared to feel able to vocally or verbally express frustration, hurt, surprise, celebration, pride, excitement and anticipation of favoured activities. It also appeared important for children to know what to expect, what was expected of them, and where the boundaries were within 
sessions. Therefore establishing a non-threatening environment that could foster these with opportunities for self-expression and routine were beneficial parts of my approach.

The planning involved within my work was highly centred on each child, as what worked with one didn't necessarily work with another. I discovered what each child was interested in and motivated by as well as their strengths and focus areas and incorporated these into the music therapy sessions. Personalized songs were developed and lyric substitution was tailored to incorporate each child's favoured words as well as target sounds. Being aware and alert to children's individual presentation and checking in with parents and carers as to what was happening for each child was an important contributing factor into what I focused on or attended to within sessions. These included children's energy levels, health or wellness issues (such as glue ear or respiratory illness), attention span, engagement, need for parent or carer's proximity, starting pre-school, as well as a child's growing independence, confidence, selectiveness and assertiveness. Knowing these kinds of influential factors and responding appropriately and individualising the approach taken with each child was evidently significant in my work.

Another important aspect of planning was collaborating with parents and carers and other specialist professionals. Reciprocal support between music therapy and home or other contexts was considered valuable, as well as sharing knowledge and observations of progress. As a part of my clinical development I identified strategies from review of the literature and incorporated these where appropriate in my practice. The physical environment was intentionally tailored to meet each child's needs. Minimising distractions and interruptions was considered valuable and instrument placement and positioning was planned to motivate, allow physical distance or both. It was evidently important that I was available and attentive to each child, ensuring that we were facing each other, at roughly the same eye level, often seated approximately 1 metre from each other. Other aspects of planning included keeping it simple and considering the balance between talking, singing, playing and making music. While my own spoken or sung expressive language was a valuable inclusion for modelling and extending a child's expressive language, active instrumental music making offered a musical space in which children's spontaneous speech arose. 
Working intuitively, being flexible and adaptable in response to a child's interests and actions was important. Allowing children time to respond and time to produce a sound or word also proved fruitful, prompting them with encouragement and discretion while maintaining patience. Children's speech and expressive language often occured within a playful environment. This was a strong concept evident throughout the data and was about me, as the therapist, being playful, keeping things interesting and having varied, playful activities. For example, hunting for the animals hiding, playful moments of mock fright about the crocodile puppet, and bringing the monkeys up the side of the drum and onto a child's tummy. Children appeared to experience me as someone who was focused on them, so that they were motivated to engage me further by, for example, offering a beater and saying, "here you go" or, "come on Shari". Mutually cooperative, collaborative play was extremely valuable, but was mostly led by the child.

A prominent aspect of working intuitively involved judging when to push. Even if a child's choice or meaning was understood from their physical gesture or request, it was important to judge:

- when to delay my response to increase that child's motivation to communicate;

- when to insist on a verbal choice, perhaps in conjunction with a visual, to increase the amount of speech and expressive language but also to increase functional spontaneous speech;

- when to expect more and extend a child from their use of key words for example when choosing an instrument, instead of complying in response to "that one", persisting to extend their verbal response to naming the instrument; and

- when to insist on a child's verbal contribution in a task before moving on to the next task of their choice.

Pushing more seemed increasingly possible once the relationship felt suitably established, safe and secure. Learning a child's version of words, alongside context and a parent's help interpreting, was a valuable part of developing music therapy sessions. However it was then important to reflect that child's meaning and model 
accuracy and intelligibility, extend and push them where possible so that interpretation became less necessary. Being able to judge was highly related to an increasing awareness of influential factors, for example taking caution to avoid escalating a child's frustration.

Providing avenues for children's choice(s) was about offering structured strategies for children to make decisions and gain an empowering sense of control. Further, it was about responding to and incorporating children's expressed suggestion(s). The use of visuals evidently empowered children to choose an instrument, song, animal, people, and activity. Consideration of how many and how to present them was dependant on what seemed to best suit each child. Regularly updating visuals and therefore what instruments, songs and activities were offered was considered, for example keeping a child's favourites but adding new ones to maintain interest, and visuals were also used at home. Visuals were used to extend Zach's communication through Makaton sign language and gesture, and it was noted that with increased confidence over time Yvan was able to communicate his preferences verbally without the use of visuals. A choice of instrument was offered from what was in the room and by opening up the instrument cupboard. When children got to play their choice they seemed more motivated and worked harder. Within the lyrics of the song What's Next? (Ritholz \& Robbins, 1999, p. 62), at times adapted in the moment during sessions, clients are offered the opportunity and prompted to choose what to play or do next. Being open, accepting, encouraging and responding to a child's independence and selectiveness was important for fostering choice. Communication and vocal contribution increased following my positive response to children's spontaneous communications to include their parent, carer or sibling, to initiate endings, or to agree or disagree.

\subsection{Engaging in and enhancing verbal, musical and non-verbal behaviour}

How I was behaving in my role as a therapist in music therapy sessions impacted children's contributions. Occurences of children's spontaneous vocal activity, immediate and deferred verbal imitation or response were often in response to or in conjunction with what I was doing. Three concepts of my behaviour were identified through axial coding and comprise of musical, verbal and non-verbal behaviours (see 
Table 2). Later, with the formation of my 'client-centred approach' as a main construct, these three concepts within the behaviour construct were redefined as follows.

Aspects of my verbal behaviour pertain to both speech and song. Modelling, a very common aspect of my work, often prompted children's immediate and deferred imitation and was considered valuable in contributing to increased intelligibility, phrase length, and use of adjectives and nouns. Imitating children's vocal activity in a way that met or matched their dynamic or vocal quality or both proved fruitful. Further, incorporating children's key words and spontaneous speech and expressions in an extended phrase or sentence often led to children imitating or saying more. In this way I was also able to initiate incorporating target sounds and words and develop consistency. For example the "st' cluster in "stuck", sometimes pronounced "duck", became more consistent for one child during the 'hand-stuck' game (see Table 2 for an example of this game). Verbally reflecting the child's actions or behaviour back to them also included meeting their frustration in dynamic and vocal quality with "you can do it!" and then celebrating their efforts and success.

Repetition was a prominent aspect of my verbal behaviour and was emphasised in communications as being crucial for children's development particularly at pre-school age. Repetitive phrase exchange incorporated turn-taking or a structured pattern that the child was familiar with. An important aspect of this was that children knew what to expect, they got something out of it and there was a known end result at the end of the game. Exaggerating vocal sounds including consonants sometimes led to a more accurate approximation of the word, for example when a child said, "ash" I modelled, "Ccccrash ccccrash" and the child then imitated, "cyash Shayi, cyash Shayi" (crash Shari). Pausing in anticipation for children to fill-in-the-gap or complete the phrase or sentence was used extensively, for example, "We've got -" spoken with a rising, anticipatory tone followed by waiting for the child to respond. Being "less wordy" and using concise, clear language at each child's level, for example one-part instructions, was important throughout.

It became clear that I was more or less direct in terms of the way I phrased questions depending on the child and their presentation in that moment or session, which related to influential factors. It was particularly important with one child to judge when to 
sing or say expectant phrases such as "can you play" which had the potential for failure. Being direct was considered the most appropriate avenue when a child was frustrated, or to engage them within an activity or song "Hey, what's that?" or "What's up there?" At times this was supported with an anticipatory pause (described above) such as "It's a -". At times when children gestured physically I invited, for example "Shall we play the [instrument]?" or offered an open choice, "What would you like?" Offering options for choice was perhaps the most useful type of question, in that it did not allow for a yes or no response and encouraged the use of nouns, functional words and phrases. For example, when a child gestured physically I asked, "Would you like [this] or [that]?" At times I imitated children's vocal activity with an ascending 'questioning' inflection in my tone (with an imperfect cadence) to clarify what I had heard. However at other times I reflected the opposite of what I understood to be the child's meaning with the intention of motivating the child to correct me. It was important that this be used with discretion and judging when to push in order not to increase frustration levels with feeling misunderstood.

My musical behaviours often elicited or evoked children's speech and expressive lanugage. Modelling, matching and reflecting children's actions or behaviour musically, improvising, and developing musical exchanges and interactions such as turn-taking elicited children's spontaneous vocal activity including laughter but also communication, for example "my turn". Pairing rhythm with speech was a strategy which proved fruitful at times in supporting and extending children's speech or singing. Varying musical elements including dynamic, key, speed, phrasing and timbre also fostered and extended children's vocalisations.

Harmonic cadences were valuable musical resources, as were melodic cadences wherein the final note of a melodic phrase implied suspense or resolution. The use of imperfect cadences at the end of a phrase emphasised the feeling of incompleteness and my anticipation or expectation of the child's response. For example, when I modelled, sang questions, or paused in anticipation for the child to fill in the gap. Plagal cadences were often used when I was accepting the child's choice. I used perfect cadences for example when I imitated or reflected a child's vocal activity to celebrate their contribution and to portray that they had the answer or that they had completed the phrase. Rhythmic cadences were also useful and supportive of melodic or harmonic phrasing. For example, playing a drum roll while vocalising "aah" in 
ascending pitch with crescendo, from soft to loud, led children to say "snap" in the song Teasing Mr Crocodile (see Appendix 12); "crash" on the cymbal or as various animals bounced off a drum; and was also used to extend "and" leading to "bumped his head" in the song Five Little Monkeys (see Appendix 13). Musical gesture such as these proved useful in prompting and expressing anticipation of children's contribution, for them to throw a monkey off the 'bed' or say the final word, as well as providing an avenue for free vocalising.

Aspects pertaining to my non-verbal behaviour were affirmed through analysis of the audiovisual recordings. Matching a child's gestures such as dancing side-to-side along with them, pointing when they pointed, holding my hands up and outspread as the child did to indicate "what was that?" or surprise seemed to nurture the sense that I was engaged with the child and was often followed by their verbal or vocal expression or communication. Taking a deep breath or gasp either emphasised that I was waiting in anticipation or modelled the breath intake needed to play a wind instrument, and I was also able to encourage children's contributions with physical gesture. For example I often wagged my finger as I sang the lyrics, "no more monkeys jumping" in Five Little Monkeys (see Appendix 13) or wagged my head as I sang the lyrics, "You can't catch me" in Teasing Mr Crocodile (see Appendix 12). Emphasising the physical action supported verbal activity such as that of bringing the lips together to form labial sounds ' $\mathrm{p}$; $b$; $\mathrm{m}$ '. To show engagement, excitement or anticipation of something happening I used facial expression, for example raising my eyebrows and forming an 'o' with my lips.

\subsection{Capturing children's preferences and vocal activity in the content and structural aspects of playful but focused song}

The content and structural aspects of song comprise of a number of considerations as to what songs I incorporated and how I adapted or incorporated them when planning sessions as well as in the moment during sessions (see Table 3).

Framing or supporting a child's participation was a prominent aspect of the content within songs. Hello and goodbye songs structured sessions, established routine and were a way of creating context for children. Reflecting or supporting a child's actions was possible in song, naming us, about us making music, about our music making in 
the music room, or putting a frame around a child's play. Incorporating children's vocal activity was also valuable within improvised song, or lyric substitution in the moment. Incorporating children's preferences or known motivators was often preplanned or continued from previous sessions, including picking up on interests such as pirates or something from home that children initiated or that parents or carers might have mentioned. One other aspect was fostering children's play of wind instruments by singing about the sound it makes or incorporating the sound into a song, for example about trains.

It was clear that playful content of a song supported or contributed to but was distinct from the playful, client-centred approach. Songs that involve play or games were uniquely useful in their own right. Examples include Teasing Mr Crocodile (see Appendix 12), improvised song about a child being the 'king of the castle', and substituting the lyrics of Frere Jacques with Are You Hiding (see Appendix 14), which could further explore prepositions for example "in the cupboard". Cognitive skills including counting and sequences, colours, size, nouns, prepositions including in/out, in front/behind, on/under, open/shut or closed were incorporated into song such as Five Green and Speckled Frogs (see Appendix 15) and hide and seek games.

Incorporating and encouraging animal sounds within song proved highly engaging, as was supporting eating actions and sounds through song and using children's names. The use of a song about a popular animated character was particularly poignant and powerful for one child, who responded and participated enthusiastically because his name was incorporated within it. Composed, improvised and precomposed songs targetting each child's known focus areas in terms of sound or word productions including initial sounds, final plosive sounds such as in "pop", front sounds and softer sounds such as ' $\mathrm{t}$ ' when ' $d$ ' was easier. It was important to know which sounds were consistent (or not) for each child and which sounds not to target yet because they were not within the zone of proximal development. This also tied in with children being able to say their own name.

The structure of songs used was another key concept of supporting speech and expressive language development. I used pre-composed music during sessions, but often substituted the lyrics of tunes known to be familiar to each child. This was either planned (to target a child's focus areas or incorporate known motivators) or 
improvised in the moment and then continued in ensuing sessions. Improvising lyrics and song sometimes developed from a precomposed song or planned lyric substitution and was adapted in the moment in response to the child to support or incorporate their vocal activity. The structure of songs provided opportunities for repetition and practising and refining sounds or words and facilitated increased self confidence and self-esteem. Repetition of the word "toot" in the Toot Toot song (see Appendix 16), which was sung across the treatment period, was infered as having facilitated outcomes. Improvising within the song to include repetition of a consonant targetted a sound for a child to produce, for example " $\mathrm{t} t \mathrm{t} t$ toot". Another aspect for consideration involved choosing whether or not to accompany the voice harmonically on guitar or piano.

Pausing for children to fill-in-the-gap sometimes led to children's lengthy responses as well as choice, however any vocal activity, sound or word approximation was aimed for. Leaving a gap may set up an expectation that is too demanding for some children, and evidently was at times too demanding for children in relation to external influential factors (see 4.1). As such care and consideration about when to incorporate this strategy and judging when to push for more was important. At times when I continued playing the guitar or piano or other instrument between verses of a song this provided space for free vocal activity that was perhaps less demanding than pausing for that child to fill in the gap. Within song if children anticipated their role coming up, for example to choose an animal for the next verse, they often participated and even preempted this. It was important to ensure that the role established was at that child's level of capability. For example, the structured turn-taking within the song Toot, Toot (see Appendix 16) was a reasonable expectation and goal to work towards with some children but not necessarily others.

\subsection{Incorporating children's preferences for themed and functional instruments}

Instruments were an integral resource within music therapy and served both as stimuli and support. This was a slightly different construct from the others as the concepts appeared to be interconnected while being very distinct and having their own distinguishable functions. Including a child's known favourite or motivator was something I found consistently helpful. Incorporating wind instruments, animal- 
themed and food-themed instruments, instruments with the potential for onomatopoeia and object metaphor, providing a variety of sizes and including a microphone were all important constructs of the type of instrument chosen to support speech and expressive language development (see Table 4).

When playing their favourite instrument or an instrument known to motivate them, children were engaged and contributed more in terms of both speech and expressive language but also other goals including sensorimotor activity. Children were consistently interested in and motivated by animal-themed instruments, which provided stimuli for play and making animal sounds. For example, the sound of the action on a frog guiro is likened to a frog's "croak". I believe it was the animal itself that motivated children to make the animal sounds and the animal-themed instruments brought those motivators into the room to be used towards therapeutic goals. A range of fruit-themed shakers including a banana, orange and apple, as well as a lollipop drum proved very useful within songs to support eating actions, but also to support choice and use of nouns.

The use of wind instruments such as reed horns, recorders and swanee whistles develop labial closure, oral muscle tone and coordination and strength of air flow. Further, free exploration with vocalisations is also facilitated by the kazoo, while an additional aspect of horns explored by children was using the bell as an echo chamber. These aspects can also contribute to addressing wet voice and excess salivation. Consideration of potential frustration at failure to master the recorder and swanee whistle was important, as was the potential for confusion between playing the reed horns and kazoo. Ensuring no instrument swapping was also important due to hygiene and child susceptibility. Vocalising the sound an instrument or animal makes, a form of onomatopoeia, was often initiated by children, including "crash" as we played the cymbal, "kk" as we played the claves or used them in a sword fight, and was incorporated into the song Toot, Toot (see Appendix 16).

The association of an instrument to a different object, object metaphor, provided a platform for experiences. A glockenspiel and xylophone provided a metephor for train tracks for a child to ride the trains along and say "ug ug ug" (chug) and "oo". A guiro was used as a rocket ship, inspiring play and phrases such as, "To infinity and beyond", taken from an animated movie. Providing instruments with a variety of 
sizes also proved fruitful. For example, including a variety of sized frog shaped percussion in sessions often led to children's spontaneous description of the larger ones as "big" or as the "mummy" or "daddy". Including a microphone provided an empowering avenue for free vocalisation and singing. Consideration of how to support this harmonically was important, particularly with a child who tended to disengage when I went to the piano but who connected well with drumming to support.

\subsection{Summary}

Through the process of this research four meaningful aspects of music therapy were evidently valuable toward supporting children's speech and language development during my clinical practice. My client-centred approach arose to incorporate many foundational aspects of the work including establishing a relationship and environment, planning, working intuitively and offering strategies for children's choice. How I, as the music therapist, behaved musically, verbally and non-verbally made an impact. The content and structural aspects of songs were important resources to consider as were the particular use of themed and functional instruments. A tree model has been used to capture these four meaningful aspects of music therapy, as shown in Figure 1 (see page 34), and the vignette that follows illustrates many of the concepts described here. 


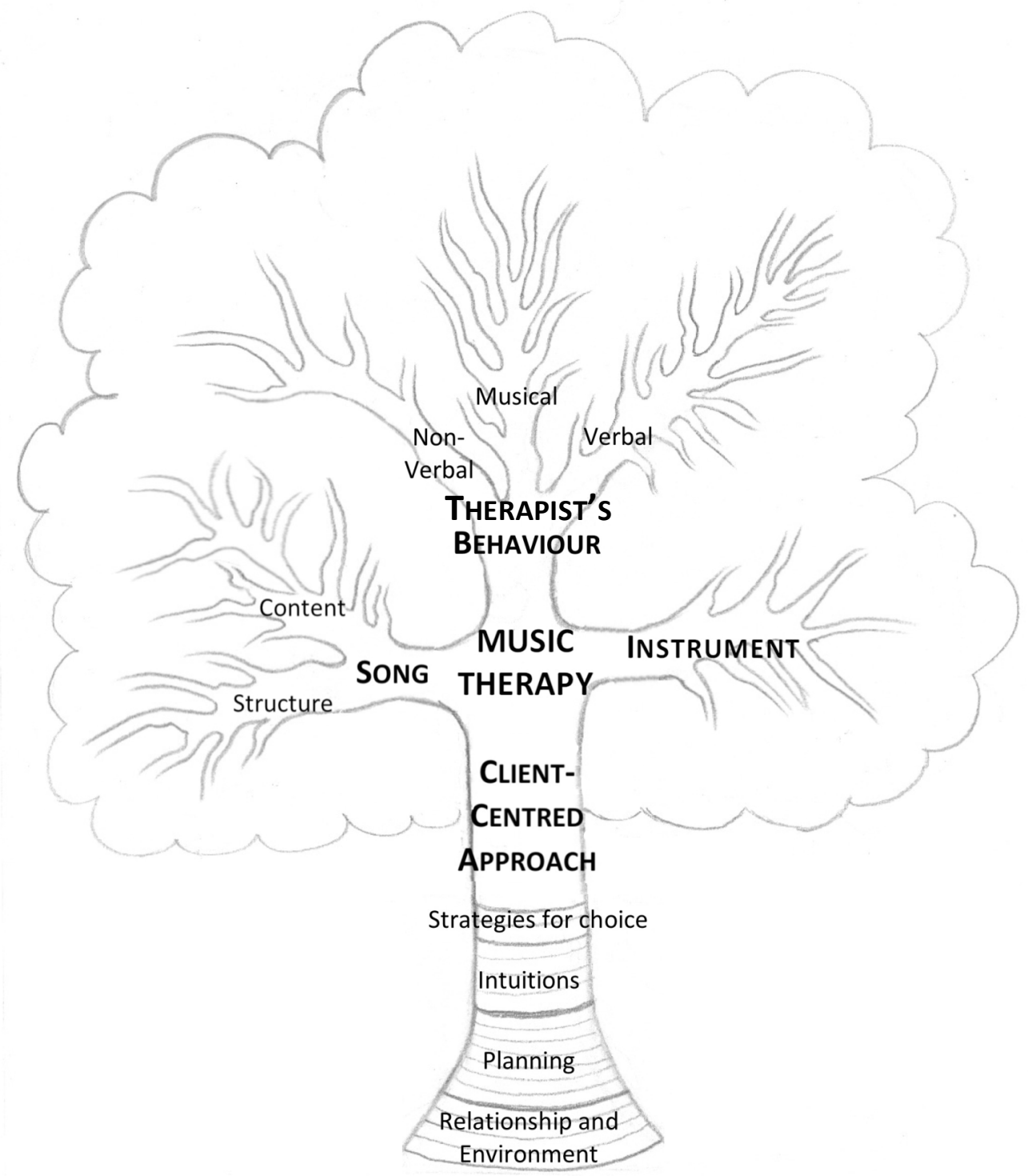

Figure 1: Tree model used to capture the four meaningful constructs that represent how music therapy has been used to support speech and expressive lanugage development for pre-school children with special needs. 


\section{Chapter 5. Vignette}

The following vignette comprises a session excerpt that has been chosen because it has a particularly concentrated set of examples that capture my theory and illustrates much of what I have found through this research process. Some of the constructs and concepts developed through theory building are exemplified by words in bold through the text. The excerpt conveys insights into the musical and behavioural processes that invited words and conversation, various playful, intuitive strategies employed within a client-centred approach and a child's high motivation and delighted engagement and enthusiasm with certain instruments and within song.

\section{Background}

Zack (pseudonym) is a lively four-year-old with a diagnosis of global developmental delay. Music therapy was recommended to the family by Zack's speech and language therapist and at the time of referral Zack (3) reportedly had no recognisable words and used some Makaton sign language to communicate. During the initial assessment period I noted that Zack's speech was not always clear however he had spoken approximately 20 recognisable words during music therapy. The most common words were "frog(s)" within the fill-in-the-gap song Galoop went the little green frog (see Appendix 17) as well as in response to questions with options for what to play, "crash" alongside the cymbal being played, "horn" and "stuck" with his fisted hand held in the bell of the horn, "what's that?" and "hello" spoken into the bell of the horn. Within these Zack's intelligibility varied, final sounds were not yet consistent, middle sounds ' $r$ ' and ' $\mathrm{l}$ ' approximated by a ' $w$ ' or ' $y$ ' sound and initial consonants ' $\mathrm{t}$ ', 'st' or 'th' were absent or pronounced ' $\mathrm{d}$ '.

I met with Zack's mother following the initial assessment period to review Zack's music therapy and we recognised that he was still getting used to the environment without either parent in the room. We agreed that music therapy sessions could offer a playful and creative environment that could focus on supporting his communication skills and sensorimotor development. Zack had a total of 21 sessions between March and October. Framed by a greeting and goodbye song, our individual 30-minute sessions were client-led, allowed choice and offered opportunities for structured 
music and activities, free improvisation and collaborative play that could motivate goal-related outcomes.

\section{Session 17}

Upon seeing me in the waiting area Zack smiled at me and quickly ran over to clasp his dad. I smiled, greeted them both, then with a beckoning hand gesture and breathy, excited voice I invited Zack, "Let's go and find the animals hiding in our music room". We all walked to the room then without a backwards glance to his dad Zack headed directly to the large gathering drum with animals pictured on the side and began swiping the animal-shaped percussion and finger puppets off the drum.

After a few minutes of exploring the room he looked over to a finger puppet that had earlier landed on the floor. Observing that his attention was newly engaged I sang, "What shall we play with next?" with a sung imperfect cadence, which might have suggested to him to go further. Zack retrieved the puppet, answering, "a moynkey". I gasped in excitement and he quickly turned to show me it, saying "a cow". "Oh, it's a cow" I said, in a tone to show mutual understanding then sang, "What noise does a cow make?" with an imperfect cadence, giving a musical invitation for his answer. Zack responded, "moo" in a growly voice as he crawled towards another finger puppet on the floor by the wall. I imitated his growly cow noise as I crawled over to the large gathering drum near him, then sang, "What have we got in the music room?", repeating the melody and imperfect cadence from earlier. "A na, a moynkey!" Zack said, standing up and turning around to show me the monkey puppet he had found. I playfully modelled the pronounciation by improvised singing, "a monkey" six times, melodically alternating between implied chords I and V and on the last time sang "in the music room" with a perfect cadence, giving a sense of the ending of this sequence.

As I sang I lifted the large gathering drum upright and Zack came to stand next to me. Looking at the drum, he put the animal puppets he had on top, played it briefly then looked around in a way that made me think he either couldn't decide or didn't know what to do next or how to initiate it. I invited, "Shall we sing a song about the animals?" and waited for a few seconds until Zack replied, "yes”. I modelled, "Let's sing a song" as a functional phrase, and moved around to face him across the drum as we fell into hand drumming with a steady pulse which he had initiated. I began 
singing Teasing Mr Crocodile, familiar to our previous sessions (see Appendix 12, verse 1), but this time substituted the lyrics to include the puppets Zack had brought onto the drum (see Appendix 12, verse 2). When I got to the first line of "You can't catch me" Zack had stopped drumming and began dancing side to side and as that line repeated he sang along with me at pitch, "You (can't catch) me". When that line ended Zack continued with another "you" but seemed to realise that I wasn't still singing, paused and his head and body dropped slightly. Observing this, I quickly sang another line of it and he sprang back into dancing action.

Substituting the lyrics "along came the cow, moooo" incorporated Zack's vocalisation from earlier, and he joined in with "moo". Jumping up and down Zack then vocalised a mixture of consonants as I sang an ascending vocal glissando on "and" with crescendo as I brought the cow slowly closer toward the monkeys he was holding. When I reached the monkeys I playfully bounced them all apart exclaiming, “crash!" but didn't immediately begin the next line, and Zack then imitated, "cya". In the second verse (about one little monkey) Zack again joined in the second line with more sounds, "you ca(n't) ca(tch) me". To build on his contribution I repeated the line again, at a slower speed, exaggerating the final sounds of each word, "cannn't, catccch, crassshh".

I continued singing the same tune, adapting the lyrics as we went to incorporate each of our contributions - Zack copied me as I crouched behind the drum and brought a small plastic frog up onto the drum and as Zack climbed onto the drum I repeatedly sang, "one little monkey climbing on the drum" with a surprised expression on my face. When Zack brought a monkey puppet up the side and onto the drum he sang, "one li-wo monkey cyimbi(ng) on", with an emphatic loud tone, matching the rhythm of the tune. With a surprised but excited expression on my face and eyebrows raised I exclaimed, "oh there's a monkey on the drum" emphasising "on the drum" loudly, clearly, striking the drum on each word. Later, Zack grabbed a horn from beside the pile of animals on the floor and we spontaneously took quick turns blowing a note each before Zack said, "toot". The first time I had heard him approximate the initial ' $\mathrm{t}$ ' consonant, I interpreted this as Zack initiating the Toot Toot song, used in previous sessions (see Appendix 16). So I changed gear and began singing this and the session progressed. 


\section{Chapter 6. Discussion and Conclusion}

Throughout the learning process as a student music therapist my inquiry predominantly revolved around how to address my clients' goals and how I could meet their needs through music therapy. Using the principles of grounded theory I was able to identify and categorise four main constructs regarding how I supported speech and expressive language development in music therapy when working with pre-school children with special needs. The use of a tree metaphor helped bring together and make coherent sense of my main finding, that client-centred music therapy with individual pre-school children, involving playful but focused songs, behaviours and instrumental play, can enhance their speech and expressive language development. This discussion addresses the importance of music therapy for developing speech and expressive language in young children, several implications for my developing and future clinical practice that arose through this research and how these relate to the existing literature. I outline some limitations of the research process and make recommendations for future research.

\subsection{Music therapy principles and methods}

Many of the constructs and concepts that arose through this research are not exclusively specific to this area of work and many relate back to general music therapy principles and methods. Central music therapy texts discuss the empowering nature of clients' decision-making, the value of a common history of expectations (routine) and unconditional positive regard within an appropriate therapeutic clienttherapist relationship and within a stable, safe environment in music therapy (Bruscia, 1998; Bunt \& Hoskyns, 2002; Darnley-Smith \& Patey, 2003; Wheeler et al., 2005; Wigram, Pedersen, \& Bonde, 2002). The finding of the importance of a client-centred and individualised approach was congruent with the review of the literature and is further supported within the literature in occupational therapy, speech and language therapy, early intervention and child development. "As we observed...it is the spontaneous initiation of ideas by the child that seems to be important at this stage [of development]" (Bunt, 1994, p. 86). It is considered a vital part of the work with preschool children to work at their level and individualise the approach to meet each child's particular needs (Aldridge, 1996; Beathard \& Krout, 2008; Bunning, 2003; 
DeThorne et al., 2009; Grosz et al., 2010; Hoskyns, 2009; Malloch \& Trevarthen, 2009; Oldfield, 2006; Wright \& Kersner, 2001).

Further findings congruent with music therapy principles include planning and considering the physical environment, collaborating, working intuitively, allowing time and using space and silence, and the importance of being flexible (Bunt \& Hoskyns, 2002; Oldfield, 2006; Wheeler et al., 2005; Wigram et al., 2002). On a fundamental level clients are encouraged to explore instruments playfully and imaginatively and develop positive associations with the sounds and music they create (Bunt \& Hoskyns, 2002). Imitation and turn-taking are described as 'responseevoking techniques' (Wigram et al., 2002) and are emphasised as important behaviours in the development of language, joint attention and understanding (Bunt, 1994). Other therapeutic techniques such as accompanying, reflecting, and matching and the use of recitative and sprechstimme are also discussed and relevant within this area of work (Bruscia, 1998; Bunt \& Hoskyns, 2002). Authors consider a continuum between words and music and the need for common sense, appropriate clinical techniques and balanced integration, particularly within a student music therapist's developing theoretical orientation (Bunt \& Hoskyns, 2002; Oldfield, 2006; Wheeler et al., 2005).

These aspects of the work that could be considered part of a music therapist's everyday tool box were evidently part of my work. They were perhaps enhanced or focussed on when aiming to support speech and expressive language development. Findings suggest a number of aspects that are perhaps a set of tools from that tool box for specific consideration.

\footnotetext{
${ }^{11}$ Other clients in my caseload included children with intellectual disability, cerebral palsy, epilepsy and autism spectrum disorder
} 


\subsection{A music therapist's 'speech-and-expressive-language-specific' tool set}

\subsubsection{Finding a balance: Children's choice and control}

In focussing on extending children's speech and expressive language I placed a different emphasis within my approach, planning, use of resources and behaviours within sessions. For example, I provided strategies for children's choice. Also, the balance between talking, singing, playing and making music was noted to be different from that within my work with other children ${ }^{11}$. Oldfield (2006) also talks about the way her work with this client group is different than others, including the use of a slower pace, allowing time, and providing variety. In other circumstances or with other clients I might have encouraged them to manage my choices and extend their engagment with a wider range of instruments towards other goals. There are two interesting aspects that arise from this.

First, it is not to say that other goals can not be worked toward at the same time. From my experience it was possible to build in multiple goals. For example, I used a song about animals with a verse to encourage reproducing the noise an elephant makes, and the next verse to encourage a child to stretch his neck like a giraffe (see Appendix 18). Other goals, planned or unexpected, at times took precedence over speech-related goals during sessions due to children's presentations. This required me to be flexible in the moment, manage children's arising needs alongside those they were originally referred for, but also to judge when to push and challenge them (Leung, 2008; Oldfield, 2006). Moreover, although I was working toward speech and expressive language goals, playing, interacting, collaborating and creativity, which are goals in their own right, were all a part of the work. This is supported by research that indicated that it may the holistic scope within music therapy that supports and integrates aspects of development (Grosz et al., 2010).

Second, regarding allowing children's choice and control and judging when to push. With reference to my personal background (see the introduction) and a client-centred approach, careful consideration was required as to what felt the most appropriate response to behavioural issues, assertiveness and non-compliance within the boundaries of the therapeutic framework. When I met with a child's parent to review 
his music therapy I noted that these had increased along with verbal communication. It was very powerful for me to experience this child's progress and self-assertiveness, to set limits and offer choice, hear "no" in response to all but one of the choices on offer, and for him to then spontaneously and repeatedly insist "shush Shari". While enabling children with decision-making and control was valuble in enhancing and motivating their speech and expressive language as well as confidence and independence, it was important that the balance was a constant consideration, age appropriate, and within the boundaries of the session - time, safety and otherwise.

Several authors address the issue of control and the province for a music therapist to respect and provide choice for children who have very little control over their environment and aspects of their lives, even less than other children (Lorenzato, 2005; Oldfield, 2006). Findings within this research are consistent with research in the late 1970s and early 1980s which provided significant positive empirical evidence for the efficacy of music therapy with young children with diverse needs, including the area of vocal activity, language use and communication skills, particularly turn-taking (Bunt, 1994). In a comparison of music therapy and play sessions it became apparent that in music therapy what began as child-centred therapy with adult support then progressed toward more adult direction, turntaking, reciprocal interaction and a sense of partnership, while the opposite was seen in play sessions (The Hackney Project, as cited in Bunt, 1994). Part of working intuitively and engaging a child in mutually cooperative, collaborative play involved letting them be in control, leading our exchanges. Their awareness of this evidently contributed to their enjoyment and increased readiness to respond to and accept my direction over time.

Oldfield's descriptive case study with a five-year-old boy with a language disorder resonated in many ways with casework data collected in this research (Oldfield, 1991). Her description of building a relationship, playing games, providing choice and control, the use of song and pausing for the child to fill in the gap, the development of spontaneous speech and free vocalising, and the child's frustration felt synonymous with the concepts emerging in this research. Oldfield began with the premise that music therapy could provide her client with a setting for communication with an adult without needing receptive or expressive verbal language. Upon reflection I wonder if I could have provided a space without recourse to words for longer following the assessment period and come back to it more often throughout the work with my 
clients. Conversely what works for one child (or therapist) does not necessarily work for others, highlighting the importance of working intuitively, individualising the approach, and judging when to push in order to best meet each child's needs.

\subsubsection{Motivating children}

What I found consistently helpful was incorporating and building strategies around the instruments I found to be each child's favourite or known motivator. I continue to wonder if it was the fact that I had noticed and affirmed their choice or if it was the instrument itself, or both, that led to children's use of speech and expressive language. Regardless, incorporating their interests, using and repeating what motivated and engaged children provided a context in music therapy which seemed to optimise each child's motivation and confidence to vocalise and verbalise, something which is recognised by other therapists (Hoskyns, 2009). The use of particular wind instruments was in response to children's evident interest and to develop labial closure, oral muscle tone, and strength of air flow. Nordoff and Robbins (1983), pioneers of the Creative Music Therapy model, wrote, "Children find the sound of the reed horns stimulating and satisfying. The directness with which the clear tone results from their blowing helps them learn to place their tones with conscious intention. The controlling of breath necessary to play the horns loudly or softly, and to sustain tones, challenges the players' abilities and produces immediate musical results" (p. 85).

Free exploration of vocal activity, which is an additional element of kazoos as a wind instrument, can be a lot of fun and motivating for children with speech and expressive language difficulties (Beathard \& Krout, 2008; Hoskyns, 2009). Providing opportunities for self-expression and a wide variety of free vocal exploration including vowel sounds such as 'ah' and 'oo' is supported in other music therapists' description of the work (Bunt, 1994; Oldfield, 2006). These are further linked with Stern's 'affect attunement' (1977), Piaget's stages of a child's natural development (as cited in Bjorklund, 2005), Bateson's 'proto-conversation' (1979; Malloch \& Trevarthen, 2009) and concepts of musical interactions leading to vocalisations, preverbal babbling exchanges and later to the beginnings of speech. "Encouraging and stimulating all kinds of vocal activity through musical interaction becomes an important feature" (Bunt, 1994, p. 94). 
When children were engaged with me and with the music they communicated with increasing readiness and duration. They volunteered to communicate their preference, to name or describe something or someone, to redirect the session or to express an emotional response within the context of music making, a song, a game, when playing with the animals, or when initiating their interests or something from home. I became aware during the research process that this was about the environment I established, responding to and providing avenues for children's choice, being aware of and incorporating their interests and favourite instruments within music therapy. As noted in the review of the literature, spontaneous speech is an aspect of the work of increasing interest. There is great potential for this to be explored in further research, including the quantity and quality of spontaneously emerging vocalisations as identified by Bunt (1994), the mechanisms and strategies by which these occur and any contributing factors and influences. Of particular interest are findings indicating the possible efficacy of singing as opposed to speech for unprompted productions (Kouri \& Winn, 2006).

\subsubsection{Providing structure and context}

Particular deliberation as to the content and structure of songs used in music therapy was centred on speech and expressive language. It appeared that multiple strategies were often used within song, such as incorporating a child's preference, using their name, targetting their as yet undeveloped or inconsistent sound and word productions as well as pausing during song for them to fill in the gap. As illustrated in the vignette about Zack, expressive interactions and language use unfolded when there was flexibility, adaptability in response to him, use of lyric substitution, varied musical elements and playfulness. Moreover, repetition within the song did not appear to be silly or annoying for Zack, exaggeration and emphasis could facilitate development without it being monotonous practice, and therefore more was possible in the music therapy context. This is supported by Oldfield's description of her work with Jane and Joshua (2006).

Pairing rhythm patterns with speech patterns was reported to significantly improve working memory and speech production (Leung, 2008; Silverman, 2007). However, I found that the use of this strategy was client-dependant and although considered useful with other children in my caseload, this only worked a handful of times with 
the children within this research. Nordoff and Robbins (1983) note the opposite effect, that the use of a spoken phrase or name can support a child in grasping the rhythmic pattern, exemplifying the concept of reciprocal impact between music and language. "Converging evidence supports the use of melody and exaggerated prosody to faciliatate children's attempts and accuracy at speech production" (DeThorne et al., 2009 , p. 139). The questions that arose in the reflective journal around the efficacy and relevance of pairing rhythm and speech patterns toward speech and expressive language goals with pre-school children warrant further clinical exploration and investigative research of this specific approach.

Research in adult behaviour and corresponding effects on children was identified as having been more carefully researched since the 1960s (Bunt, 1994). When I noticed that children's vocal or verbal responses were often accompanied by their physical gesture, emotional and/or behavioural response, I was prompted to look back at what I was doing, which revealed that I also paired physical and verbal combinations. By making eye contact or pointing at an instrument when I named it, for example, I was perhaps creating or adding contextual information for children to aid their learning and understanding (Bjorklund, 2005; Jentschke et al., 2005; Loewy, 2004). From my experience, remembering to phrase questions in the 'right' way was difficult, and looking back over the audiovisual material it was clear that had I asked in different ways at certain points, different outcomes might have then evolved.

Modelling and repetition were important aspects of my therapeutic intervention. As one specialist professional said, "the more input they get, the better it is" (Note from communication). Collaborating with parents as to what can be done at home and what strategies could be supported and employed both in and out of music therapy was particularly important. This aspect of music therapy is discussed at length in the texts Music therapy with children and their families (Oldfield \& Flower, 2008) and Integrated Team Working (Twyford \& Watson, 2008). However, I feel that more analysis is needed to confirm that modelling and repetition were perhaps the most commonly used strategies within my practice.

Meeting with other specialist service professionals involved with our shared clients was extremely useful, particularly in clarifying my observations and wonderings and helping me make sense of specialist information. As other therapists have reported 
(McCarthy et al., 2008), the exchange of knowledge was valuable in these cases and I look forward to exploring the potential for developing collaborative work in my future clinical practice. For example, knowing that a child was undertaking a feeding programme with their speech and language therapist made me think of imaginative ways in which I could support eating actions. During the writing-up stage of this research I was alerted that techniques I referred to as 'fill-in-the-gap' and 'anticipatory' phrases are similar to 'auditory closure technique', 'cloze procedure' or 'carrier phrases' in the speech and language therapy literature (DeThorne et al., 2009). My experiences and the supporting literature suggest the value of working collaboratively, sharing appropriate goals, understanding terminology and developing the process of each therapy to support or complement the other (DeThorne et al., 2009; McCarthy et al., 2008; Twyford \& Watson, 2008).

\subsubsection{Play and playfulness}

Having immersed myself and gone back to my data to ensure I was not forcing it, I feel quite strongly that playfulness could be considered to be an overarching, all encompassing, core construct of the work. This was considered important by other specialist professionals, was evident from communications with parents, indicated as having rich meaning in my notes and reflections, and was evident in the audiovisual analysis. However, in reading accounts of how grounded theory works (Corbin \& Strauss, 2008; Daveson et al., 2008), given where I am in my career and given that this research is based on two children I feel unable to safely adopt a core category. Therefore, I propose that the concept of 'playfulness' be considered as a 'working hypothesis' that has the potential to develop into an emerging theory through further evidence from additional children. Being playful, having playful activities and songs, and engaging in collaborative play with children was consistently helpful and is likely to be an essential element in successful music therapy work towards the development of speech and language in young children.

I think that it is when he is engaged in an activity or playing that he is more compliant and more readily fills in the gaps I offer, and is also when he more readily volunteers or offers a whole string of words that appear to be an effort to communicate, perhaps to describe something, or talk about something with me. Reflective Journal 29/06/11 
Several authors discuss the role of play and playfulness. Free-play and play methods of communication are considered crucial for learning and support children in making sense of experiences, reality and the world as part of themselves, enable exploration and creativity toward discovery of a sense of self over fear of failure or consequence (McMahon, 2009; Stern, 1977; Winnicott, 1971). Three essentials for play, identified as safe boundaries, autonomy and no serious consequences, are summarized in The Handbook of Play Therapy and Therapeutic Play, which also discusses the roles of sensory, physical, exploratory, social, symbolic or pretend play (McMahon, 2009). "The pleasure and excitement of playing, the intensity and concentration, the freedom to experiment, to explore and to create, to find out how things and people work and what you can do with them, to give the imagination free rein, and to fill the gap between reality and desire, all these derive from the fact that in play the child is in charge" (p. 6).

These accounts of play resonate with those within the music therapy literature, much of which draws on and extends from the wealth of thought instigated by Winnicott (1971) and Stern (1977). Music therapists discuss the ways in which play, creativity and collaboration, having fun, and spontaneity were useful and important techniques particularly when working in early childhood (Beathard \& Krout, 2008; Hoskyns, 2009; Malloch \& Trevarthen, 2009; Wilkinson, 2008). The 'social currency' of singing, finger play and little chants, setting up peek-a-boo games and playful use of animal and vehicle sounds and playful musical interactions are used within music therapy to address stress or anxiety, establish and develop communication, sharing, connectedness, coordination and cognitive skills with pre-school children (Beathard \& Krout, 2008; Hoskyns, 2009; Oldfield, 2000, 2006). Musical interaction in itself is play, we play musical instruments, and this environment encourages young children to explore the instruments and their use of voice in playful ways (Bunt, 1994). Playfulness is therefore conceptually meaningful within the context of this research as well as having broader applications for music therapy theory and practice. I consider this to be the most important finding in terms of what I have learned through my endeavours with this research. 


\subsection{Limitations}

As previously mentioned it was beyond the scope of this research to consider all areas of interest related to supporting communication through music therapy. I chose to limit my research question to focus on aspects of expressive language due to the complexities involved in the analysis of receptive language development. I was not able to use standardised tools of assessment as these were outside the scope of usual clinical practice at the centre, nor was I able to compare with control subjects, which is common practice in some forms of research. Other researchers have utilised rating scales such as the Nordoff-Robbins music therapy assessment scales including "musical communicative ability", Rosetti speech and language scale, speech development tests, intelligence tests, assessment of developmental age including the Griffiths Scales of Assessment and working memory which may be useful in ensuing research (Aldridge, 1996; Grosz et al., 2010).

However this project sought to form an account of observations and insights drawn from a student music therapist's usual clinical practice. One of the advantages of this form of research, as opposed to test environments, is that it is grounded so thoroughly in my usual clinical practice and looks back at data that is recorded through usual clinical practice. Grosz et al. (2010) acknowledged the Hawthorne effect, wherein children receiving music therapy treatment in a study may respond or improve due to an awareness of participation. By employing secondary analysis of data within this research wherein the children were not direct participants the Hawthorne effect was not a concern and findings were drawn from natural music therapy settings.

There was a complex dual role for me as both researcher and clinician, wherein I was a student music therapist learning about how to do the work, a clinician aiming to address my clients' speech and expressive language-related goals, and a researcher theorising about my practice. Further, there are particular issues related to looking back over six-week blocks of data while continuing to work with clients including the potential for changed practice. However with an awareness of this I sought to minimise any potential for over-influencing or distorting my practice. Alongside discussion of the nature of grounded theory procedures (Corbin \& Strauss, 1990) it is feasible to say that my findings may have been influenced by my previous experience as well as my awareness of my future use of clinical data sources. 
As a beginning researcher there are many issues involved, and I sought to maintain research integrity throughout. Familiarising myself with and adhering to the process of grounded theory, immersing myself in the data but attempting to retain some distance as the researcher, and maintaining thorough, accurate, reflexive analytic memos proved highly useful in bringing my findings together. As it was both mine and my research supervisor's first encounter with grounded theory, several questions arose including the difficulties in staying true to the data, the challenges involved in recognising the saturation point (Amir, 2005), the place of existing literature (Hawker \& Kerr, 2007; McCallin, 2003; Payne, 2007) and concerning the debate in the literature as to the necessity of the development of one core category in order to form a complete grounded theory (Daveson et al., 2008). I acknowledge that the findings I have developed are based on the saturation point reached within secondary analysis of data pertaining to two clients of one student music therapist, myself. Therefore my findings are not generalisable, and considering the limitations of the research the findings should be interpreted with care and an awareness of the context.

However, there is truth in meaning and I believe my findings to be rich in meaning for these children and provide insight into the ways in which I used music therapy to support their speech and expressive language development. I was excited by the way my practice became more transparent and my strategies clearer as I worked through the research process. As a student this had particular value in making me aware of the importance of ongoing careful consideration for my behaviours as well as what instruments and songs to use with certain children, how they can be used and why. The experience has shown me that it is also valuable that these types of considerations are balanced with an open therapeutic attitude, remaining attentive and responsive to what each child brings. Further, perhaps what is most important is the uncovering of a more fundamental idea about what it means to be 'playful' with children in a therapeutic setting.

\footnotetext{
"Since grounded theory is considered to be theory-building research, the results can be seen as "building blocks to generalizations" (Aigen, 1995a, $p$ 336). That means that other music therapists who become familiar with the categories can use them to describe their own work, and researchers can use these already existing categories to investigate their own areas of interest and add more categories to the theory" (Amir, 2005, pp. 375-376).
} 


\subsection{Future Research}

To better understand how music therapy can support speech and expressive language development for pre-school children with special needs, it would be useful for researchers to explore which theorised aspects are most effective in doing so, to determine the specifics of what certain aspects are having an effect on and to measure the extent of this effect, i.e. children's progess. Further theoretical sampling by means of additional children, while not possible within the scope of this research, could serve to test and validate the findings within this research. This could also serve to further deductively examine the potential role of 'playfulness' as a key, overarching aspect of the work.

Research within speech and language therapy and other fields, such as that indicating the superiority of cloze technique and expansions over combined direct questions and modelling during book reading (Bradshaw, Hoffman, \& Norrise, as cited in DeThorne et al., 2009), would also be of interest to investigate further and compare within a music therapy setting. Given the value of collaboration within the context of this research and the existing literature, there is need for more documentation of the work (McCarthy et al., 2008) and further exploration is needed regarding practice possibilities. Moreover, the constructs identified in this research would need to be explored further as to their relevance when working with other age groups toward similar communication goals.

Across each of the data sources in this research, observations of children's development and progress that could be measured in further quantitative or mixed methods research included increased frequency, volume and duration of vocalisations, the use and extention of key words or phrases, attempts at intentional verbal communication and approximations, attempts made in response to questions or in the gaps left by the therapist, as well as the development of two-way meaningful conversation. Increased phrase length, improved intelligibility and consistency of target sound/word productions could be assessed and the use of reed horns and other wind instruments could be explored as a measure of breath control development. Comparison of preverbal, vocal and verbal communication over time is of further interest, as is the occurance and context of spontaneous speech. While it was not 
possible to explore these within the scope of this research, these observations certainly indicate the potential for and possible hypotheses for further exploration.

The use of video microanalysis, quantitative behavioural analysis and the use of sophisticated but user-friendly computer programming is discussed by several authors (Wosch \& Wigram, 2007). Cross-over studies employing the use of waiting-list controls and alternative treatment-no treatment periods enable research of natural or normal music therapy practice and further control for normal development and other therapeutic interventions (Aldridge, 1996; Grosz et al., 2010). While not possible within time and resource constraints of this project, I believe these and computer assisted data analysis would be valuable, systematic assets within further exploration of this topic (Corbin \& Strauss, 2008). The audiovisual recordings were an extremely valuable source of information towards the creation and development of several constructs in this research. Musical and non-verbal behaviours as well as aspects of the physical environment were particularly benefited, and served to develop a more comprehensive representation of the work. In music therapy "very small changes can offer important information about development and therapeutic progress, making microanalysis a useful tool for assessment and evaluation" (Scholtz, Voigt, \& Wosch, 2007, p. 68).

The wider literature and theory has established a number of important contributing factors towards language acquisition and development in early childhood as well as how music and language are related. Given my research findings it is evident that music therapy can address, provide and support a number of these factors for preschool children with special needs. To support the efficacy of music therapy services in alignment with other professions and disciplines but also to develop music therapists' understanding of the work within broader theory, deductive research could be undertaken. This may involve grounded theory and may likely include, but not be limited to, how music therapy can support speech and language development through the development of vocal utterances, the rhythmic-prosodic qualities of child-directed speech, reciprocal imitation, motivation, structure, as well as context and the role of the socio-emotional environment. 


\subsection{Conclusion}

Client-centred music therapy with individual pre-school children, involving playful but focused songs, behaviours and instrumental play, can enhance their speech and expressive language development. Music is an attractive, appealing, accessible, unpressured medium that encourages and motivates children to communicate more intensively, effectively and confidently. Through meaningful development and integration of several senses as well as shared meaning and expression in individualised music making and song, music therapy can provide a supportive and sensitive approach in addressing the needs of children for whom speech production, language processing or expressive communication may be delayed or impaired. Music therapy can address many contributing factors identified in the wider literature as essential for language acquisition and development including motivation, structure, child-directed speech and reciprocal imitation as well as context.

Through the process of this research I found that with the specific goal of speech and expressive language development in music therapy there are a wide variety of nonthreatening, un-pressured, enjoyable resources and strategies that can be developed collaboratively between mutually engaged child and therapist. Exaggerated, elongated vowel sounds, emphasised oral muscle action, strengthening air flow, these behaviours and concepts and more could be explored within "Copy me" type activities, but are much more naturally incorporated and extended within collaborative song and active music making. I could model words like "crash; bang; toot" for a child to imitate to target specific sounds, phonemes, initial or final consonants. Or, I could put an instrument in the room that inspires willing, co-creative play about trains or naturally elicits a child's delighted response of "crash!" Together, the child and I could create an environment filled with empowering opportunities for choice, control and self-expression with a client-centred approach individualised to meet each child's needs and motivators. Moreover, these concepts could all be enhanced in a playful, engaging way. 


\section{References}

Aldridge, D. (1996). Music therapy research and practice in medicine : from out of the silence. London Bristol, Pa.: J. Kingsley.

Amir, D. (1993). Moments of Insight in the Music Therapy Experience. Music Therapy, $12(1), 85-100$.

Amir, D. (2005). Grounded Theory. In B. L. Wheeler (Ed.), Music Therapy Research (2nd ed., pp. 365-378). Gilsum, N.H.: Barcelona Publishers.

Baker, F., \& Uhlig, S. (Eds.). (2011). Voicework in music therapy : research and practice. London Philadelphia: Jessica Kingsley Publishers.

Bannan, N., \& Woodward, S. (2009). Spontaneity in the musicality and music learning of children. In S. Malloch \& C. Trevarthen (Eds.), Communicative musicality : exploring the basis of human companionship (pp. 465-494). Oxford New York: Oxford University Press.

Bateson, M. C. (1979). 'The epigenesis of conversational interaction': a personal account of resarch development. . In M. Bullowa (Ed.), Before speech: The beginning of interpersonal communication (pp. 63-78). Cambridge, New York: Cambridge University Press.

Beathard, B., \& Krout, R. E. (2008). A music therapy clinical case study of a girl with childhood apraxia of speech: Finding Lily's voice. Arts in Psychotherapy, 35(2), 107-116. doi: 10.1016/j.aip.2008.01.004

Bjorklund, D. F. (2005). Children's thinking : cognitive development and individual differences (4th ed.). Australia ; Belmont, CA: Thomson/Wadsworth.

Bruscia, K. E. (1998). Defining music therapy (2nd ed.). Gilsum, NH: Barcelona Publishers.

Bruscia, K. E. (2005a). Data Analysis in Qualitative Research. In B. L. Wheeler (Ed.), Music Therapy Research (2nd ed., pp. 179-186). Gilsum, N.H.: Barcelona Publishers.

Bruscia, K. E. (2005b). Developing Theory. In B. L. Wheeler (Ed.), Music Therapy Research (2nd ed., pp. 540-551). Gilsum, N.H.: Barcelona Publishers.

Bunning, K. (2003). Speech and language therapy intervention : frameworks and processes. London: Whurr.

Bunt, L. (1994). Music therapy : an art beyond words. London ; New York: Routledge.

Bunt, L., \& Hoskyns, S. (Eds.). (2002). The handbook of music therapy. London: Routledge.

Chamberlain, K. (1999). Using Grounded Theory in Health Psychology: Practices, Premises and Potential. In M. Murray \& K. Chamberlain (Eds.), Qualitative health psychology : theories and methods (pp. 183-201). London Thousand Oaks, Calif.: Sage Publications.

Chiovitti, R. F., \& Piran, N. (2003). Rigour and grounded theory research. Journal of Advanced Nursing, 44(4), 427-435.

Cohen, N. S. (1992). The effect of singing instruction on the speech production of neurologically impaired persons. Journal of Music Therapy, 2, 87-102.

Cohen, N. S. (1994). Speech and song: Implications for therapy. Music Therapy Perspectives, 12(1).

Corbin, J., \& Strauss, A. (1990). Grounded Theory Research: Procedures, Canons, and Evaluative Criteria. Qualitative Sociology, 13(1), 3-21. 
Corbin, J., \& Strauss, A. (2008). Basics of qualitative research : techniques and procedures for developing grounded theory (3rd ed.). Los Angeles, Calif.: Sage Publications, Inc.

Darnley-Smith, R., \& Patey, H. M. (2003). Music therapy. London; Thousand Oaks, Calif.: Sage Publications.

Daveson, B., O'Callaghan, C., \& Grocke, D. (2008). Indigenous music therapy theory building through grounded theory research: The developing indigenous theory framework. Arts in Psychotherapy, 35(4), 280-286. doi: 10.1016/j.aip.2008.06.005

DeThorne, L. S., Johnson, C. J., Walder, L., \& Mahurin-Smith, J. (2009). When "Simon says" doesn't work: Alternatives to imitation for facilitating early speech development. American Journal of Speech-Language Pathology, 18(2), 133-145. doi: 10.1044/1058-0360(2008/07-0090)

Dissanayake, E. (2009). Root, leaf, blossom or bole: Concerning the origin and adaptive function of music. In S. Malloch \& C. Trevarthen (Eds.), Communicative musicality : exploring the basis of human companionship (pp. 17-30). Oxford New York: Oxford University Press.

Grosz, W., Linden, U., \& Ostermann, T. (2010). Effects of music therapy in the treatment of children with delayed speech development - results of a pilot study. BMC Complementary and Alternative Medicine, 39. doi: 10.1186/14726882-10-39

Hawker, S., \& Kerr, C. (2007). Doing Grounded Theory. In E. Lyons \& A. Coyle (Eds.), Analysing Qualitative Data in Psychology (pp. 87-97). London: Sage Publications.

Hoskyns, S. (2009). Promoting readiness for learning in a pre-school child with features of developmental dyspraxia: some strategies from music therapy. Paper presented at the New Zealand National Music Education Conference, Christchurch.

Jentschke, S., Koelsch, S., \& Friederici, A. D. (2005). Investigating the Relationship of Music and Language in Children. Annals of the New York Academy of Sciences, 1060(1), 231-242. doi: 10.1196/annals.1360.016

Juslin, P. N., \& Västfjäll, D. (2008). Emotional responses to music: The need to consider underlying mechanisms. Behavioral and Brain Sciences, 31(05). doi: $10.1017 / \mathrm{s} 0140525 \mathrm{x} 08005293$

King, B. (2007). Language and Speech: Distinguishing Between Aphasia, Apraxia, and Dysarthria in Music Therapy Research and Practice. Music Therapy Perspectives, 25(1), 13.

Kouri, T. A., \& Winn, J. (2006). Lexical learning in sung and spoken story script contexts. Child Language Teaching and Therapy, 22(3), 293-313. doi: 10.1191/0265659006ct309xx

Leung, M. (2008). A Collaboration Between Music Therapy and Speech Pathology in a Paediatric Rehabilitation Setting. Voices: A World Forum For Music Therapy, 8(3).

Levitin, D. (2009). The World in Six Songs. London: Aurum Press Ltd.

Loewy, J. (2004). Integrating Music, Language and the Voice in Music Therapy.

Lorenzato, K. (2005). Filling a need while making some noise : a music therapist's guide to pediatrics (1st American pbk. ed.). London ; Philadelphia: Jessica Kingsley Publishers. 
Malloch, S., \& Trevarthen, C. (Eds.). (2009). Communicative musicality : exploring the basis of human companionship. Oxford New York: Oxford University Press.

McCallin, A. (2003). Grappling with the literature in a grounded theory study. Contemp Nurse, 15(1-2), 61-69.

McCarthy, J., Geist, K., Zojwala, R., \& Schock, M. Z. (2008). A survey of music therapists' work with speech-language pathologists and experiences with augmentative and alternative communication. Journal of Music Therapy, 45(4), 405-426.

McFerran, K. (2009). Quenching a Desire for Power: The Role of Music Therapy for Adolescents with ADHD. Australasian Journal of Special Education, 33(1), $72-83$.

McMahon, L. (2009). The handbook of play therapy and therapeutic play (2nd ed.). Hove, East Sussex ; New York: Routledge.

Michel, D. E., \& Jones, J. L. (1991). Music for Developing Speech and Language Skills in Children: A Guide for Parents and Therapists (Vol. 9). Saint Louis: MMB Horizon Series.

Mills, J., Bonner, A., \& Francis, K. (2006). The Development of Constructivist Grounded Theory. International Journal of Qualitative Methods, 5(1).

Newham, P. (1998). Therapeutic voicework : principles and practice for the use of singing as a therapy. London Philadelphia: Jessica Kingsley Publishers.

Nordoff, P., \& Robbins, C. (1983). Music therapy in special education (2nd ed.). St. Louis, Missouri: Magnamusic-Baton.

Norton, A., Zipse, L., Marchina, S., \& Schlaug, G. (2009). Melodic Intonation Therapy. Annals of the New York Academy of Sciences, 1169(1), 431-436. doi: 10.1111/j.1749-6632.2009.04859.x

Oldfield, A. (1991). Preverbal communication through music to overcome a child's language disorder. In K. E. Bruscia (Ed.), Case studies in music therapy (pp. xvii, 638). Phoenixville, PA: Barcelona Publishers.

Oldfield, A. (2000). Listening: The first step toward communicating through music. In P. M. a. B. Carolin (Ed.), Time to Listen to Children: Personal and Professional Communication (pp. 188-199). London and New York: Routledge.

Oldfield, A. (2006). Interactive music therapy : a positive approach : music therapy at a child development centre (1st American pbk. ed.). London Philadelphia: Jessica Kingsley Publishers.

Oldfield, A., \& Flower, C. (2008). Music therapy with children and their families. London ; Philadelphia: J. Kingsley Publishers.

Overy, K., Norton, A., Cronin, K., Winner, E., \& Schlaug, G. (2005). Examining Rhythm and Melody Processing in Young Children Using fMRI. Annals of the New York Academy of Sciences, 1060(1), 210-218. doi: 10.1196/annals. 1360.014

Ozdemir, E., Norton, A., \& Schlaug, G. (2006). Shared and distinct neural correlates of singing and speaking. NeuroImage, 33(2), 628-635. doi: 10.1016/j.neuroimage.2006.07.013

Panksepp, J., \& Trevarthen, C. (2009). The neuroscience of emotion in music. In S. Malloch \& C. Trevarthen (Eds.), Communicative musicality : exploring the basis of human companionship (pp. 105-146). Oxford New York: Oxford University Press. 
Patel, A. D. (2008). Music, language, and the brain. Oxford New York: Oxford University Press.

Payne, S. (2007). Grounded Theory. In E. Lyons \& A. Coyle (Eds.), Analysing Qualitative Data in Psychology (pp. 65-86). London: Sage Publications.

Powers, N., \& Trevarthen, C. (2009). Voices of shared emotion and meaning: Young infants and their mothers in Scotland and Japan. In S. Malloch \& C. Trevarthen (Eds.), Communicative musicality : exploring the basis of human companionship (pp. 209-240). Oxford New York: Oxford University Press.

Purdy, S. C. (2011). The language of music: research on speech and song. Paper presented at the Brain Day, University of Auckland.

Ritholz, M. S., \& Robbins, C. (1999). Themes for therapy : from the Nordoff-Robbins Center for Music Therapy at New York University : new songs and instrumental pieces. New York, NY: C. Fischer.

Scholtz, J., Voigt, M., \& Wosch, T. (2007). Microanalysis of interaction in music therapy (MIMT) with children with developmental disorders. In T. Wosch \& T. Wigram (Eds.), Microanalysis in music therapy : methods, techniques and applications for clinicians, researchers, educators and students (pp. 67-78). London Philadelphia: Jessica Kingsley Publishers.

Seybold, C. D. (1971). The Value and Use of Music Activities in the Treatment of Speech Delayed Children. Journal of Music Therapy, 8, 102-110.

Silverman, M. J. (2007). The effect of paired pitch, rhythm, and speech on working memory as measured by sequential digit recall. J Music Ther, 44(4), 415-427. doi: 0022-2917-44-4-415 [pii]

Stern, D. N. (1977). The first relationship : infant and mother. London: Open Books.

Turner, R., \& Ioannides, A. A. (2009). Brain, music and musicality: Inferences from neuroimaging. In S. Malloch \& C. Trevarthen (Eds.), Communicative musicality : exploring the basis of human companionship (pp. 147-184). Oxford New York: Oxford University Press.

Twyford, K., \& Watson, T. (2008). Integrated team working : music therapy as part of transdisciplinary and collaborative approaches. London ; Philadelphia: Jessica Kingsley Publishers.

Wheeler, B. L., \& Baker, F. A. (2010). Influences of music therapists, worldviews on work in different countries. The Arts in Psychotherapy, 37(3), 215-227. doi: 10.1016/j.aip.2010.04.006

Wheeler, B. L., Shultis, C. L., \& Polen, D. W. (2005). Clinical training guide for the student music therapist. Gilsum, N.H.: Barcelona Pub.

Wigram, T., Pedersen, I. N., \& Bonde, L. O. (2002). A comprehensive guide to music therapy : theory, clinical practice, research and training. London: Jessica Kingsley.

Wilkinson, C. J. (2008). Reflections and analysis to improve clinical practice: A student music therapist's journey with a preschool child with special needs. Master of Music Therapy, New Zealand School of Music, Wellington.

Winnicott, D. W. (1971). Playing and reality. London,: Tavistock Publications.

World Federation of Music Therapy. (2011). FAQ Music Therapy, from http://musictherapyworld.net/WFMT/FAQ_Music Therapy.html

Wosch, T., \& Wigram, T. (Eds.). (2007). Microanalysis in music therapy : methods, techniques and applications for clinicians, researchers, educators and students. London Philadelphia: Jessica Kingsley Publishers.

Wright, J. A., \& Kersner, M. (Eds.). (2001). Speech and language therapy : the decision-making process when working with children. London: David Fulton. 


\section{Appendices}

\section{Appendix 1: $\quad$ Ethical decision tree}

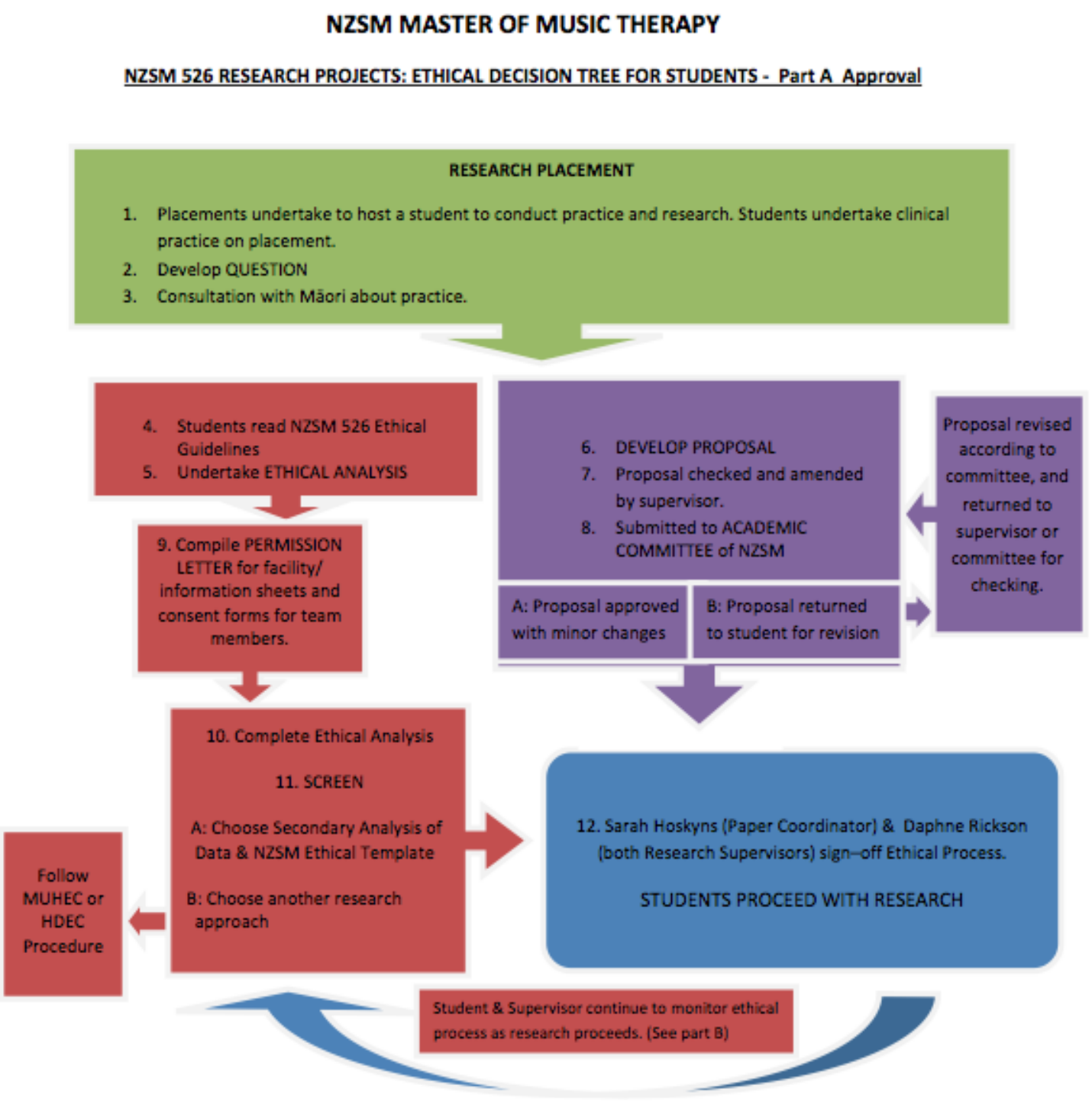




\section{NZSM 526 RESEARCH PROJECTS: ETHICAL DECISION TREE - PART B Ongoing Ethical Review}

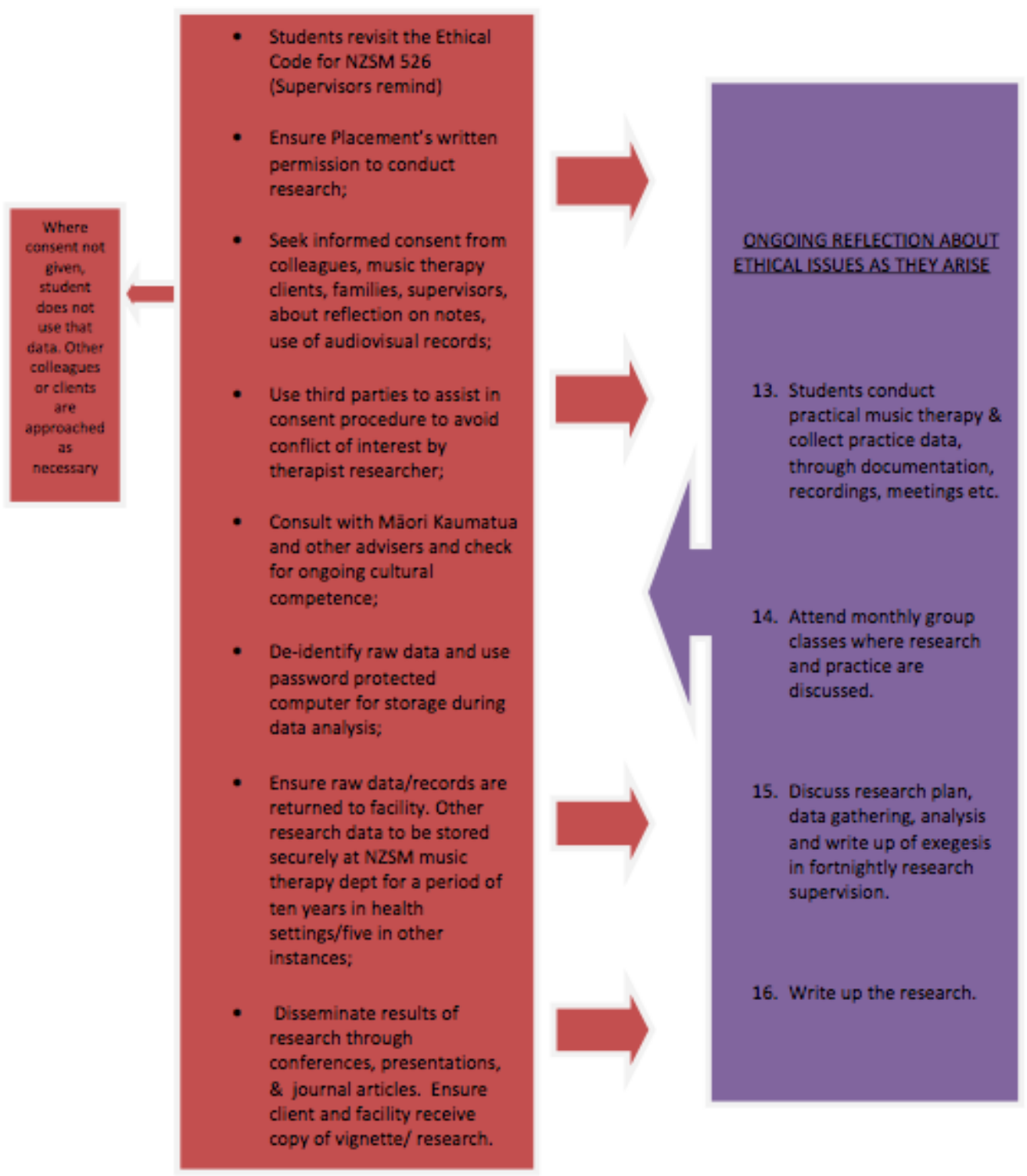




\section{Appendix 2: $\quad$ Facility information sheet}

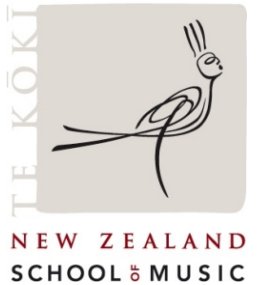

MUSIC THERAPY PROGRAMME (MMUSTher)

\section{Research Title: How music therapy can be used to support speech and language development for pre-school children with special needs.}

Dear

As you know I am a second year Master of Music Therapy student undertaking a clinical placement at your facility, As part of my training I am required to research an aspect of my practice by undertaking secondary review of clinical practice data. I have chosen to explore how music therapy has been used to support speech and language development.

The purpose of the research is to improve my learning and to inform other music therapy students and practitioners of particular issues involved in the work. With informed consent from all affected parties, I would closely observe and critically reflect on this practice, and produce my interpretation of its value. I am required to include a case vignette from practice which might involve an individual case, a group, or the practice setting as a whole, to illustrate a particular point in their exegesis.

Following our discussion earlier in the year, this communication is to ask written permission for the research to take place in As part of my research process I would like to ask for your assistance in approaching families of children I currently work with, on my behalf. This would involve taking families through the information sheet (please find attached) and asking for their permission for their child to be involved in my research. If appropriate, the client involved could also be approached for assent by way of, for example, "Shari would like to write a story about your music sessions, would that be okay?" It would be important to emphasize to families that if they decide not to allow data related to their child to be used in my research, it would be fine, that I have other families I can approach, and that there would be no changes to their child's ongoing music therapy.

I would like to inform you that this project has been reviewed and approved by the New Zealand School of Music Postgraduate committee. The Chairs of Massey University Human Ethics and Health and Disability Ethics Committees have given generic approval for music therapy students to conduct studies of this type. The music therapy projects have been judged to be low risk and, consequently, are not separately reviewed by any Human Ethics Committees. The supervisor named below is responsible for the ethical conduct of this research. If you have any concerns about the conduct of this research, please contact the supervisor or, if you wish to raise an issue with someone other than 
the student or supervisor, please contact Professor John O'Neill, Director, Research Ethics, telephone 06350 5249, email: humanethics@massey.ac.nz".

If you are in agreement with this research taking place at .........., please sign both copies of the enclosed consent form and return one to me. Please do not hesitate to contact my research supervisor, Sarah Hoskyns, if you have any questions or wish to discuss this further. Ph: or email:

Yours sincerely,

Shari Ludlam

Student Music Therapist

$\mathrm{Ph}$ : or email: 


\section{Appendix 3: Facility consent form}

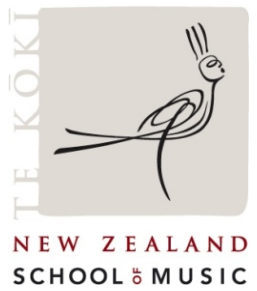

Research Title: How music therapy can be used to support speech and language development for pre-school children with special needs.

\section{Facility Consent Form}

I, .(name/position), give consent for data which has been collected for clinical purposes at , to be used in the research project 'How music therapy can be used to support speech and language development for pre-school children with special needs' to be carried out by Shari Ludlam (Student Music Therapist) as part of the requirements for her Master of Music Therapy at the New Zealand School of Music.

I understand that clients' real names will not be used in any publication or presentation arising from this research. I understand that clients' music therapy would occur in a standard and usual way and there would be no expectation of extra attendance or sessions.

I understand that the secondary review and analysis will take place at or, if the data is deidentified and kept on a password protected computer, at the student music therapist's place of study (home office). In accordance with policies, data will belong to the centre and all originals will be stored securely for five years after the case is closed and then destroyed. Any copies of the data, used for research purposes, will be destroyed upon completion of the research project, March 2012.

I understand that consent forms will be kept until January 2035 (at which time all clients involved will be at least 26 years of age) and will be stored at the New Zealand School of Music, Music Therapy Department, in a locked cupboard or filing cabinet, and files will be marked 'confidential'. The research supervisors would have access to the data and would be responsible for its safe-keeping.

I understand that the student music therapist will provide a summary of the results of the study to , and provide copies of the summary and vignette to clients' families and team members who may be represented in the data.

I understand that the student music therapist may present the work, if appropriate, to the facility where the research was undertaken, and/or to the New Zealand School of Music (MMus Ther) staff/students. If the work is of suitable quality, findings may be published in suitable music therapy or other professional journals, in collaboration with the research supervisor, Sarah Hoskyns. 
I understand that this project has been reviewed and approved by the New Zealand School of Music Postgraduate committee in addition to the Chairs of Massey University Human Ethics and Health and Disability Ethics Committees. I understand that if I have any questions, concerns, or wish to discuss this further I can contact the student music therapist's research supervisor, Sarah Hoskyns.

This has been discussed with me by Shari Ludlam (student music therapist and researcher).

Signed.

Print Name.

Date. 


\section{Appendix 4: Information for Families about Music Therapy Research}

2011: Shari Ludlam

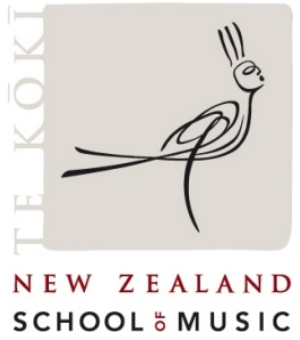

MUSIC THERAPY PROGRAMME (MMUSTher)

Research Title: How music therapy can be used to support speech and language development for pre-school children with special needs.

Information Sheet

Dear

As you know I am a second year Master of Music Therapy student undertaking a clinical placement at As part of my training I am required to research an aspect of my practice by looking back at the records I have kept about children's music therapy at As communication appears to be a common area of need for pre-school children with special needs, I have chosen to explore how music therapy has been used to support speech and language development. The purpose of the research is to improve my learning and to inform other music therapy students, practitioners and carers of particular issues involved in the work.

My research process will involve looking back (secondary review) over the clinical notes that I have written following music therapy sessions, re-examining notes that I have written in my reflective journal, and reviewing video footage. The reflective journal is part of a music therapists' usual practice and is a way to document personal reflections, learning process, critical thinking and the like. As part of clinical evaluation, I regularly review video footage of music therapy sessions, and I would like to do so here with a specific interest in the aspects of the session relevant to speech and language development.

Through these avenues I intend to explore how music has been used within a developing therapeutic relationship to motivate, increase confidence in, and provide opportunities for children with special needs to develop their speech and language. I will be looking closely at the key methods, techniques and strategies documented within the sources of information discussed above in order to find trends, themes or patterns, and produce my interpretation of their value. 
I am writing to express my interest in reviewing and analysing my practice as a student music therapist in working with your child, As part of my research write-up I am required to include a case vignette from my practice, i.e. an excerpt about my work with a client, to illustrate a particular point about my learning. Were you to allow information related to your child, and which has been collected for clinical purposes, to be used in my research, I would not use your child's real name in any publication or presentation arising from this research. Your child's music therapy would occur in a standard and usual way and there would be no expectation of extra attendance or sessions. The secondary analysis will take place at the centre or, if the data is de-identified and kept on a password protected computer, at my place of study (home office). Consent forms will be kept for ten years from the age of 16 and will be stored at the New Zealand School of Music, Music Therapy Department, in a locked cupboard or filing cabinet, and files will be marked 'confidential'. The research supervisors would have access to the data and would be responsible for its safe-keeping.

I will provide a summary of the results of the study to , and provide copies of the summary and vignette to your family and other team members who may be represented in the writing. I will present the practical case material to my examiners in private session at the end of my University degree and I may also present the work, if appropriate, to the facility where the research was undertaken. If my work is of suitable quality, findings may be published in suitable music therapy or other professional journals, in collaboration with the research supervisor, Sarah Hoskyns.

I would like to inform you that this project has been reviewed and approved by the New Zealand School of Music Postgraduate committee. The Chairs of Massey University Human Ethics and Health and Disability Ethics Committees have given generic approval for music therapy students to conduct studies of this type. The music therapy projects have been judged to be low risk and, consequently, are not separately reviewed by any Human Ethics Committees. The supervisor named below is responsible for the ethical conduct of this research. If you have any concerns about the conduct of this research, please contact the supervisor or, if you wish to raise an issue with someone other than the student or supervisor, please contact Professor John O'Neill, Director, Research Ethics, telephone 06 350 5249, email: humanethics@massey.ac.nz".

If you are in agreement with your child's involvement in my research, please sign both copies of the enclosed consent form and return one to the . If you decide not to allow data related to your child to be used in my research, this will be fine. I 
have other families I can approach, and there will be no changes to your child's ongoing music therapy. Please do not hesitate to contact the following people if you have any questions or wish to discuss this further:

Sarah Hoskyns, Research Supervisor and Music Therapy Programme Leader at the New Zealand School of Music. Ph:

Yours sincerely,

\section{Shari Ludlam}

Student Music Therapist

Email: 


\section{Appendix 5: Consent form for Families about Music Therapy Research 2011: Shari Ludlam}

Research Title: How music therapy can be used to support speech and language development for pre-school children with special needs.

\section{Consent Form}

I, ..(parent/carer name) give consent for data related to (child), and which has been collected for clinical purposes at the to be used in the research project 'How music therapy can be used to support speech and language development for pre-school children with special needs' to be carried out by Shari Ludlam (Student Music Therapist) as part of the requirements for her Master of Music Therapy at the New Zealand School of Music.

I understand that my child's real name will not be used in any publication or presentation arising from this research. I understand that my child's music therapy would occur in a standard and usual way and there would be no expectation of extra attendance or sessions.

I understand that the secondary review and analysis will take place at or, if the data is deidentified and kept on a password protected computer, at the student music therapist's place of study (home office). In accordance with policies, data will belong to the centre and all originals will be stored securely for five years after the case is closed and then destroyed. Any copies of the data, used for research purposes, will be destroyed upon completion of the research project, March 2012.

I understand that consent forms will be kept until (the year at which the client turns 26 years of age) and will be stored at the New Zealand School of Music, Music Therapy Department, in a locked cupboard or filing cabinet, and files will be marked 'confidential'. The research supervisors would have access to the data and would be responsible for its safe-keeping.

I understand that the student music therapist will provide a summary of the results of the study to and provide copies of the summary and vignette to clients' families and team members who may be represented in the data.

I understand that the student music therapist may present the work, if appropriate, the facility where the research was undertaken, and/or to the New Zealand School of Music (MMus Ther) staff/students. If the work is of suitable quality, findings may be published in suitable music therapy or other professional journals, in collaboration with the research supervisor, Sarah Hoskyns.

I understand that this project has been reviewed and approved by the New Zealand School of Music Postgraduate committee, in addition to the Chairs of Massey University Human Ethics and Health and 
Disability Ethics Committees. I understand that I can withdraw my consent by informing the Centre in writing at any time up to the completion of research analysis, October 15th 2011.

This has been discussed with me by. (staff member's name).

Signed.

Print Name

Date. 


\section{Appendix 6: Information for Specialist Service Professionals about Music Therapy Research 2011: Shari Ludlam}

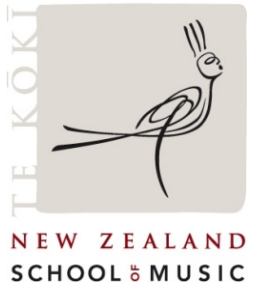

MUSIC THERAPY PROGRAMME (MMUSTher)

Research Title: How music therapy can be used to support speech and language development for pre-school children with special needs.

Dear

As you know I am a second year Master of Music Therapy student undertaking a clinical placement at As part of my training $\mathrm{I}$ am required to research an aspect of my practice by undertaking secondary review of clinical practice data. As communication appears to be a common area of need for pre-school children with special needs, I have chosen to explore how music therapy has been used to support speech and language development. The purpose of the research is to improve my learning and to inform other music therapy students, practitioners and carers of particular issues involved in the work.

My research process will involve looking back (secondary review) over the clinical notes that I have written following music therapy sessions, notes written from communication with clients' parents, carers and specialist service professionals such as yourself, re-examining notes that I have written in my reflective journal and reviewing video footage. Through these avenues I intend to explore how music has been used within a developing therapeutic relationship to motivate, increase confidence in, and provide opportunities for children with special needs to develop their speech and language. I will be looking closely at the key methods, techniques and strategies documented within the sources of information discussed above in order to find trends, themes or patterns, and produce my interpretation of their value. I am required to include a case vignette from practice which might involve an individual case, a group, or the practice setting as a whole, to illustrate a particular point in my research.

Following I look forward to speaking with you about speech and language development specifically related to 
a client we are both working with, (child). I have been fortunate to gain permission from (parent/carer name) for data related to ..(child), and which has been collected for clinical purposes to be used in the research project. I would like to request your permission to take notes from our communication in order to add to (child) file, as is usual practice with a view to potentially reviewing and incorporating aspects of our communication within my research. I would like to make an audio recording of our communication in order to add to my written notes, ensure I do not miss anything and to facilitate a more natural, fluid discussion. The recording will be kept securely at , and will be deleted after I have reviewed it.

The secondary review and analysis will take place at or, if the data is de-identified and kept on a password protected computer, at my place of study (home office). Consent forms will be kept until January 2035 (at which time all clients involved will be at least 26 years of age) and will be stored at the New Zealand School of Music, Music Therapy Department, in a locked cupboard or filing cabinet, and files will be marked 'confidential'. The research supervisors would have access to the data and would be responsible for its safe-keeping.

I will provide a summary of the results of the study to RMTC, and provide copies of the summary and vignette to the families and specialist service professionals, including yourself, who may be represented in the writing. I will present the practical case material to my examiners in private session at the end of my University degree and I may also present the work, if appropriate, to , the facility where the research was undertaken. If my work is of suitable quality, findings may be published in suitable music therapy or other professional journals, in collaboration with the research supervisor, Sarah Hoskyns.

I would like to inform you that this project has been reviewed and approved by the New Zealand School of Music Postgraduate committee. The Chairs of Massey University Human Ethics and Health and Disability Ethics Committees have given generic approval for music therapy students to conduct studies of this type. The music therapy projects have been judged to be low risk and, consequently, are not separately reviewed by any Human Ethics Committees. The supervisor named below is responsible for the ethical conduct of this research. If you have any concerns about the conduct of this research, please contact the supervisor or, if you wish to raise an issue with someone other than the student or 
supervisor, please contact Professor John O'Neill, Director, Research Ethics, telephone 06 350 5249, email: humanethics@massey.ac.nz".

If you are in agreement with your involvement in my research, please sign both copies of the enclosed consent form and return one to the If you decide not to allow data drawn from our communication to be used in my research, this will be fine. I have other professionals I can approach, and there will be no changes to ongoing music therapy. Please do not hesitate to contact the following people if you have any questions or wish to discuss this further:

Sarah Hoskyns, Research Supervisor and Music Therapy Programme Leader at the New Zealand School of Music. Ph: (04) 8015799 x 6410 or email: sarah.hoskyns@nzsm.ac.nz.

Yours sincerely,

Shari Ludlam

Student Music Therapist

$\mathrm{Ph}$ 


\section{Appendix 7: $\quad$ Consent form for Specialist Service Professionals about Music Therapy Research 2011: Shari Ludlam}

Research Title: How music therapy can be used to support speech and language development for pre-school children with special needs.

\section{Specialist Service Professional Consent Form}

I, (name/position), give consent for data drawn from communication with Shari Ludlam (Student Music Therapist) related to (child) and speech and language development, which has been collected for clinical purposes at to be used in the research project 'How music therapy can be used to support speech and language development for pre-school children with special needs' to be carried out by Shari Ludlam (Student Music Therapist) as part of the requirements for her Master of Music Therapy at the New Zealand School of Music.

I do/do not give consent for the student music therapist to make an audio recording of our communication. I understand that the recording will be kept securely at , and will be deleted after the student music therapist has reviewed it.

I understand that clients' real names will not be used in any publication or presentation arising from this research. I understand that clients' music therapy would occur in a standard and usual way and there would be no expectation of extra attendance or sessions.

I understand that the secondary review and analysis will take place at the centre or, if the data is deidentified and kept on a password protected computer, at the student music therapist's place of study (home office). In accordance with policies, data will belong to the centre and all originals will be stored securely for five years after the case is closed and then destroyed. Any copies of the data, used for research purposes, will be destroyed upon completion of the research project, March 2012.

I understand that consent forms will be kept until January 2035 (at which time all clients involved will be at least 26 years of age) and will be stored at the New Zealand School of Music, Music Therapy Department, in a locked cupboard or filing cabinet, and files will be marked 'confidential'. The research supervisors would have access to the data and would be responsible for its safe-keeping.

I understand that the student music therapist will provide a summary of the results of the study to and provide copies of the summary and vignette to clients' families and team members who may be represented in the data. Further, that the student music therapist may present the work, if appropriate, to the facility where the research was undertaken, and/or to the New Zealand School of Music (MMus Ther) staff/students. If the work is of suitable quality, findings may be published in suitable music therapy or other professional journals, in collaboration with the research supervisor, Sarah Hoskyns. 
I understand that this project has been reviewed and approved by the New Zealand School of Music Postgraduate committee in addition to the Chairs of Massey University Human Ethics and Health and Disability Ethics Committees. I understand that if I have any questions, concerns, or wish to discuss this further I can contact the student music therapist's research supervisor, Sarah Hoskyns.

This has been discussed with me by Shari Ludlam (student music therapist and researcher).

Signed.

Print Name.

Date. 


\section{Appendix 8: Examples of grounded theory data analysis process:}

\section{Analytic Memos}

6. After coding one session of clinical data I went back to the beginning of my clinical data to compare, clarify, and revise the units I identified and the categories I labeled them as.

7. I reminded myself of:

a. X's favourites: beaters, cymbal, horn, snare drum

b. X's un-favourites: piano, m.g. drum (only lifts it to find the beaters), floor tom, animal shakers,

8. I went back to client $Y$ to compare via axial coding.

a. Questions: Does instrument need sub categories? Can it simply be Client's preferred instrument in the room? Does animal percussion come under client's preference?

- Instrument
a. Placement
b. Client's preference
c. Animal percussion
d. TOP 2
e. ALL 3 IIIIIIIIIIIIIIIII

9. This resulted in re-labelling one from Instrument $>$ Client preference to realising it was actually "volunteered > to communicate preference" (p7) but also made it clear that I could merge these subcategories into one and call it:

- Instrument; Client's preferred instrument; Known motivator instrument

- is it an MTS strategy of including the client's preferred instruments in MT? I decided it is - but is the fact that you've 


\section{Appendix 9: Examples of grounded theory data analysis process: Coding}

\section{Clinical Notes}
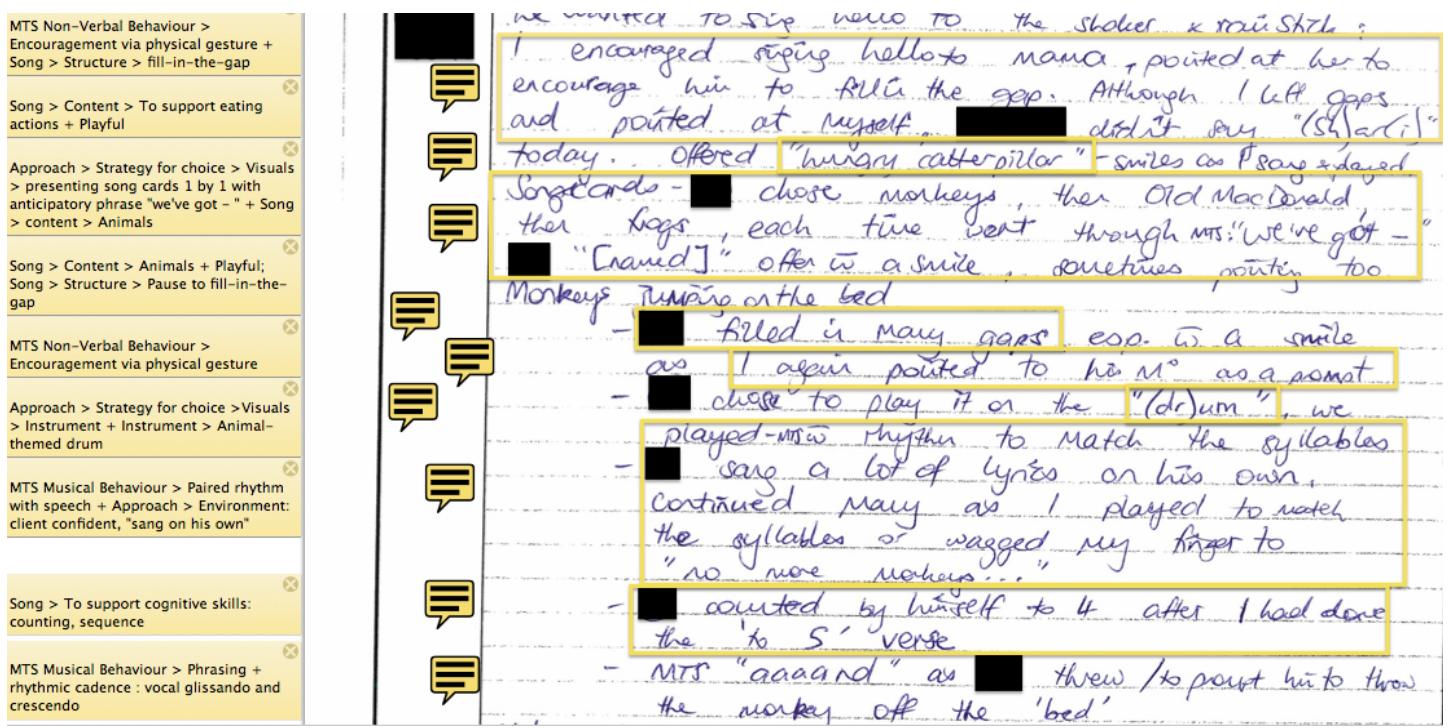

\section{Reflective Journal}

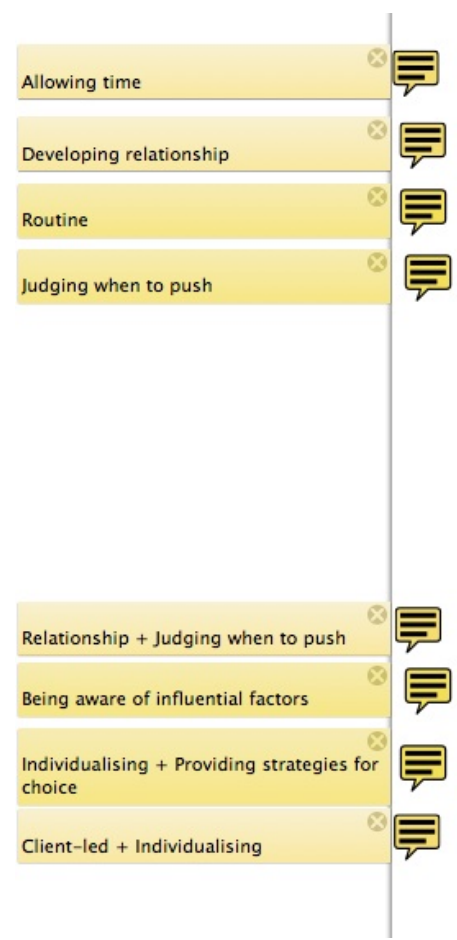

I had a few thoughts today. $03 / 08 / 11$

Sometimes, as the therapist, not saying something gives them the opportunity to say it for themselves. I think as the relationship begins, there is a lot of ground work that goes on to develop the trust and mutual understanding of just what will happen in sessions, what will happen between you, and so on. As that relationship begins to feel more settled, more grounded, more developed you can begin to consider pushing. New things can happen. In thinking specifically around our beginning was very much about creating a safe, familiar environment in which could work towards separating from his parent readily, come into the session, and manage to stay in the room for 30 minutes without becoming upset. Now that I have seen progress with $\square$ in that, with time and space given, he now readily follows me, or goes first, into the room, sometimes with a "see you" to his parent(s) but sometimes without even a backwards glance. During the session today he only went to the door with 5 minutes to go, after I had said "it's time to sing goodbye". At that point, at which as a therapist I felt comfortable and secure enough in our shared musical experiences and play, I felt able to begin pushing, expecting just that little bit more. s short attention span and high energy levels mean that our sessions are very active, often moving from one thing to another quickly, and some strategies that one might consider using to support SLD do not hold or capture his attention.

Where 'Heeeeee - + drum roll' has captured the attention and musicality of other clients - older - this did not seem to interest? he simply continued in his exploration of the instruments in the room. 


\section{Audiovisual material: Session 9}

\begin{tabular}{|c|c|c|c|}
\hline \multirow[t]{2}{*}{$\begin{array}{l}\text { Physical environ }> \\
1 \mathrm{~m}+\text { instruments } \\
\text { between }+ \text { at eye } \\
\text { level }\end{array}$} & & & \\
\hline & 7.01 & $\begin{array}{l}\text { "ya mo(n)key, day } \\
\text { ma mo(n)keys }\end{array}$ & $\begin{array}{l}\mathrm{Z} \text { contributes as though singing } \\
\text { along with the MTS }\end{array}$ \\
\hline $\begin{array}{l}\text { MTS approximates } \\
\text { YBeh > Imitate + } \\
\text { extend + Reflects > } \\
\text { celebrates efforts } \\
+ \text { Cadence }\end{array}$ & 7.09 & "da tunnews" & $\begin{array}{l}\text { MTS reflects "You made a } \\
\text { tower of horns" pointing at the } \\
\text { horns with a plagal cadence }\end{array}$ \\
\hline \multirow{3}{*}{$\begin{array}{l}\text { Cadence + YBeh > } \\
\text { Qu to clarify - } \\
\text { client felt heard, } \\
\text { successful comm. } \\
\text { this led to more. }\end{array}$} & 7.13 & $\begin{array}{l}\text { "ma tunnin" points } \\
\text { at horn tower "a } \\
\text { tunnid, a tunnod" }\end{array}$ & $\begin{array}{l}\text { MTS: "A tunnel?" with rising } \\
\text { inflection + V-VI cadence }\end{array}$ \\
\hline & 7.18 & $\begin{array}{l}\text { "yes" nodding and } \\
\text { smiling }\end{array}$ & $\begin{array}{l}\text { MTS: "oh" (revelationary, } \\
\text { understanding tone) }\end{array}$ \\
\hline & 7.21 & $\begin{array}{l}\text { "one li(tt)le } \\
\text { mo(n)key on top o" }\end{array}$ & $\begin{array}{l}\text { Z picks up monkey, brings it to } \\
\text { the top of the tower of horns, } \\
\text { starts singing rhythmically }\end{array}$ \\
\hline $\begin{array}{l}\text { Song }>\text { Content }> \\
\text { Incorporate client's } \\
\text { vocal activity and } \\
\text { actions }+ \\
\text { continuation of } \\
\text { Repetition, animals }\end{array}$ & 7.27 & $\begin{array}{l}\text { Z watches as the } \\
\text { MTS sings and } \\
\text { plays, then nods as } \\
\text { though to agree } \\
\text { about it sitting }\end{array}$ & $\begin{array}{l}\text { MTS "is the monkey going to } \\
\text { jump on top of the homs?" } \\
\text { launches into song "the } \\
\text { monkey jumps on the horn, the } \\
\text { monkey jumps on the horn - } \\
\text { boing boing! The monkey } \\
\text { jumps "/ the monkey's sitting } \\
\text { on the hom" once it's on top. }\end{array}$ \\
\hline $\begin{array}{l}\text { Song }>\text { Content }> \\
\text { Incorporate client's } \\
\text { vocal activity and } \\
\text { actions }\end{array}$ & 7.45 & "no monkey on da" & $\begin{array}{l}\mathrm{Z} \text { interrupts + points " "MTS } \\
\text { responds "the monkey jumps } \\
\text { off the horn - boing boing!" } \mathrm{Z} \\
\text { watches as MTS bounces a }\end{array}$ \\
\hline
\end{tabular}

\section{Notes from Communication}
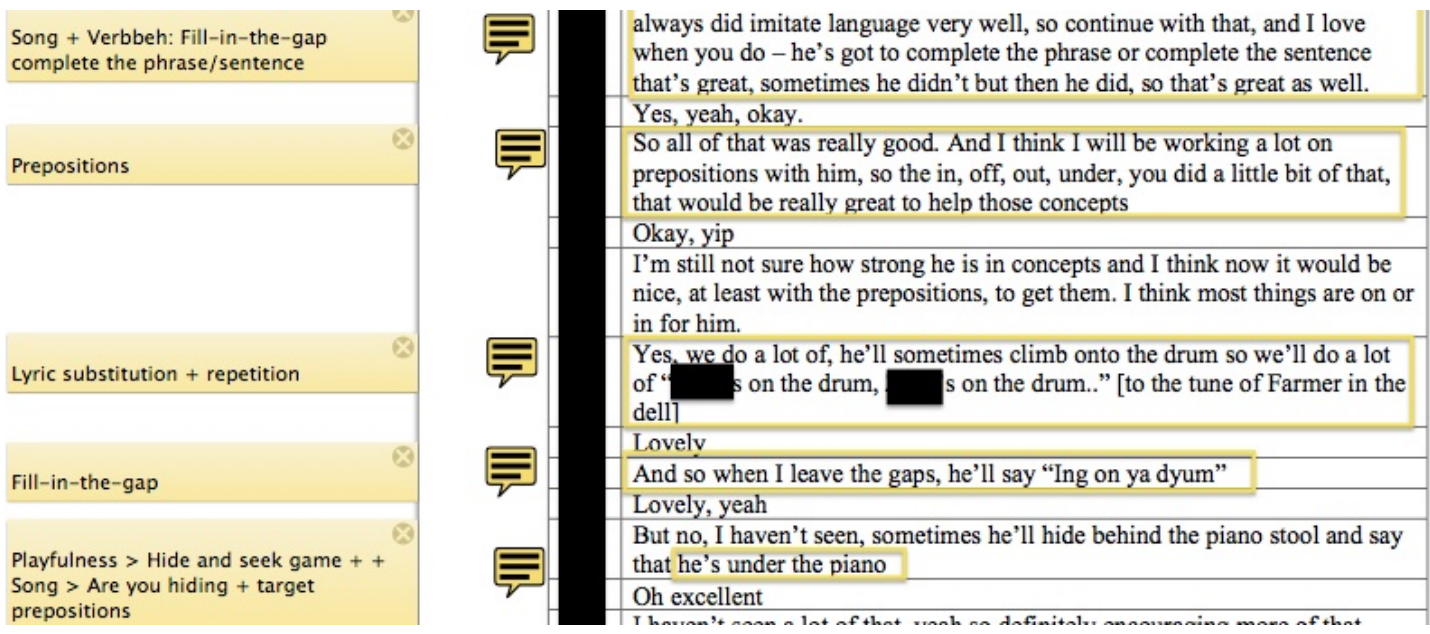


\section{Appendix 10: Examples of grounded theory data analysis process: Initial list of categories}

\begin{tabular}{|c|c|c|c|}
\hline - Attending MT & - Overall & $\begin{array}{l}\text { - Placement of } \\
\text { instrument }\end{array}$ & $\begin{array}{l}\text { - MT's directive } \\
\text { suggestion }\end{array}$ \\
\hline $\begin{array}{l}\text { - MT's open question } \\
\text { for choice }\end{array}$ & $\begin{array}{l}\text { - MT's options for } \\
\text { choice }\end{array}$ & - Client's name in song & - Modelling \\
\hline $\begin{array}{l}\text { - Volunteered within } \\
\text { song }\end{array}$ & $\begin{array}{l}\text { - Incorporate client's } \\
\text { expressed suggestion }\end{array}$ & - Animal percussion & $\begin{array}{l}\text { - Given space } \\
\text { between verses }\end{array}$ \\
\hline $\begin{array}{l}\text { - Volunteered within } \\
\text { established strategy }\end{array}$ & - Picture cards & $\begin{array}{l}\text { - Pause in song to fill- } \\
\text { in-the-gap }\end{array}$ & - Musical interaction \\
\hline
\end{tabular}

1. Attending MT

a. Entering centre

b. New words

c. Overall
i. Seizures/energy level/tiredness
ii. Short attention span
iii. "Took time"
iv. Related to/Needed Mo's (parent/carer)'s close proximity

2. MTS

a. Modelling

b. Incorporating client's expressed suggestion then led to more vocalizing/verbalizing

c. Incorporating client's words/vocalisations into a sentence, extending.

d. Direct question - Sung or spoken

e. Invitation/question - Sung or spoken

f. Directive suggestion - Sung or spoken

g. Open question for choice - Sung or spoken

h. Options for choice - Sung or spoken

i. Anticipatory phrase e.g. "It goes..." - Sung or spoken

j. Pause for client to fill-in-the-gap

k. Deep breath/gasp - to emphasise I'm waiting

I. Musical interaction

$$
\text { i. Reflection }
$$

m. Musical gesture

i. "aah"+drum roll+"op!" game

ii. Playful

n. Paired rhythm

o. Plan

i. Identify potential to incorporate strategy from lit review

p. Physical gesture accompanied vocalization/speech

q. Strategy to deal with separation anxiety

i. Naming the bells/horns

ii. Playful environment - finding the animals hiding

r. Matching/mirroring vocalization - leads to Client verbalizing/vocalizing again/more

i. Extend through song

s. Describing/reflecting the client's

actions/hehayiour

t. Keeping it simple

3. Instrument

a. Client's preference

b. Client favourite?

c. Animal percussion

d. Placement:

i. the placement of an instrument leads to client vocalizing/verbalizing

ii. Placement of favourite inst. You know will motivate them?

e. Onomatopaeia-sound of the instrument/animal/animal's action

f. Kazoo-vocalization

4. Song

a. Creating context

i. led to vocalization/verbalization

ii. supported client's actions/play

b. Incorporating client's preference c. Use of client's name

d. Space between verses

e. Pause for client to fill-in-the-gap

5. Picture Cards

a. Choice of instrument

b. Choice of song

c. Choice of anima

d. To take home

e. To name the MTS.

6. Volunteered

a. Within established strategy

$$
\text { i. Transition object }
$$

b. Within context of a game

c. Motivated to include Mo./Fa/parent/carer/sibling

d. To communicate preference i. Key words - incl return, no, okay, mum.

To disagree

f. To name/describe

i. Interpreted as a way of querying?

ii. Related to/on topic with MTS

iii. An object

iv, The MTS

g. Direct question - motivated to ask

h. While at/playing an instrument

$$
\text { i. Playful }
$$

i. Musical interaction

1. To express

$$
\text { i. Frustration }
$$

Having hurt himself

ii. Celebration

iv. Surprise

Motivated to engage me in his playing > "Come

7. $\mathrm{Mo} / \mathrm{Fa}$ on shari

a. Direct question

b. Suggestion

8. Emotional response accompanied vocalization/speech (ERaccSLD)

a. Facial expression e.g. smile/grin

b. Laughter/giggles.

9. Behavioural response accompanied vocalization/speech (BRaccSLD)

a. Eye contact

$$
\text { i. With instrument }
$$

ii. With $\mathrm{MT}$

10. Physical gesture accompanied vocalization/speech (PRaceSLD)

a. Pointed

b. Nodded (often enthusiastically)

c. Shook head

d. Waved

e. Action/play with instrument/within song

11. Physical gesture instead of vocalization/speech (PGinsSLD) 


\section{Appendix 11: Examples of grounded theory data analysis process: Axial Coding}

\section{Category table as at 21/08/11}

\begin{tabular}{|c|c|c|c|c|c|}
\hline \multicolumn{3}{|c|}{$\begin{array}{l}\text { Preceded by or in response to MTS } \\
\text { (Music Therapy Student) }\end{array}$} & \multirow{2}{*}{$\begin{array}{l}\begin{array}{l}\text { Volunte e red by } \\
\text { the client }\end{array} \\
\text { Within } \\
\text { established } \\
\text { strategy }\end{array}$} & \multirow{2}{*}{$\begin{array}{l}\text { Song } \\
\text { Use of } \\
\text { client's name }\end{array}$} & \multirow{2}{*}{$\begin{array}{l}\begin{array}{l}\text { Picture } \\
\text { Cards }\end{array} \\
\text { Instrument }\end{array}$} \\
\hline $\begin{array}{l}\text { Musical } \\
\text { Behaviour }\end{array}$ & \begin{tabular}{|l} 
Verbal \\
Behaviour
\end{tabular} & $\begin{array}{l}\text { Non-Verbal } \\
\text { Behaviour }\end{array}$ & & & \\
\hline Modelling. & Modelling & $\begin{array}{l}\text { Pause for client } \\
\text { to fill-in-the-gap }\end{array}$ & $\begin{array}{l}\text { Within the } \\
\text { context of a } \\
\text { game }\end{array}$ & $\begin{array}{l}\text { Pause for } \\
\text { client to fill- } \\
\text { in-the-gap }\end{array}$ & Song \\
\hline Matching & $\begin{array}{l}\text { Repeating } \\
\text { client's vocal } \\
\text { activity }\end{array}$ & $\begin{array}{l}\text { Deep } \\
\text { breath/gasp - } \\
\text { to emphasise I } \\
\text { am waiting }\end{array}$ & $\begin{array}{l}\text { To communicate } \\
\text { preference: } \\
\text { - Key words } \\
\text { - To include } \\
\text { parent/carer } \\
\text { - To include MTS }\end{array}$ & $\begin{array}{l}\text { To create } \\
\text { context, a } \\
\text { situation } \\
\text { song that } \\
\text { supports the } \\
\text { client's } \\
\text { actions/play }\end{array}$ & Animal \\
\hline Reflecting & $\begin{array}{l}\text { Extending } \\
\text { client's vocal } \\
\text { activity, } \\
\text { incorporating } \\
\text { into a } \\
\text { sentence }\end{array}$ & $\begin{array}{l}\text { Incorporating } \\
\text { client's } \\
\text { expressed } \\
\text { suggestion }\end{array}$ & $\begin{array}{l}\text { To name or } \\
\text { describe: } \\
\text { - An object } \\
\text { - The MTS } \\
\text { - To query } \\
\text { - Related to/on } \\
\text { topic with MTS }\end{array}$ & $\begin{array}{l}\text { Incorporates } \\
\text { the client's } \\
\text { preference }\end{array}$ & MTS \\
\hline Gesture & & $\begin{array}{l}\text { Playfulness e.g. } \\
\text { hunting for the } \\
\text { animals hiding. }\end{array}$ & $\begin{array}{l}\text { To express: } \\
\text { - Frustration } \\
\text { - Hurt } \\
\text { - Celebration } \\
\text { - Surprise }\end{array}$ & $\begin{array}{l}\text { Space } \\
\text { between } \\
\text { verses }\end{array}$ & \\
\hline
\end{tabular}

\section{Category table as at $07 / 10 / 11$}

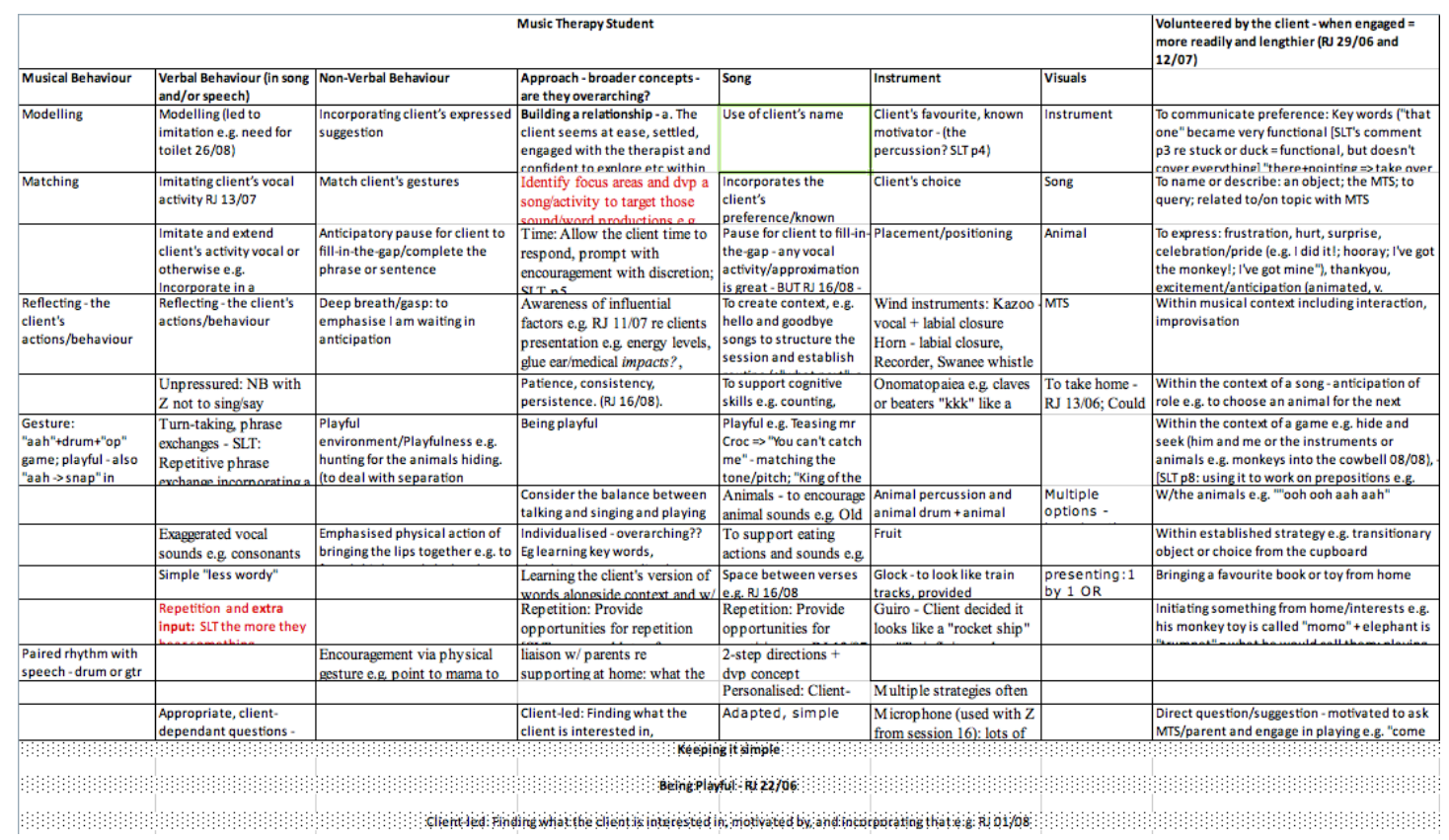




\section{Appendix 12: Main findings}

\section{Table 1}

A client-centred approach, drawing on strategies for choice, intuition and planning to enhance the relationship within the environment

\begin{tabular}{lll}
\hline Concept & Sub-concept & Examples of text relating to concept \\
\hline $\begin{array}{l}\text { Establishing a } \\
\text { therapeutic }\end{array}$ & $\begin{array}{l}\text { Non-threatening, } \\
\text { engaging, }\end{array}$ & $\begin{array}{l}\text { The dread of physical exercises [and] the thought of having to } \\
\text { work on moving your mouth would be dreary. So, the music }\end{array}$ \\
$\begin{array}{l}\text { within a } \\
\text { stable, safe } \\
\text { confling, fostering } \\
\text { environment }\end{array}$ & $\begin{array}{l}\text { explore } \\
\text { offers a non-threatening avenue to the same end, the client } \\
\text { begins to work on something, they try something new or hard, } \\
\text { with ease because they feel at ease and the music is supporting } \\
\text { their attempt. Reflective Journal 16/08/11 }\end{array}$
\end{tabular}

Fostering selfexpression

Establishing routine

Planning Individualising

Being aware of influential factors

Collaborating with parents, carers and other specialist professionals

Identifying potential use of strategy

Tailoring the physical environment

Keeping it simple

Considering the balance between
[Zack] picking up the claves with the castanet - MTS modelled, [Zack] copied, and persisted in trying [with a song to encourage the mastery of the action] $=>$ [Zack] "I did it!" MTS "You did it! Hooray" MTS and [Zack] "Hooray!". Clinical notes, Session 17

Little episodes like that, and repeating them, so he knows the pattern, he knows what's expected, and he get something out of it, he knows that there's an end result at the end of the game. Notes from communication

Where 'Heeeeee - + drum roll' has captured the attention and musicality of other clients - older - this did not seem to interest [Zack] in the least, he simply continued in his exploration of the instruments in the room. Reflective Journal 01/08/11

My current thinking is around how emotional state and energy levels can so largely influence and effect a person's capability, desire, and/or motivation for engaging in and participating in activities that may challenge them. [Yvan], who is so very clearly still not $100 \%$, still not well, physically tired and drained of energy was this week still so keen to come to music therapy... I still felt as though he was able to make connections and have an empowering sense of control within this time by being able to communicate. Reflective Journal 12/07/11

Supporting parent/carers' use of certain songs, activities, use of oral toys at home to provide extra input and repetition for clients to support their progress... A book of laminated photos of [the client] playing instruments with a simple word or sentence underneath for clients to share and talk about their musicmaking at pre-school and home. Notes from communication

I am reminded of the chant "I think I can, I think I can" from the children's series, and must remember to incorporate that - what a great motivational tool for a child. I also see a lot of potential for vocalizing using trains songs 'chuga chuga' and 'choowoo' and 'toot toot' and pulling on a brake 'eee' and coming to a stop 'stooooooop' Reflective Journal 16/08/11

[Zack] seemed at ease, lots of eye contact with me especially when speaking, I faced him directly across the drum - available and attentive - shared cooperative play... Physical distance $\sim 1$ metre while on the floor. Audiovisual observations, Session 6

[MTS asked] Can you ring [your brother's] bell for him?" - this seemed to confuse [Zack], who then called for [his brother]. Clinical notes, Session 8

But it was all more play than musical. Is this okay? Do I revert to talking/singing too much? I feel as though it is such an agile 


\begin{tabular}{|c|c|c|}
\hline & $\begin{array}{l}\text { talking, singing, } \\
\text { playing and } \\
\text { making music }\end{array}$ & $\begin{array}{l}\text { aspect of my ability as a music therapist - because [my voice] is } \\
\text { right with me. Reflective Journal } 22 / 06 / 11\end{array}$ \\
\hline $\begin{array}{l}\text { Working } \\
\text { intuitively }\end{array}$ & Being flexible & $\begin{array}{l}\text { It struck me today that [Zack] was so assertive and decisive } \\
\text { about what he wanted to do and not do. It is as though he has } \\
\text { access to all of these words and phrases now that he didn't have } \\
\text { before, and now that he has them he is trying them out, and } \\
\text { seeing just what/where they'll get him. I felt that it was } \\
\text { important to facilitate his sense of control in the session today. } \\
\text { At the same time it meant that we did very little music making } \\
\text { and that we didn't do a lot of the activities that I had planned } \\
\text { and had previously been significant for [Zack]'s progress. } \\
\text { Reflective Journal 02/09/11 }\end{array}$ \\
\hline
\end{tabular}

Allowing time

Being playful

Judging when to push

Providing avenues for children's choice(s)
Offering structured strategies
Give him the time to produce it, even if it's not exactly right, any approximation is good, and then with practice he'll refine it. Note from communication

He made progress in coming into and staying in the session without getting upset, and was hardly distracted by his family being in the waiting room - which is a great move on from previous weeks. I felt as though he had done so well, and continued to do so well by being engaged in playful interaction with me that I didn't want to push his engagement in speech and motor skills. Instead I fostered his play, facilitated his use of the instruments to play, became involved in the role of "playmate", in order to develop our relationship and celebrate how well he was managing in the session. Occasionally, because he was so engaged in play, he did verbalise in the gaps I left, vocalized lots of "kk" and "ssh" [as we had a sword fight]. Reflective Journal 22/06/11

[Zack] added 'wee' and 'whoa' and 'crash' as the monkeys were pushed off the drum. Clinical notes, Session 11

We all kind of tune in to what he says, and he's very good at gestures, so with the two combined we can kind of work out what he's meaning to say... rather than giving in to his gesture requests [expect him] to say something and that could be used in conjunction with the picture... use a model "open it [Zack]" or "open it please" and he will say that Note from communication.

Perhaps...leaving a gap sets up expectations, perhaps having the drumming to match allows a freer more inviting opportunity. One is required to judge when you can expect things from your clients, however I feel as though you can expect [similar outcomes] through different media and if they are working on [speech and expressive language development] then why not?... As the relationships have started to feel well grounded, I feel I can begin pushing more. Reflective Journal 17/08/11

Song cards: [MTS presenting them one by one]: "we've got..." [Yvan] named each one and placed them on the drum... Clinical notes, Session 11

[Yvan] pointed and nodded and vocalized at the pictures offered to indicate he wanted to play Old MacDonald at the piano "ano". Here he was again very focused, vocalized the name and pointed at each animal in the picture in the gap offered for him to choose which animal to sing about next. Clinical notes, Session 8

[Zack] was highly motivated by opening the cupboards, and used many words around this - key, this one, open it, open this one, that one (pointing at instrument), guitar (meaning ukulele), 
no, okay, yes, beaters - to then choose instruments to bring into the room. Clinical notes, Session 19

"[Zack's attention wanders], he rolls over on the floor. I begin singing "What next", then add one hand on the piano. [Zack] grabs his mother's hand and leads her to the drums and cymbal" Audiovisual observation, Session 3

Responding to [After a game with the shakers and guitar, Zack] went to get the and incorporating guitar stand "pu(t) $\mathrm{i}(\mathrm{t})$, put it". MTS "What shall we do with the children's guitar, shall we play more or put it -?" [Zack] "down" MTS expressed "let's put it down" Five minutes to go, [Zack] offered "time to suggestion(s) ti(d)y up" repeatedly, helped me put things away...MTS "We did it, hooray!" [Zack] "hooray!" and clapped my high five I offered. Clinical notes, Session 17

\footnotetext{
Note. Spelling and other aspects of style used in New Zealand are used in the quotations Note. All examples of text in the tables have been attributed to the data source they originated from Note. Brackets indicate the following: [paraphrased as appropriate]; (vocal sound not pronounced) Note. MTS is an abbreviation for Music Therapy Student
} 
Table 2

Engaging in and enhancing verbal, musical and non-verbal behaviour

\begin{tabular}{|c|c|c|}
\hline Concept & Sub-concept & Examples of text relating to concept \\
\hline \multirow[t]{10}{*}{$\begin{array}{l}\text { Verbal } \\
\text { behaviour }\end{array}$} & Modelling & $\begin{array}{l}\text { [Yvan] went through the shakers saying "purple elephant, green } \\
\text { giraffe, pink rhino" and when I said the monkey was brown, he } \\
\text { said "(br)own". Clinical notes, Session } 9\end{array}$ \\
\hline & $\begin{array}{l}\text { Imitating client's } \\
\text { vocal activity }\end{array}$ & $\begin{array}{l}\text { In putting [the] beater away in the frogs hole it dropped to the } \\
\text { floor. [Zack] "uh-oh"; MTS "oops, you can do it, wriggle, } \\
\text { wriggle"; [Zack] "waaaye"; MTS increases volume to } \\
\text { meet/match [Zack's] dynamic "wriggle, wriggle, you can do it!" } \\
\text { with an ansty/trying vocal quality to meet his frustration. } \\
\text { Audiovisual observation, Session } 3 \text { [6.41] }\end{array}$ \\
\hline & $\begin{array}{l}\text { Imitating and } \\
\text { extending client's } \\
\text { vocal activity }\end{array}$ & $\begin{array}{l}\text { [Zack] "to infinity and beyond!" with arm up in the air, dropped } \\
\text { an animal shaker - [MTS] copied; this continued for some time, } \\
\text { big smiles. [MTS] added "aah" crescendo + ascending to bring } \\
\text { the shakers back up high and continue => "crash" - [Zack] } \\
\text { joined in with these" Clinical notes, Session } 17\end{array}$ \\
\hline & Reflecting & $\begin{array}{l}\text { In response to [Zack] putting horn in mo's horn + "oh no!" } \\
\text { MTS: "they keep getting stuck!" Audiovisual observation, } \\
\text { Session } 3[10.30]\end{array}$ \\
\hline & $\begin{array}{l}\text { Repeating and } \\
\text { providing extra } \\
\text { input }\end{array}$ & $\begin{array}{l}\text { "With lots of repetition [the client] generally does improve...he } \\
\text { needs the extra input and lots and lots of practice...to see your } \\
\text { face, to see your mouth... The more [clients] hear something, } \\
\text { hopefully they'll learn it and refine it." Notes from } \\
\text { communication }\end{array}$ \\
\hline & \multirow{2}{*}{$\begin{array}{l}\text { Turn-taking, } \\
\text { repetitive phrase } \\
\text { exchange }\end{array}$} & $\begin{array}{l}\text { MTS “Are you ready, are you steady?" [Zack] "go" Clinical } \\
\text { notes, Session } 4\end{array}$ \\
\hline & & $\begin{array}{l}\text { 'Hand-stuck' game: Began with [Zack] saying "stuck" and } \\
\text { showing me his hand in the bell of the [reed] horn [a favoured } \\
\text { instrument]. Verbally I extended it "Oh no, your hand is stuck!" } \\
\text { [then] "Oh no, my hand is stuck too!" [then] "How will we get } \\
\text { free? Help!" [and] "I will help you: one, two three!" [I extended } \\
\text { this into a lyrical game of getting each other's horn free and in } \\
\text { this way I was able to build on Zack's spontaneous speech and } \\
\text { initiate incorporating target sounds and words.] Zack also began } \\
\text { to extend and use some of the sentences I modelled during the } \\
\text { game [including] "uh-oh, help; I help; hand stuck; two, three" } \\
\text { [after I counted one, two leading to getting the horn free]; } \\
\text { [Zack] offered: "I got it; thank you Shari; yay" Clinical notes, } \\
\text { Session } 13\end{array}$ \\
\hline & $\begin{array}{l}\text { Exaggerating } \\
\text { vocal sounds }\end{array}$ & $\begin{array}{l}\text { MTS sings "Zachary rolled over the drum..whoa crash"; [Zack]: } \\
\text { "ash"; MTS modelled "Ccccrash ccccrash"[which led to the } \\
\text { client imitating] "cyash Shayi, cyash Shayi" [crash Shari]. } \\
\text { Audiovisual observation, Session } 9 \text { [14.06] }\end{array}$ \\
\hline & $\begin{array}{l}\text { Using simple } \\
\text { lanugage and } \\
\text { being "less } \\
\text { wordy" }\end{array}$ & $\begin{array}{l}\text { [Zack] took the blue kazoo I held out, straight away put it into } \\
\text { his mouth, then turned it over when I said "other end" - then he } \\
\text { made it sound! Clinical notes, Session } 5\end{array}$ \\
\hline & $\begin{array}{l}\text { Pausing in } \\
\text { anticipation for } \\
\text { clients to fill-in- } \\
\text { the-gap or } \\
\text { complete the } \\
\text { phrase or sentence }\end{array}$ & $\begin{array}{l}\text { In response to "are there more frogs in the room?" [Zack] looks } \\
\text { excitedly at and goes to get another. MTS "We've got two - " } \\
\text { [Zack] "frogs" Clinical notes, Session } 4\end{array}$ \\
\hline
\end{tabular}




\begin{tabular}{|c|c|c|}
\hline & $\begin{array}{l}\text { Asking } \\
\text { appropriate, } \\
\text { client-dependant } \\
\text { questions }\end{array}$ & $\begin{array}{l}\text { [Zack] wanted to open the cupboards, and with a question with } \\
\text { choice - close or open - he changed from saying 'that one' to } \\
\text { 'open the door' - significant Clinical notes, Session } 18 \\
\text { MTS (in song, IV - V): "What's that animal going roar? It's a - } \\
\text { "; [Zack]: "Sy-a-a-ke"; MTS (having understood 'snake'): "Is it } \\
\text { a cheetah going roar?" [Zack] (emphatic tone): "No, a nake!" } \\
\text { Audiovisual observation, Session } 6 \text { [12.10] }\end{array}$ \\
\hline \multirow[t]{12}{*}{$\begin{array}{l}\text { Musical } \\
\text { behaviour }\end{array}$} & Modelling & $\begin{array}{l}\text { [Playing kazoos] MTS - ascending gliss, [Zack] copied at the } \\
\text { same pitch, twice! Clinical notes, Session } 5\end{array}$ \\
\hline & Matching & $\begin{array}{l}\text { [Zack] picked up horn again and vocalised "huh" [into the bell } \\
\text { of the reed horn] in an ascending inflection. MTS "hello" } \\
\text { copying [Zack's vocal] inflection Clinical notes, Session } 4\end{array}$ \\
\hline & Reflecting & $\begin{array}{l}\text { When [MTS] moved to the piano and played (high register) in } \\
\text { response to each time he played the windchimes [Yvan] smiled } \\
\text { broadly and vocalised what seemed a satisfied "hnn" Clinical } \\
\text { notes, Session } 8\end{array}$ \\
\hline & Improvising & $\begin{array}{l}\text { [Zack] initiated shaking the shakers up high [and said] "up, up, } \\
\text { up", holding them up Clinical notes, Session } 2\end{array}$ \\
\hline & & $\begin{array}{l}\text { MTS prompts [Zack] to begin playing by gasping and putting } \\
\text { her hand to her ear and singing "Can I hear you play on the } \\
\text { drums today"; [Zack] begins playing large percussion as MTS } \\
\text { begins improvising around the theme melody of Pirates of the } \\
\text { Carribean on the flute. [10.11]: [Zack] looks up at MTS, smiles, } \\
\text { says "arrgh rreerree"" (perhaps making a pirate sound). } \\
\text { Audiovisual observation, Session } 18 \text { [9.45] }\end{array}$ \\
\hline & $\begin{array}{l}\text { Developing } \\
\text { musical } \\
\text { interaction }\end{array}$ & $\begin{array}{l}\text { We shared a [musical] turntaking exchange, with me sneakily } \\
\text { playing the drum between us each time he vocalised. [Zack] } \\
\text { grinned at this and seemed to understand his role and control. } \\
\text { This continued for some time Clinical notes, Sesssion } 17\end{array}$ \\
\hline & & $\begin{array}{l}\text { Often following moments of engagement and shared play and } \\
\text { the like, both [clients] start talking in lengthy sentences. } \\
\text { Reflective Journal, 13/07/11 }\end{array}$ \\
\hline & $\begin{array}{l}\text { Pairing rhythm } \\
\text { with speech }\end{array}$ & $\begin{array}{l}\text { Oh my gosh, the drumming with rhythm to match syllables } \\
\text { worked today!!! During the monkeys on the bed, which [Yvan] } \\
\text { had chosen to play on the drum, I drummed a rhythm to match } \\
\text { the syllables in the lyrics - and this both supported and extended } \\
\text { [Yvan]'s singing! Reflective Journal 16/08/11 }\end{array}$ \\
\hline & $\begin{array}{l}\text { Varying musical } \\
\text { elements }\end{array}$ & $\begin{array}{l}\text { [Zack] reaches for the monkey now on the floor, MTS holds it } \\
\text { out "what can you see?" [Zack] looks straight at MTS with a } \\
\text { smile "a banana". MTS modulates [as she sings] "the monkey } \\
\text { eats a banana!" [ensuing eating noises] Audiovisual observation, } \\
\text { Session } 9 \text { [8.03] }\end{array}$ \\
\hline & & $\begin{array}{l}\text { MTS in the space between verses, then says "the tiger goes - " } \\
\text { waits briefly "the tiger goes roar" - raspy voice, like a tiger's } \\
\text { roar. [Zack] "(th)e (t)iger woarch" Audiovisual observation, } \\
\text { Session } 6[11.37]\end{array}$ \\
\hline & & $\begin{array}{l}\text { [Zack] puts [the horns] in [the tunnel i.e. drum] then sticks his } \\
\text { head in, calling "He-yu! He-yu!" MTS grumbling voice } \\
\text { "hello", calls into the drum. Z copies "hello" with clear /1/ } \\
\text { sound. Audiovisual observation, Session } 9[11.08]\end{array}$ \\
\hline & $\begin{array}{l}\text { Varying/utilising } \\
\text { harmonic or } \\
\text { rhythmic cadence }\end{array}$ & $\begin{array}{l}\text { [Zack] "da tunnews"; MTS reflects "You made a tower of } \\
\text { horns" with a plagal [IV-I] cadence, pointing at the horns; } \\
\text { [Zack] "ma tunnin" points at horn tower "a tunnid, a tunnod"; }\end{array}$ \\
\hline
\end{tabular}


MTS "a tunnel?" with rising inflection and V-VI [imperfect] cadence" [Zack] "yes" nodding and smiling Audiovisual observation, Session 9 [7.09]

Non-verbal Matching client's [Yvan] also waved at times towards the person/animal, and behaviour gestures pointed to his mum in the gap Clinical notes, Session 12

Taking a deep breath or gasp

Hello song - MTS: deep breath and pause - [Yvan] "hello" Clinical notes, Session 12

Emphasising the physical action You may want to just over exaggerate slightly, the target sound for verbal activity that he's not getting, because he might just need that extra input, to see your face, to see your mouth... when you do the /b/ you can emphasise that the lips are closed, you can model it for him - /p/, /b/, /m/...exaggerating the /t/ in the Toot Toot song. Notes from communication

Encouraging via [MTS] encouraged singing hello to mama, pointed at her to physical gesture encourage [Yvan] to fill in the gap Clinical notes, Session 16

Using facial expression

[MTS] screws up her face, curling her lips as she says "grrump" with a growly voice each time she clasps a clave with a castanet; [Zack] copies "gump" with a growly voice Audiovisual observation, Session 15 [10.05] 


\section{Table 3}

Capturing children's preferences and vocal activity in the content and structural aspects of playful but focused song

\begin{tabular}{|c|c|c|}
\hline Concept & Sub-concept & Examples of text relating to concept \\
\hline Content & $\begin{array}{l}\text { Framing or } \\
\text { supporting } \\
\text { children's } \\
\text { participation }\end{array}$ & $\begin{array}{l}\text { [Yvan] seems to respond happily and positively when I incorporate what } \\
\text { he is doing, his play, into song. Last week for example - putting the } \\
\text { frame of "Are you hiding" in song around his play of the farm animals. } \\
\text { Did it give his play a sense of purpose? Was it the encouragement and } \\
\text { reinforcement of his play that he responded to, that extended his play, } \\
\text { and then extended his opportunities to be involved verbally as well? Was } \\
\text { it simply the fact that I was with him, in his play, that I come with my } \\
\text { singing, and by singing about what he is doing I am meeting him and } \\
\text { playing with him on his level as though we are on the same level, } \\
\text { together in the experience... also settles the client, seems to help reassure } \\
\text { them as to why they're there. Reflective Journal } 12 / 07 / 11 \text {. }\end{array}$ \\
\hline
\end{tabular}

Supporting Five Little Speckled Frogs with frogs on the glockenspiel - [Yvan] cognitive skills counted to five. Clinical notes, Session 16

Supporting understanding of the concept of wet and dry to reduce dribbling, including concepts of a wet chin, giving it a wipe, swallow two-part instructions into song. Notes from communication

Incorporating Lots of communicative vocalising and verbalising within "Hand-stuck" playfulness game, playing with the animals, filling in the gaps Clinical notes, and games $\quad$ Session 14

MTS "Ga [pausing] lloop" + clamping on [Zack's] jumper (arm) [Zack] giggled, lots of smiles, MTS voice in a growl. [then] [Zack] "I've got the monkey!" - very clearly... "uh-oh" - putting the monkey puppet in the castanet [game ensues of getting the monkey out] => "that one; got mine; I've got mine; I've got crocodile" - proud tone of voice. Clinical notes, Session 15

Incorporating [At the client's] level, for speech sound work a lot of it has been animal animal sounds sounds and that sort of thing, like the snake goes 'hss'. Notes from communication

Old MacDonald at the piano - rooster first, [Yvan] offered two very quiet "cockadoodle"s; named the horse he rides "Honeypuff" and shook and sighed loudly for the noise she makes in the song; very clear and loud "oink"s and "mmm(oo)"s. Clinical notes, Session 10

Supporting Singing a song about a very hungry caterpillar who goes around the eating actions and sounds music room to find food - considered useful in support of my clients' feeding programme with his speech and language therapist. Notes from communication

Using clients' If we could get him to produce the '[middle consonant]' consistently in names his name, that would be a great goal. And for most children [to say their name] Notes from communication.

Targetting My client initiated our 'Toot Toot' song!!! We had been playing with the clients' focus animals, then all of a sudden he grabs a horn, we start taking turns with a areas and sound/word productions note each, then even more of a sudden he says "toot!" It was a wet /t/, yes, but it was distinctly different from his /d/ - yay! After months of singing it here he is initiating it! Reflective Journal 26/08/11

Structure Choosing a type MTS starts singing "There are four little monkeys on the snake" to the tune of She'll be coming; [Zack] turns to watch... [Zack] contributes "ya mo(n)key, day ma mo(n)keys, as though singing along with the MTS. Audiovisual observations, Session 9 [6.49] 
Incorporating It seems that jumping on whatever tidbits the client offers, and offering repetition opportunities for them to say what they are already able to offers a great amount of encouragement and nurtures an increasing sense of self confidence, that they can do it. Reflective Journal 16/08/11

Accompanying [Yvan] played with more enthusiasm and exploration and for longer with or not this structured song as accompaniment as opposed to piano accompaniment in previous weeks...after a few lines [Yvan] looked at and said "mama" Clinical notes, Session 11

Pausing for [Yvan's] vocalising/verbalising today was often in response to my gaps clients to fill-in- left in a song, Hello song - MTS: ["Hello, hello to - "] gap and pause the-gap Yvan: "[Yvan]; mama; e(1)ephant; (fr)og; (Sh)ar(i)". Clinical notes, Session 12

Providing space [Yvan] counted by himself to four after I had [sung] the 'to five' verse between verses [of the Monkeys jumping on the bed song]

Just finished a verse of frog song, [Zack] and MTS beating the frogs and playing with them - manoevuring the beater into the hole [Zack] "hey doweey" put the beater back in the frog's hole MTS: "We've put it away". Audiovisual observation, Session 3 [5.55]

Establishing a [Yvan] patted the strings and...sang "goodbye" at the very end, and in role for the client the gaps [in the goodbye song] for [MTS] "come back again next week and play the - "[Yvan] "(p)iano" and "(g)uitar"

[During Old MacDonald Yvan] made the noise "neigh, oink, (c)o(ck)idood(l)e(d)oo and mm(oo). Clinical notes, Session 11 


\section{Table 4}

Incorporating clients' preferences for themed and functional instruments

\begin{tabular}{|c|c|}
\hline Concept & Examples of text relating to concept \\
\hline $\begin{array}{l}\text { Including clients' } \\
\text { known favourite } \\
\text { or motivator }\end{array}$ & $\begin{array}{l}\text { [Yvan] was very interested and engaged with the monkeys and the crocodile - I } \\
\text { need more songs about these animals - as well as the animal percussion. Clinical } \\
\text { Notes, Session } 12\end{array}$ \\
\hline $\begin{array}{l}\text { Incorporating } \\
\text { animal-themed } \\
\text { percussion, drum } \\
\text { and sounds }\end{array}$ & $\begin{array}{l}\text { [Zack] played creatively with the animals, bouncing them off each other, crashing } \\
\text { into each other, put the monkey puppet on to play. [Zack] excitedly said "monkey" } \\
\text { and later (after I modeled) said "ooh ooh aah aah", volunteered "crocodile", } \\
\text { "frogs", "snake" and lots of "boing" Clinical notes, Session } 7\end{array}$ \\
\hline $\begin{array}{l}\text { Incorporating } \\
\text { food-themed } \\
\text { instruments }\end{array}$ & $\begin{array}{l}\text { Lovely moment of interaction [with Yvan] when playing and singing about the } \\
\text { hungry caterpillar [who goes around the room finding different food to eat] } \\
\text { Clinical notes, Session } 17\end{array}$ \\
\hline $\begin{array}{l}\text { Incorporating } \\
\text { wind instruments }\end{array}$ & $\begin{array}{l}\text { A great goal for him would also be to have better lip closure, and that's where the } \\
\text { horns come in and to develop those muscles... The kazoos will help with that lip } \\
\text { closure, and also the vocal activity...And I think he'd get a lot of enjoyment out of } \\
\text { kazoos as well, lots [of] feedback that [will] motivate him. Notes from } \\
\text { communication }\end{array}$ \\
\hline $\begin{array}{l}\text { Incorporating the } \\
\text { potential for } \\
\text { onomatopoeia }\end{array}$ & $\begin{array}{l}\text { MTS [crescendo] cymbal roll + "crash" => MTS [crescendo] cymbal roll => } \\
{[\text { Zack] "crash" and "my turn" Clinical notes, Session } 3}\end{array}$ \\
\hline $\begin{array}{l}\text { Incorporating the } \\
\text { potential for } \\
\text { object metaphor }\end{array}$ & $\begin{array}{l}\text { [Yvan] Vocalising during play with Thomas and Flora engines on the drum and } \\
\text { glock "u u u u" = (ch)u(g)? and "ooo" Clinical notes, Session } 17 .\end{array}$ \\
\hline \multirow[t]{2}{*}{$\begin{array}{l}\text { Providing a } \\
\text { variety of sizes }\end{array}$} & $\begin{array}{l}\text { [Yvan] called one of the [big] frogs "(gr)an(d)ma" and another one [his carer's } \\
\text { name]. Clinical notes, Session } 14\end{array}$ \\
\hline & $\begin{array}{l}\text { MTS resumes song "..then there were -“" pause; [Zack] "big” + eye contact... "big } \\
\text { fwog" Audiovisual observation, Session } 6 \text { [14.30] }\end{array}$ \\
\hline $\begin{array}{l}\text { Including a } \\
\text { microphone }\end{array}$ & $\begin{array}{l}\text { [Zack] found a microphone - lots of singing and free vocalisaion, big smile and } \\
\text { dancing as he sang, I played Bodhran as he sang. Clinical notes, Session } 16\end{array}$ \\
\hline
\end{tabular}




\section{Appendix 13: Adaptation of children's song Teasing Mr Crocodile}
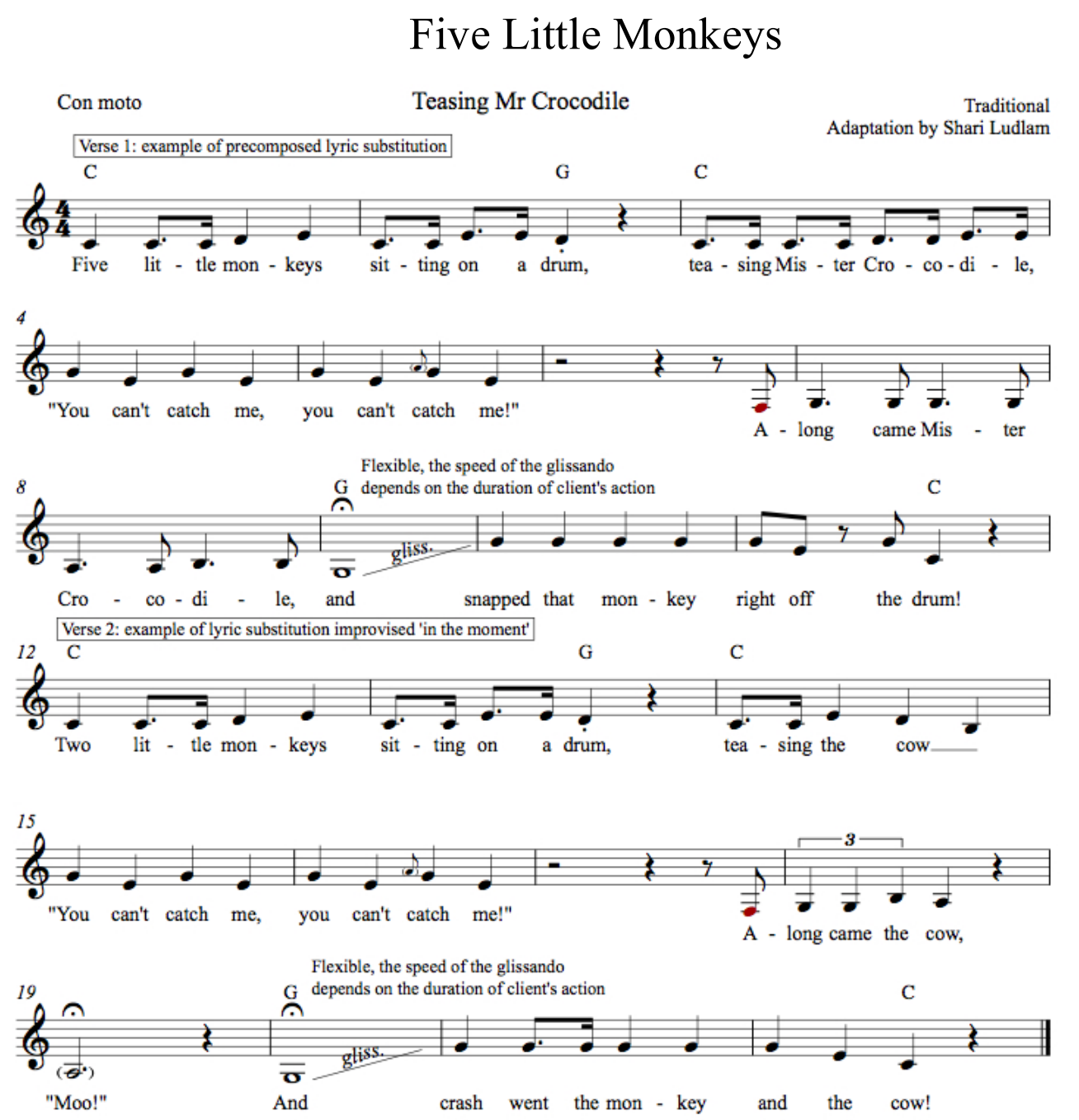

Ensuing verses progressively count down from the number of animals started with 
Appendix 14: Children's song Five Little Monkeys Jumping on the Bed

\section{Five Little Monkeys}

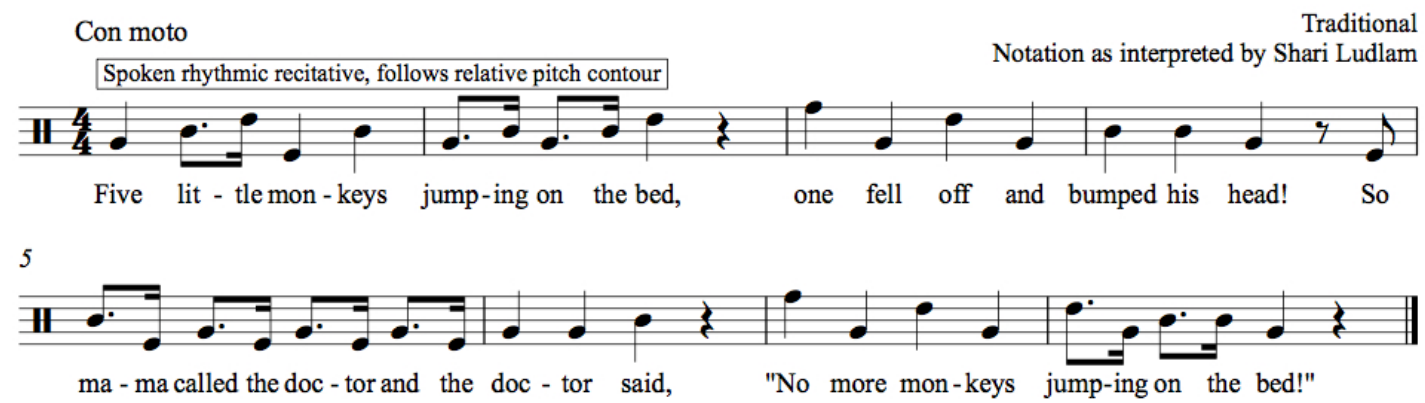

Ensuing verses progressively count down from the number of monkeys started with; Final verse last line "Put those monkeys back in bed!" 


\section{Appendix 15: Adaptation of children's song Are You Sleeping}

\section{Are You Sleeping}
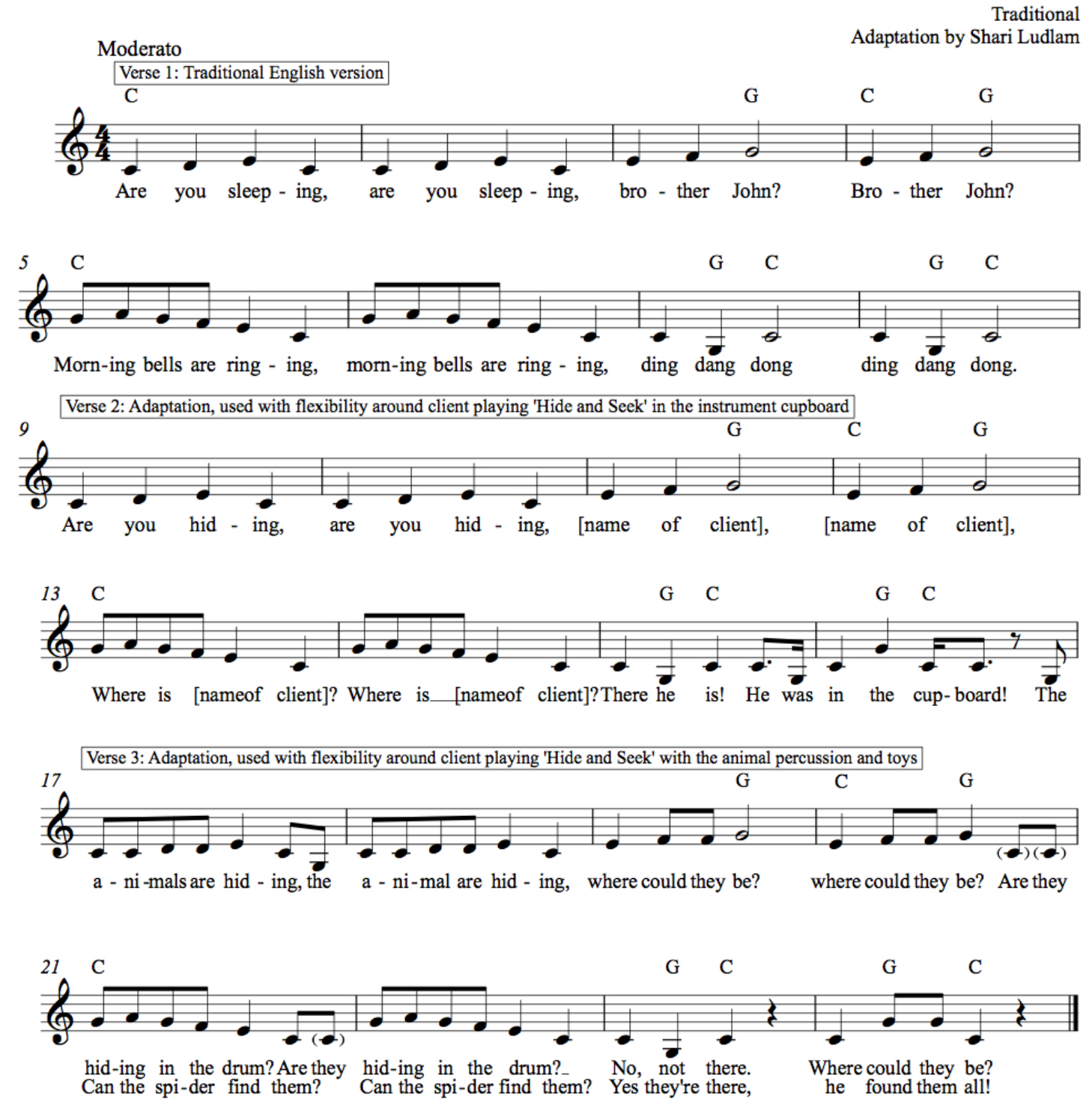
Appendix 16: Traditional children's song Five Green and Speckled Frogs

(also known as Five Little Speckled Frogs)

Five Green and Speckled Frogs

Traditional
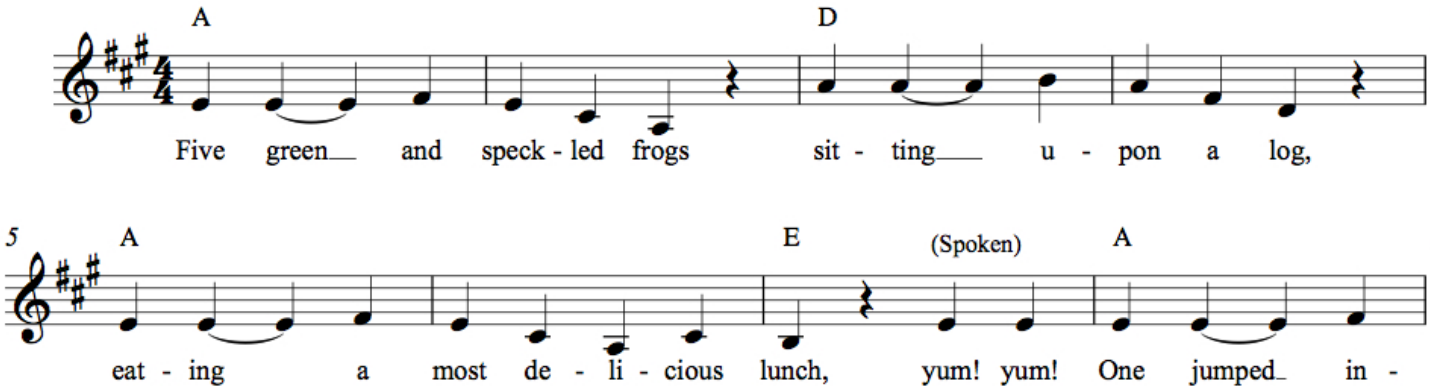

(Speed of glissando depends on
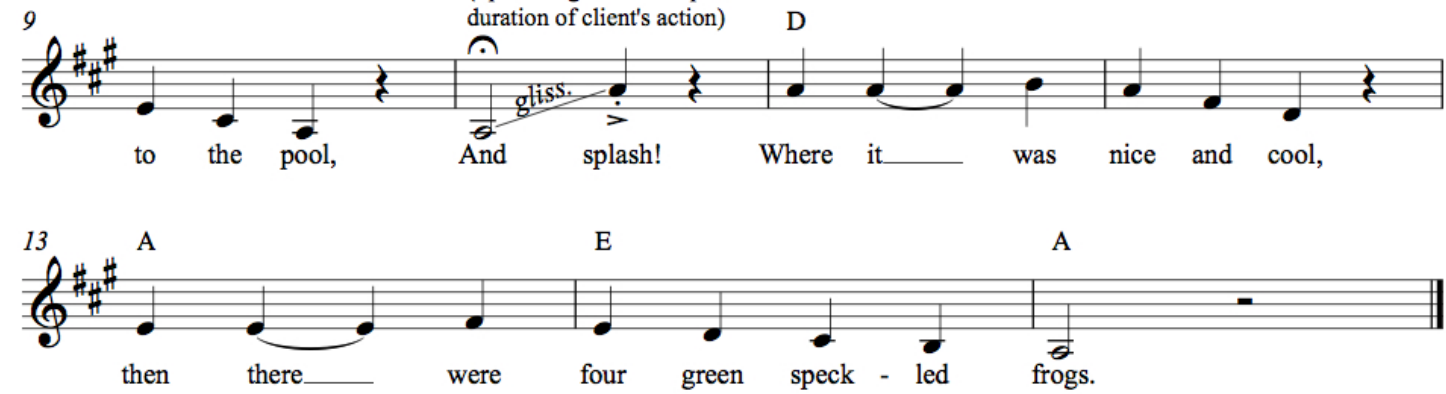

Ensuing verses progressively count down from the number of frogs started with 


\section{Appendix 17: $\quad$ Toot Toot}

\section{Toot, Toot}

(C) Shari Ludlam 2011
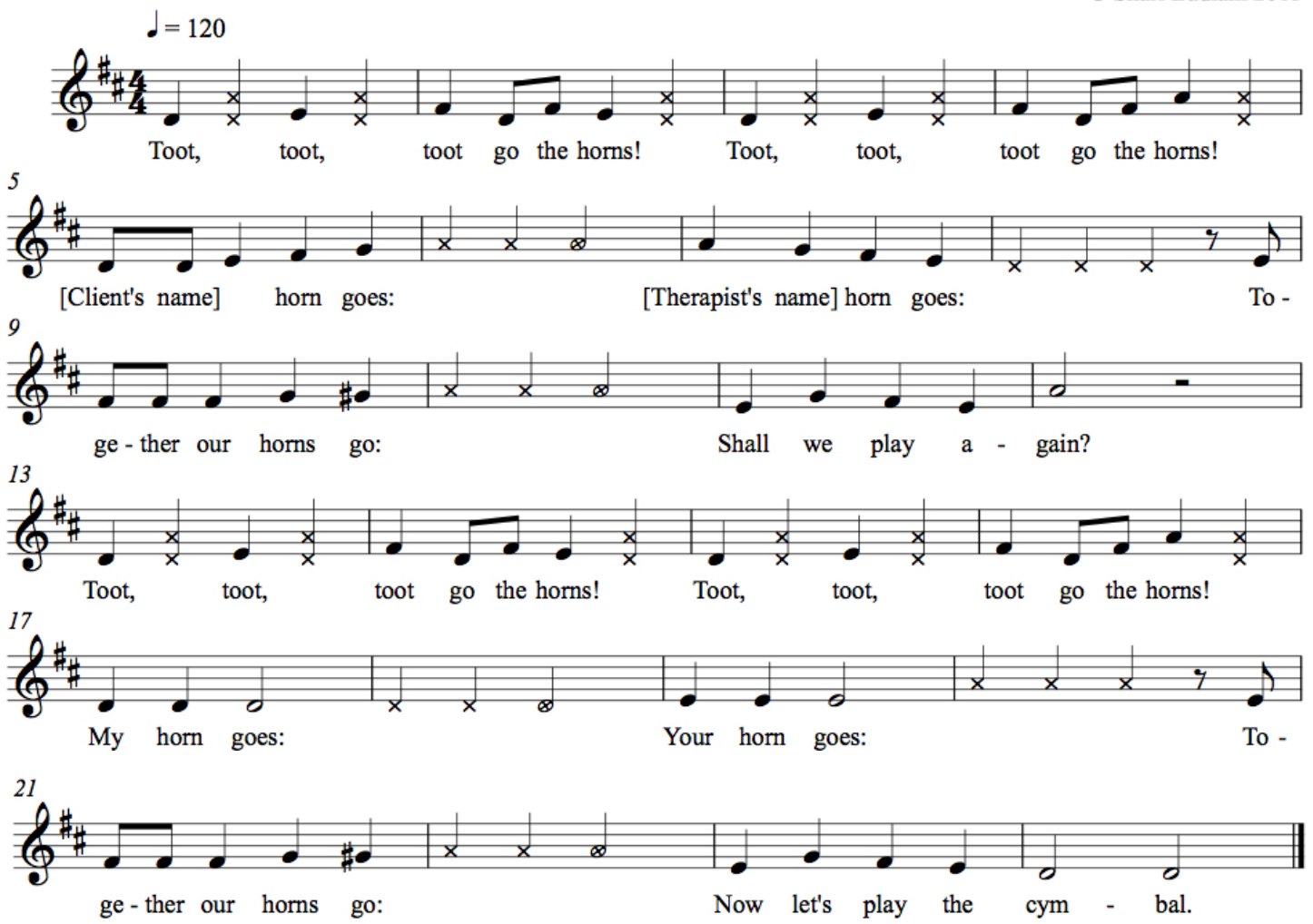

This score has two verses of the Toot, Toot song (b1-12 and b13-24) in order to show adaptations possible including:

* The order of who plays first, therapist or client, was dependent on the client's ability to wait and if modelling first helped the client to participate

* Different melody in bar 5 versus bar 17 in order to prompt the client

* Use of names or pronouns was client-dependant

* Possible lyrics for the final phrase - as a question for the client to choose or directive, again clientdependant

* I often gave the client the fifth note of the key, i.e. A if in D major 
Appendix 18: Adaptation of children's song Galoop Went the Little Green Frog

\section{Galoop Went the Little Green Frog}
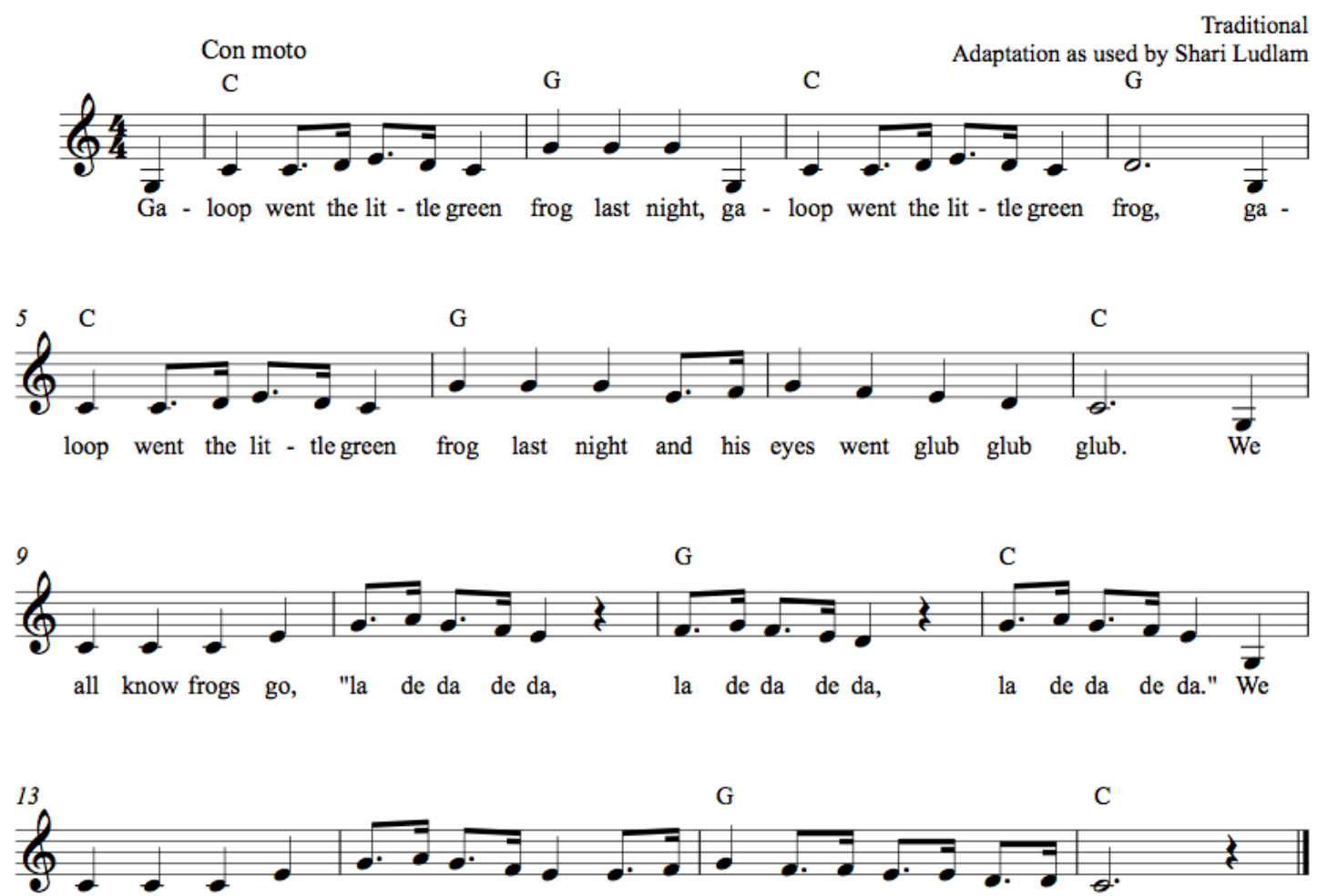

all know frogs go, "la de da de da," but they don't go ga-loop ga-loop ga-loop. 


\section{Appendix 19: Down in the Jungle}

\section{Down in the Jungle}
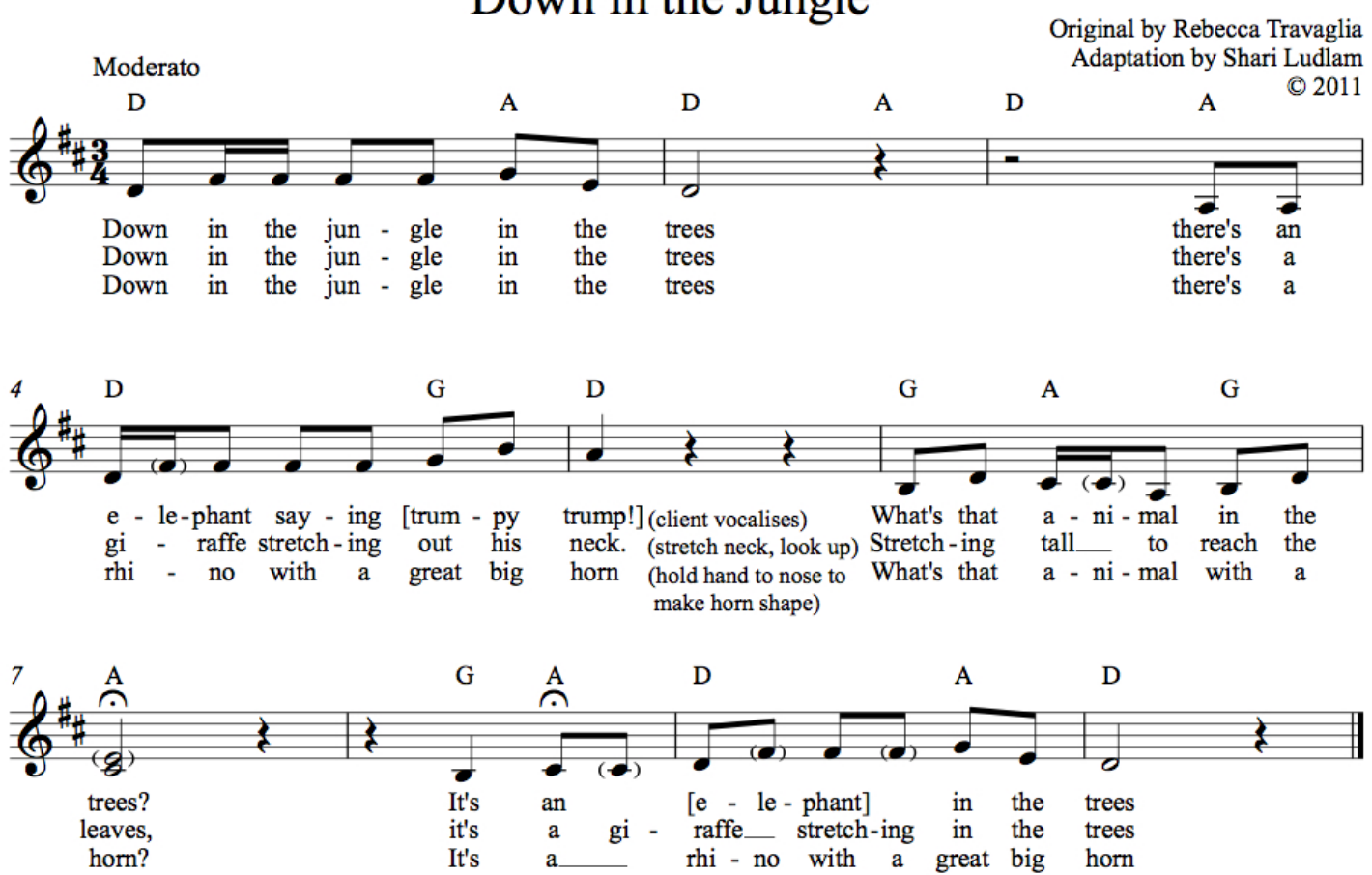

Down in the jungle in the trees

There's a monkey calling ooh ooh aah aah (client vocalises)

What's that animal in the trees?

It's a monkey calling ooh ooh aah aah

Down in the jungle in the trees

There's a snake slithering, hss hss (client vocalises)

What's that animal in the trees?

It's a snake slithering, hss hss

Down in the jungle in the trees

There's a monkey swinging in the trees (swinging arm action)

Swinging swinging in the trees

It's a monkey swinging in the trees

And many more possibilities for animals, sounds, movement and more

- Sustained engagement facilitated by varying musical elements such as modulation, tempo change

Establishing a role (keep it simple, consider perhaps only one or two):

- Opportunities for vocalising and movement as seen in score

- Opportunity to pause on certain words for clients to fill in the gap, such as "elephant saying -" or "great big -"

- Opportunity for client's role to be saying "in the trees" at the end of every line

- Opportunity to ask for client's choice of which animal to sing about next

- Opportunity to sing this alongside an animal-themed drum, using the pictures of animals as avenue of choice 